\title{
ARTE RUPESTRE DEL RÍO GRANDE, CUENCA DEL RÍO LIMARÍ, NORTE CHICO, CHILE
}

\author{
ROCK ART OF THE RÍO GRANDE, BASIN OF THE LIMARÍ RIVER, \\ NORTE CHICO, CHILE
}

\author{
Hans Niemeyer Fernández* y Dominique Ballereau**
}

\begin{abstract}
Describimos y analizamos seis estaciones y grupos de estaciones rupestres situadas a lo largo del río Grande, IV Región de Coquimbo, entre las localidades de Mialqui y Tulahuén: Mialqui, Panguecillo, La Rinconada de Carretón, Las Chupallas, El Cuyano y El Macano. El total de los bloques grabados registrados alcanza 257, con 342 petroglifos identificados, que dieron 329 dibujos en 36 Figuras. Después una descripción de los grabados y signos que caracterizan el estilo rupestre del valle, intentamos un estudio estadístico que toma en cuenta los 16 signos más frecuentes en cada estación. Los más significativos, y sus números, son las representaciones de seres vivos (23 mascariformes, 299 antropomorfos, 78 zoomorfos) y tres representaciones geométricas caracterícticas (18 cruces con contorno, 6 cuadriláteros con lados cóncavos, 326 círculos con apéndices exteriores). Observamos que el mascariforme, el antropomorfo, el cuadrilátero con lados cóncavos y el círculo con apéndices exteriores son los signos más frecuentes en Las Chupallas, dando a este lugar un papel importante; el zoomorfo es el más frecuente en La Rinconada de Carretón. Enseguida, comparamos estos resultados del río Grande con los obtenidos anteriormente en los ríos Hurtado e Illapel. Aparece que los mascariformes están en mayoría relativa en Hurtado, los antropomorfos en el río Grande y el zoomorfo en el río Illapel. El círculo con apéndices exteriores aparece sobrerrepresentado en el río Grande. Finalmente, los 18 criterios morfológicos utilizados anteriormente para describir los mascariformes del río Hurtado superior permiten clasificar los 23 aquí estudiados, y reconocer su pertenencia al estilo Limarí. Finalmente, hacemos un estudio comparativo entre los estilos locales ríos Hurtado, Grande y Illapel para concluir que tienen todos los aspectos morfológicos generales del estilo Limarí, aunque haya ciertas características propias, tal como el signo escalera. Analizamos el aspecto "santuario" de la estación de Las Chupallas.
\end{abstract}

Palabras claves: arte rupestre, estilo Limarí, Coquimbo, Chile.

We describe and analyze six rock art sites and groups of rock art sites: Mialqui, Panguecillo, La Rinconada de Carretón, Las Chupallas, El Cuyano and El Macano. These are located along the Rio Grande, Fourth Region of Coquimbo, between the towns of Mialqui and Tulahuén. A total of 257 engraved rocks were recorded, with 342 petroglyphs identified, of which we made 329 drawings in 36 figures. After a description of the engravings and signs, which characterize the rock art style of the valley, we looked at frequencies of the 16 most frequent signs from each site. The most significant and frequent are the representations of living beings (23 mask-like forms, 299 anthropmorphs, and 78 zoomorphs), and three geometric designs (18 enclosed crosses, 6 quadrilaterals with concave sides, 326 circles with external rays). We observe that mask-like forms and anthropomorphic signs, quadrilaterals with concave sides, and circles with external rays are most frequent in Las Chupallas, making this site significant; and zoomorphs are more frequent in La Rinconada de Carretón. We then compare these results from Rio Grande with those obtained previously in Ríos Hurtado and Illapel. Mask-like forms are in higher frequency in Hurtado, anthropmorphs in Río Grande and zoomorphs in Río Illapel. Circles with external rays appear over-represented in Río Grande. The 18 morphological criteria, used previously to describe the mask-like forms from Rio Hurtado superior, then allow us to classify the 23 mask-like forms studied here and to identify them as belonging to the Limari style. Finally, we carried out a comparative study of the local styles from Ríos Hurtado, Grande and Illapel, and conclude that they possess all the general morphological aspects of the Limarí style, although they show some distinctive characteristics such as the staircase design. Finally, we analyze the "sanctuary" aspect of the Las Chupallas site.

Key words: rock art, Coquimbo, Chile, Limarí style.

El arte rupestre de la cuenca del río Limarí, Región de Coquimbo, en la zona central del Norte Chico, quizás sea dentro de Chile el más registrado y conocido debido a la alta presencia en los diferentes valles y quebradas que la componen, y tam- bién en algunos cerros de connotación especial, tal como el cerro El Buitre. Mucho se ha hecho en su estudio, pero queda también mucho que hacer en el futuro. El conocimiento de la red hidrográfica y la orografía de la zona quizás sea un factor impor-

* Ahumada 312, Oficina 218, Santiago, Chile.

** Observatoire de Paris, Section de Meudon 5, place Jules-Janssen 92195 Meudon principal Cedex, France. dominique.ballereau@obspm.fr 
tante para explicar la profusión del arte rupestre. Es de allí que vamos a dar una idea esquemática de la cuenca del río Limarí. Una descripción sucinta de la geografía, de la prehistoria y de la protohistoria del Norte Chico se puede leer en Ballereau y Niemeyer (1999). La cuenca del río Limarí (Figura 1) se desarrolla con una extensión de $11.760 \mathrm{~km}^{2}$ en el centro de la región de Coquimbo, al sur de la del Elqui y al norte de la del Choapa. Por su caudal y ramificaciones dendríticas, es la del Limarí, sin duda, la más importante. El río Limarí, con una longitud de $64 \mathrm{~km}$, nace en la angostura de Peñones, muy cerca de la ciudad de Ovalle, de la confluencia de sus dos más importantes ríos formativos, el río Hurtado que drena la porción norte de la cuenca, y el río Grande, en la porción sur, que por su caudal es el principal. Sus principales afluentes son el río Tascadero en su curso superior, los ríos Mostazal y Rapel en su curso medio, y el río Guatulame, sin duda el principal de sus afluentes

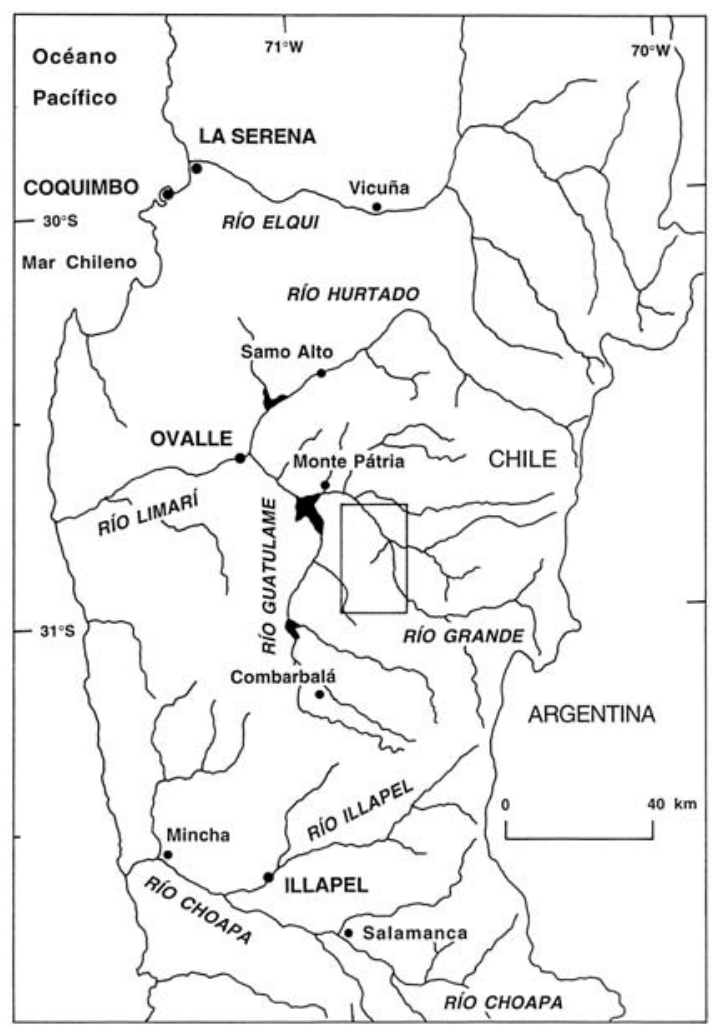

Figura 1. Cuenca del río Limarí con sus principales afluentes: El área encuadrada corresponde a aquella que fue explorada en 1997, 1998 y 1999.

Basin of the Limari River and its main tributaries. The boxed area was explored in 1997, 1998, and 1999. que proviene del sur y drena desde el ámbito de Combarbalá. No capta aguas de la cordillera andina. A partir de la confluencia del Guatulame con el río Grande, cae al río Grande una serie de quebradas laterales de poco desarrollo. A partir de la Puntilla de Peñones, el Limarí presenta sólo un afluente principal por su flanco izquierdo, el río Salala o Punitaqui, de escaso caudal por drenar áreas costeras. Sus recursos hidrológicos son pequeños, no obstante, haber sido una arteria muy poblada en su prehistoria y en su vida republicana, particularmente rica en grabados rupestres.

El trabajo de investigación de arte rupestre en el Norte Chico, que se presenta aquí, se prosiguió en los años 1997, 1998 y 1999. Siguen a varios otros, iniciados al comienzo de la década de los años 90: cerro La Silla (Niemeyer y Ballereau 1998), valle del río Hurtado superior (Ballereau y Niemeyer 1999), cuenca alta del río Illapel (Ballereau y Niemeyer 1998), y precede otro de los años 2000 y 2001 en el valle del río Guatulame.

Nuestro trabajo de campo tiene objetivos claramente orientados hacia un mejor conocimiento de la arqueología chilena, a través de una actividad en plena extensión, la rupestrología. Esta disciplina ha conocido una gran extensión desde los trabajos de Jorge Iribarren en el valle del río Hurtado, en los años 50-60, y hoy en día son numerosos sus sucesores. Estudiar las manifestaciones de arte rupestre es una meta apasionante, porque son los restos precolombinos más fácilmente accesibles al investigador de terreno. El levantamiento de todos los petroglifos de un área restringida o más extensa permite dar herramientas a los que quieren profundizar en el conocimiento de los pueblos, mediante el estudio de las formas rupestres grabadas y sus relaciones con la arqueología clásica. Además, la rupestrología permite estudios ligados con la estética. A menudo, las escenas representan auténticas porciones de la vida de una población, con sus diversas manifestaciones políticas, culturales y religiosas. Este aspecto del estudio del arte rupestre permite conseguir importantes datos sobre las civilizaciones que ocuparon este país antes de la intrusión europea.

Todas las estaciones de arte rupestre aquí descritas (Figura 2) están constituidas de bloques de tamaños variables, situados al aire libre. No hay abrigos o cuevas con adornos externos, tampoco encontramos huellas de pintura. Todos los graba- 


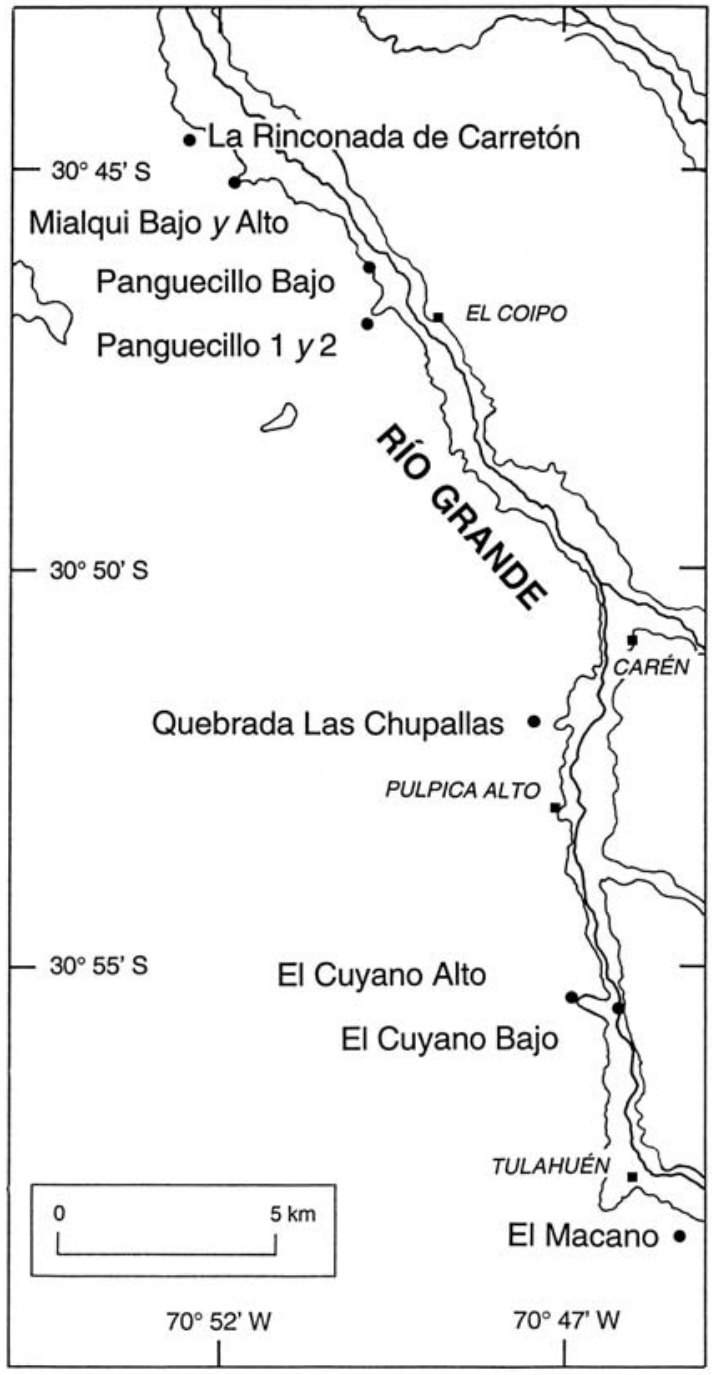

Figura 2. Localización de las estaciones rupestres del proyecto "Río Grande", entre los pueblos de Tulahuén al sur y Mialqui al norte.

Location of rock art sites, "Rio Grande" project, located between the towns of Tulahuén to the south, and Mialqui to the north.

dos fueron hechos según la técnica del picoteado directo, y las líneas de los dibujos pueden tener un ancho y profundidad variables. Los bloques son generalmente de constitución granítica o volcánica, y los contrastes de los grabados son casi siempre suficientemente altos para observarlos en buenas condiciones. En estos yacimientos, se encuentran bloques que destacan por su gran abigarramiento de dibujos con múltiples superposiciones, todo lo cual dificulta su lectura e interpretación. El método de trabajo en el terreno que los autores han desarrollado ya fue descrito en
Ballereau y Niemeyer (1998). Solamente recordaremos que todos los grabados fueron registrados con fotografías y después dibujados. Antes de llevar adelante la descripción de los sitios, debemos aclarar el vocabulario utilizado en el contexto de nuestro estudio. Llamamos "signo" a una unidad gráfica, con o sin contacto con los dibujos vecinos: un punto, un círculo, una máscara. Cuando uno o varios signos están asociados de manera contigua, con o sin contacto, y aislados de toda otra agrupación de signos, llamamos a esta asociación "grabado", o por extensión "petroglifo" (aunque este término designa una técnica, más que un dibujo). Los bloques (o piedras) portadores de grabados pueden presentar varias caras (o paneles), según la forma de éstos, cada una presentando -o no- un grabado o un signo aislado. Quiere decir que un bloque puede mostrar uno o más grabados (o petroglifos, o dibujos, o representaciones). Más raramente, dos caras más o menos llanas y contiguas de un mismo bloque, formando, por ejemplo, un ángulo en el espacio, pueden mostrar un solo dibujo que se extiende entre ellas. En este caso, indicamos en el texto este tipo particular de representación. El término "escena" se utiliza cuando un grabado exhibe varios signos obviamente "vivos", tal como antropomorfos, zoomorfos, que muestran una actividad o una situación que se puede interpretar sin dificultad: rebaño de cuadrúpedos con pastor, grupo de animales en perspectiva volcada, danzantes en acción, etc.

Damos para cada estación sus coordenadas geográficas, obtenidas con un llamado receptor-calculador Global Positioning System (GPS) así como su altura medida con un altímetro, con error de 5 a 10 metros. Generalmente, estos datos son los del primer petroglifo estudiado en dicha estación. Estas medidas fueron ulteriormente verificadas por una inspección de los mapas del Instituto Geográfico Militar de Chile de la zona, con escala de 1/50.000.

La Tabla 1 resume las estaciones rupestres registradas. Algunas tienen gran cantidad de bloques grabados (y varios paneles grabados por bloque), repartidos en una gran superficie de terreno, otras con pocos, a veces concentrados en un espacio restringido. Damos los subtotales de éstos, estación por estación, con el número de los que no fueron dibujados, por causa técnica: falta de contraste, erosión, quebradura u otro (13 petroglifos eliminados en las figuras). Sin embargo, serán tomados en cuenta en los cálculos estadísticos ulteriores. 
Tabla 1. Frecuencias de grabados en las estaciones prospectadas entre 1997 y 1999.

Frequencies of carved figures from stations surveyed between 1997 and 1999.

\begin{tabular}{lcccc}
\hline Estación & $\begin{array}{c}\text { Bloques } \\
\text { con grabados }\end{array}$ & $\begin{array}{c}\text { Total } \\
\text { grabados }\end{array}$ & $\begin{array}{c}\text { Grabados } \\
\text { dibujados }\end{array}$ & $\begin{array}{c}\text { Grabados } \\
\text { eliminados }\end{array}$ \\
\hline Mialqui, Mialqui Alto, Tucúquere y Viñita & 147 & 166 & 154 & 12 \\
Panguecillo Bajo, Panguecillo Alto 1 y Panguecillo Alto 2 & 37 & 66 & 66 & 0 \\
La Rinconada de Carretón & 18 & 33 & 32 & 1 \\
Las Chupallas & 47 & 65 & 65 & 0 \\
El Cuyano Bajo, El Cuyano Alto y El Macano & 8 & 12 & 12 & 0 \\
\hline Total & 257 & 342 & 329 & 13 \\
\hline
\end{tabular}

\section{Descripción de las Estaciones}

\section{Mialqui, Mialqui Alto, Tucúquere y La Viñita (grupo de Mialqui)}

La Comunidad de Mialqui pertenece administrativamente al pueblo de Zemita. Posee una base poblacional en la aldea de Mialqui, situada en la ribera poniente del río Grande. Es uno de los pueblos más antiguos y data del tiempo de la Colonia. En las afueras del pueblo, quedan los cam- pos de pastoreo comunitarios. En estos terrenos se encuentran dispersos numerosos bloques con grabados.

La estación rupestre de Mialqui ( $70^{\circ} 51^{\prime}$ '49" $\mathrm{W} ; 30^{\circ} 45^{\prime} 16^{\prime}$ " S; $645 \mathrm{msm}$ ) es la más importante del proyecto "río Grande", por su extensión geográfica y la cantidad de bloques grabados registrados (Figuras 3 y 4). La extensión máxima de estos terrenos con arte rupestre se estima en $3 \mathrm{~km}$, con un ancho medio de $1 \mathrm{~km}$. Los primeros bloques con petroglifos se encuentran justo al límite del

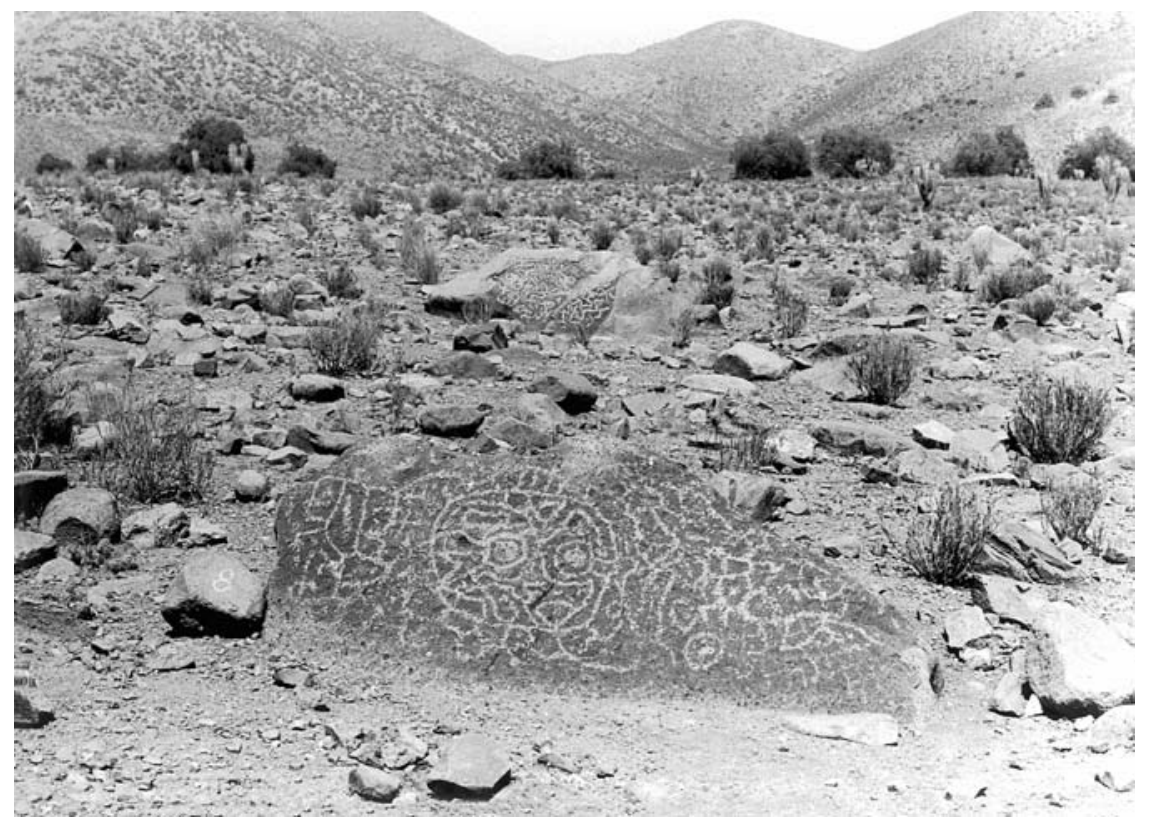

Figura 3. Estación rupestre de Mialqui, bloque $N^{\circ} 8$, con mascariforme circular en medio de una red de líneas mezcladas. Detrás se ve otra piedra con el petroglifo $\mathrm{N}^{\circ}$ 7. Se puede ver que el terreno es de poca inclinación (grabado reproducido en la Figura 13G; atrás: Figura 12D).

Rock art of Mialqui station, block $N^{o} 8$ with circular and mask-like figures in the middle of crossed lines. Behind are petroglyphs $N^{\circ}$ 7. The terrain has a gentle slope (detail reproduced in Figure 13G; behind: Figure 12D). 


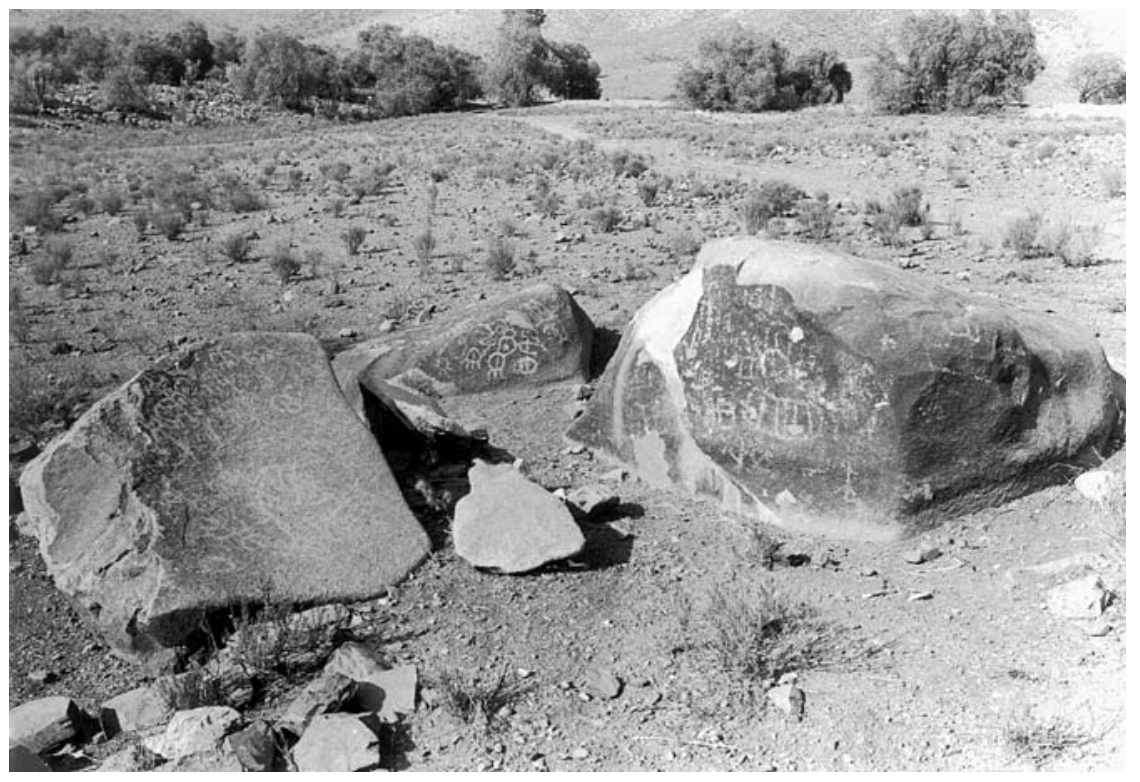

Figura 4. Bloques grabados de la estación rupestre de Mialqui, grupo $\mathrm{N}^{\circ} 15$; presentan al menos tres caras con petroglifos. El bloque de la izquierda es de roca volcánica y el contraste es débil. Los dos otros bloques de granito están más contrastados (grabados reproducidos en las Figuras 14E bloque a la izquierda, 14F centro y 14L derecha).

Engraved rocks of Mialqui rock art station, group $N^{o} 15$. Each rock has at least three sides with petroglyphs. The block on the left is volcanic rock and has little contrast. The other two are granite and have better contrast (rock art of Figure 14E left block, $14 \mathrm{~F}$ center, and 14 L right).

pueblo, al sudoeste, cerca del pequeño cementerio de Mialqui. Al norte, se extienden hasta un corto túnel del canal de riego. La densidad de la repartición de los bloques es elevada en la margen oriente de este campo, que limita con los huertos de Mialqui, y va disminuyendo hasta las inmediaciones del canal, llamado Zemita antiguamente, y de El Palqui desde que se instaló el pueblo nuevo de El Palqui. Desde el canal hacia arriba, hay también grabados sobre bloques aislados, pero disminuyen en frecuencia con la altura. La quebrada de Mialqui, de dirección SW-NE, corta este vasto campo en dos partes, y desemboca en el río Grande un poco al sur del pueblo. El acceso a este sitio es fácil por caminos laterales. Un puente sobre el canal permite la caminata hasta los altos de la quebrada de Mialqui. La estación de Mialqui Alto $\left(70^{\circ} 52\right.$ ' 22” W; $30^{\circ} 45^{\prime}$ 42” S; $740 \mathrm{msm}$ ) está situada en los altos de la quebrada de Mialqui, sobre su falda noroeste y limitada por su talweg. Encontramos aquí un total de 12 petroglifos. Si la quebrada es más estrecha, el terreno es mucho más caótico, los peñascos más abundantes y los grabados son muy dispersos, en altura como en longitud.
Tucúquere ${ }^{1}$ es una estación donde se encuentra una sola piedra grabada, que presenta poco contraste en los dibujos. Está situada a $500 \mathrm{~m}$ del extremo norte del pueblo de Mialqui, por el camino público. Actualmente, La Viñita es una pequeña estación con cinco bloques grabados, situada en el fundo de mismo nombre. La mayoría de los bloques portadores de grabados se encuentra sobre las márgenes de los potreros cultivados, removidos por la actividad agrícola. Su localización es al pie del cerro El Buitre, por su vertiente norte, frente a la ciudad de Monte Patria.

\section{Panguecillo Bajo, Panguecillo Alto 1 y Panguecillo Alto 2 (grupo de Panguecillo)}

La quebrada de Panguecillo (o de Pangue) está orientada SW-NE, desemboca en el curso del río Grande a la altura del pueblo de Panguecillo, unos pocos kilómetros aguas arriba de La Puntilla de Mialqui. Es de pronunciada pendiente y en su interior se encuentran unos baños de agua caliente. En el borde mismo de la carretera se observan algunas piedras oscuras muy ricas en grabados (Figuras 5 y 6), que denominamos Panguecillo Bajo 


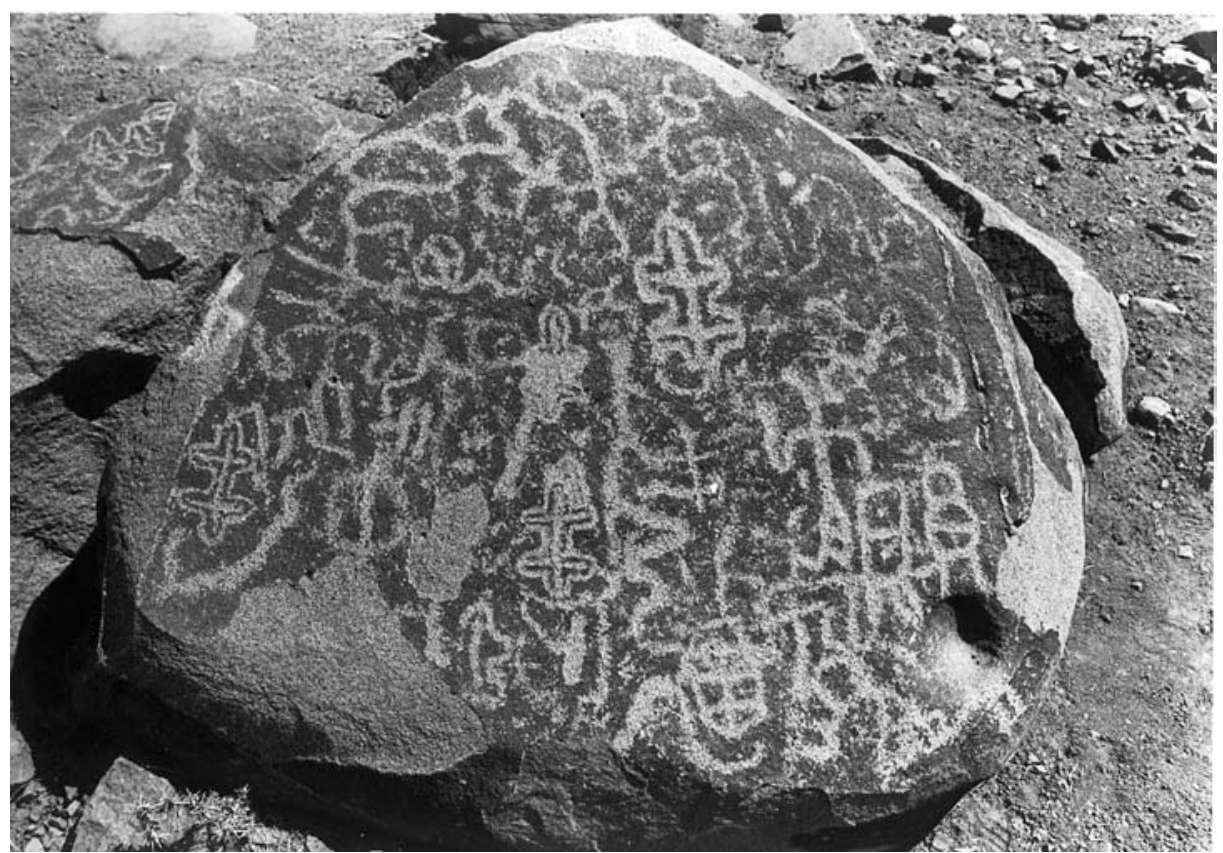

Figura 5. Roca grabada de la estación rupestre de Panguecillo Bajo (bloque $\mathrm{N}^{\circ} 1$ ). Mide 1,20 m de largo por 1,0 m de alto. Piedra destruida en su base (grabado reproducido en la Figura 13G). La cara izquierda posee grabados reproducidos en la Figura 25A. Engraving of Panguecillo Bajo rock art station (block $N^{o} 1$ ) measuring $1.20 \mathrm{~m}$ in length by $1.0 \mathrm{~m}$ in height. The rock is damaged at the base (Rock art of Figure 13G). The left side also has engraving (Rock art of Figure 25A).

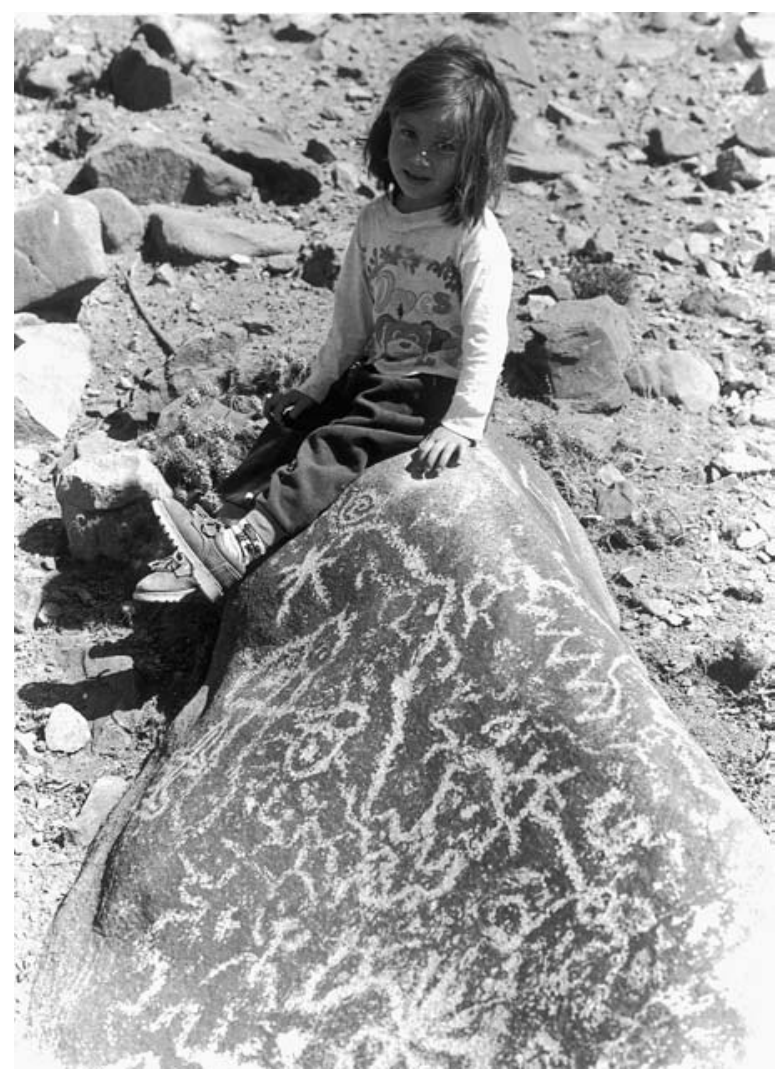

Figura 6. Vista parcial de una roca grabada de la estación rupestre de Panguecillo Bajo (bloque $\mathrm{N}^{\circ} 2$ ). Petroglifo ubicado cerca del bloque $\mathrm{N}^{\circ} 1$ (Figura 5). Abajo, la cabeza de un personaje de la cual sobresalen líneas radiales (grabado reproducido en la Figura 25B).

Partial view of an engraving from Panguecillo Bajo rock art station (Block $N^{o} 2$ ). Petroglyph near block $N^{o} 1$ (Figure 5). Below, there is the head of a personage with radiating lines (rock art of Figure 25B). 
(70 49' 58' W; 30 46’ 28' S; 610 msm). Más arriba en la quebrada, un primer yacimiento de petroglifos se observa al borde del camino, que bautizamos Panguecillo Alto $1\left(70^{\circ} 50^{\prime} 06^{\prime \prime} \mathrm{W}\right.$; $30^{\circ} 47^{\prime}$ 07” S; $685 \mathrm{msm}$ ). Más arriba, siguiendo el camino, a unos $500 \mathrm{~m}$ de Panguecillo Alto 1, se observa a la derecha, una piedra de varios metros de altura, con grabados relativamente aislados entre ellos, en su cara principal. A pocas decenas de metros de esta piedra alta, se encuentra un campo inclinado muy rico en piedras grabadas, que denominamos Panguecillo Alto 2 (70 50' $12^{\prime}$ ' W; $30^{\circ}$ 47' 18” S; 695 msm).

\section{La Rinconada de Carretón}

La quebrada de Carretón Bajo, en la cual estudiamos 18 piedras grabadas de la estación de $\mathrm{La}$ Rinconada de Carretón, es de tamaño amplio. Su desagüe está situado al norte del pueblo de Mialqui. Las piedras están agrupadas en un área circular de $200 \mathrm{~m}$ de diámetro. Como este terreno estaba destinado a transformarse en campo de árboles frutales, nuestro trabajo fue un tipo de rescate. La quebrada de La Totora, que corre más al norte, y al pie sur del cerro El Buitre, es también muy rica en grabados. Niemeyer hizo un registro fotográfico y de dibujos en los años 60.

La temática de los petroglifos de La Rinconada de Carretón es muy repetitiva y se refiere sobre todo a la figura humana (Figura 7), que muestra una actitud orante con los brazos hacia arriba, las piernas abiertas, muchas veces con el sexo masculino señalado. Hay también mezcladas algunas figuras de camélidos estilizados.

\section{Las Chupallas}

La quebrada de Las Chupallas cae al río Grande por su ribera izquierda, en la localidad de Pulpica Baja. Forma un cono de deyección amplio que ha sido cultivado con buenos rendimientos agrícolas. En el sendero de acceso, se encuentra un bosque de matorrales que se riega con un canal o acequia que atraviesa la localidad. Prevalecen aquí espinos, algarrobos y sauces entre las especies arbóreas, y olivillo, colliguay, guayacán, pingo pingo, cactos columnares, entre otros. Aquí los aborígenes seleccionaron un paño grande de terreno para establecer un verdadero santuario o lugar de culto

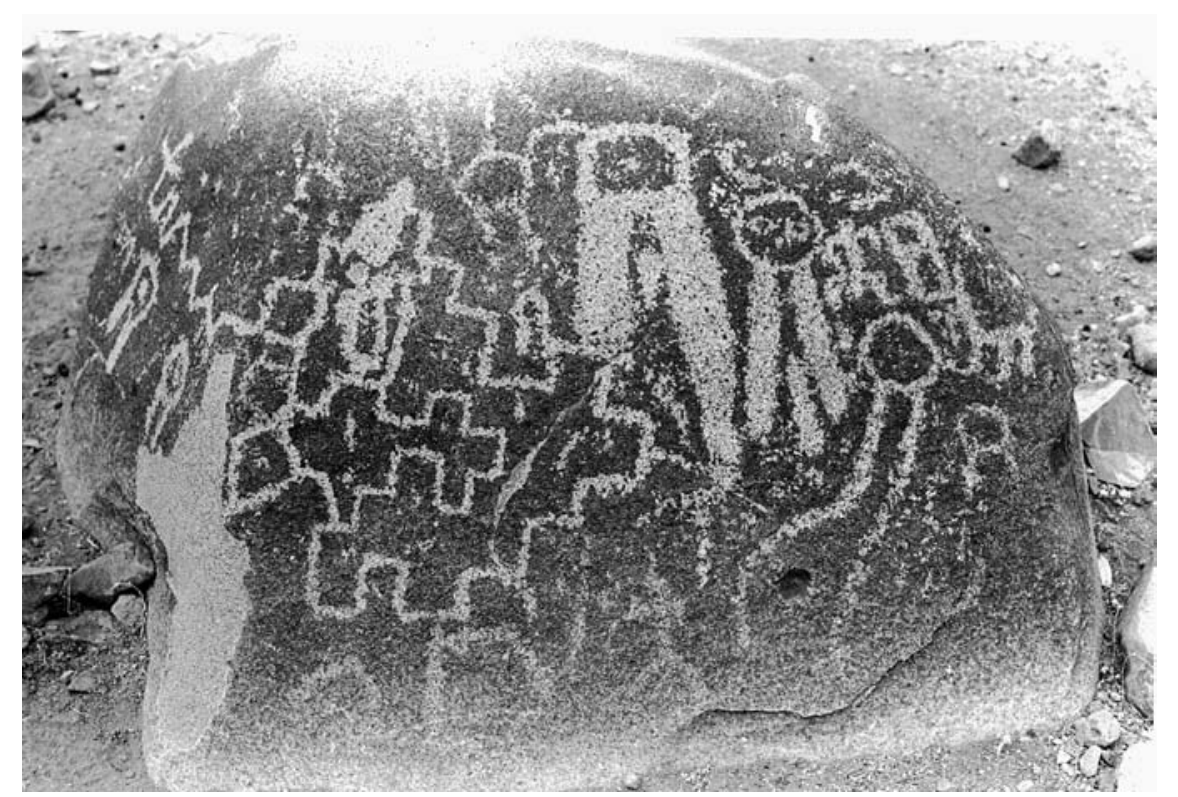

Figura 7. Roca grabada de la estación La Rinconada de Carretón (bloque $\mathrm{N}^{\circ} 11$ ). Muestra varios ejemplares del "círculo con dos apéndices (o rayas) exteriores paralelos", signo típico del Norte Chico. Sus otras caras también están grabadas (se ve una de perfil, a la izquierda). El bloque está erosionado. El grabado fue registrado y publicado por Iribarren (1975) (grabado reproducido en la Figura 37F). Engraved rock from La Rinconada station (block $N^{\circ} 11$ ). It shows several circles with two external parallel appendages (or lines), typical of the Norte Chico area. The other sides are also engraved (one is visible to the left). The block is weathered. The engraving was recorded and published by Iribarren (1975) (Rock art of figure 37F). 
con una apreciable cantidad de bloques adornados con petroglifos. Toma a pie alrededor de una hora desde el camino vehicular, remontando el bosquecillo de matorrales y luego parte de la quebrada de secano.

El conjunto de bloques está en un plano inclinado de 200 por $100 \mathrm{~m}$. Las piedras grabadas poseen unos de los conjuntos más ricos de la zona, en particular el extraordinario grabado $\mathrm{N}^{\circ} 19$. $\mathrm{Al}$ entrar en la estación $\left(70^{\circ} 47^{\prime} 32^{\prime}\right.$ ' W; $30^{\circ} 52^{\prime}$ ' $15^{\prime \prime} \mathrm{S}$; $860 \mathrm{msm}$ ) se encuentra frente a una alta piedra de cara llana, vertical y de color claro, sobre la cual se observan decenas de figuras circulares. El número total de piedras grabadas es de 46 , donde se registraron 65 petroglifos (Figuras 8 y 9).

\section{El Cuyano Bajo y El Cuyano Alto (grupo de El Cuyano)}

Es en el pueblo de El Cuyano que se encuentra un petroglifo muy famoso en Chile, que se com- pone de una figura humana encabezada por un atavío cefálico gigante (Figura 10). Llamamos a este sitio El Cuyano Bajo (70 46’ 32" W; $30^{\circ} 55^{\prime} 56^{\prime \prime}$ $\mathrm{S} ; 875 \mathrm{msm})$.

La estación de El Cuyano Alto (70 46 '43" $\mathrm{W} ; 30^{\circ} 55^{\prime} 40^{\prime \prime} \mathrm{S}$; $930 \mathrm{msm}$ ) es accesible por un camino que sube desde el pueblo de El Cuyano. Registramos 7 piedras grabadas, con un total de 10 petroglifos. En la Figura 11, se observa un bloque que ha perdido casi toda su superficie de origen, por causas naturales o vandalismo. Sólo aparecen elementos aislados del dibujo inicial.

\section{El Macano}

En este lugar encontramos un único petroglifo (70 45' 20” W; 30 58' 22” S; $1.040 \mathrm{msm}$ ), situado en la cumbre de un cerrito de $20 \mathrm{~m}$ de altura. Está al borde de la carretera al sur de Tulahuén, muy cerca de un cementerio. La piedra portadora es blanca y el contraste es débil.

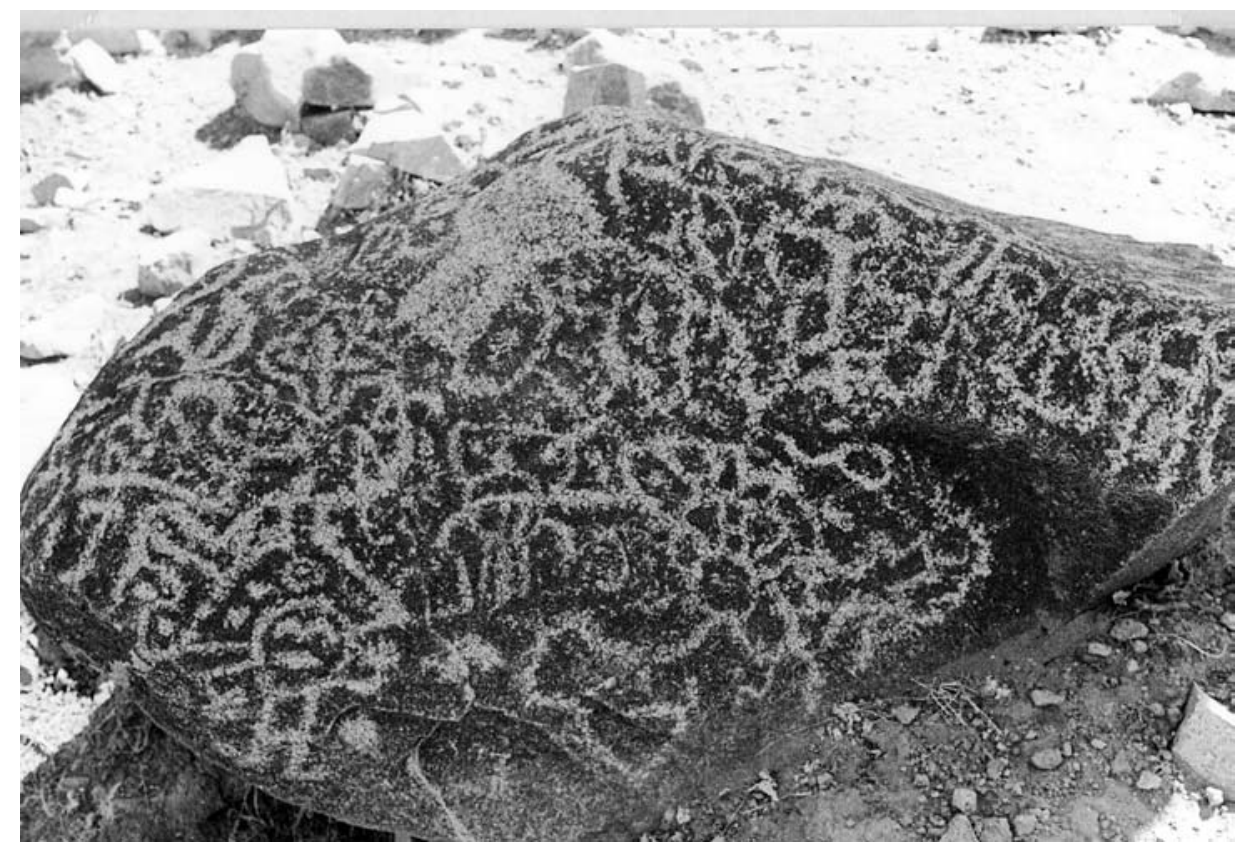

Figura 8. Roca grabada de la estación Las Chupallas (bloque $\mathrm{N}^{\circ} 22$ ). Ejemplo del estilo rupestre que considera que ningún vacío debe existir sobre la cara del bloque. Decenas de símbolos mezclados rellenan el espacio. Se reconoce un personaje con atavío cefálico, a la izquierda y encima la superposición de un círculo con dos apéndices exteriores paralelos (grabado reproducido en la Figura 41B).

Carved rock from Las Chupallas (block No. 22). This is an example of rock art that does not leave open spaces on the face of the block. Dozens of mixed symbols fill the space. To the left a personage with headdress is visible, and on the top is a superposition of a circle with two external parallel appendages (Rock art of Figure 41B). 


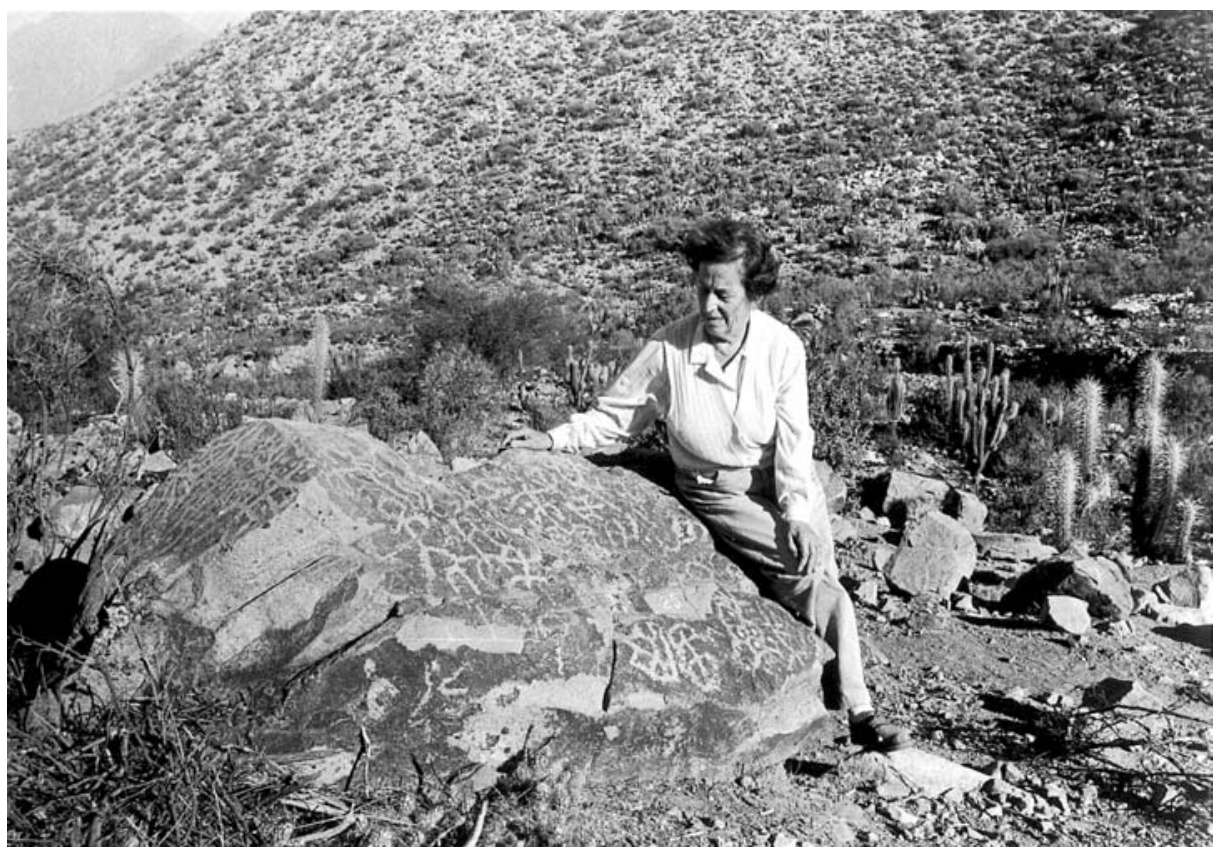

Figura 9. Roca grabada de la estación de Las Chupallas (bloque $\mathrm{N}^{\circ} 25$ ). Muestra las dos caras ornadas de un bloque aislado. La de la derecha posee varios tipos de antropomorfos (grabado reproducido en la Figura 42D).

Engraved rock from Las Chupallas station (block $N^{\circ} 25$ ). Two decorated faces are visible. The right has various anthropomorphic designs (rock art of Figure 42D).

Figura 10. Roca grabada de la estación de El Cuyano Bajo (bloque $\mathrm{N}^{\circ} 1$ ). Representa el mascariforme de grandes proporciones de El Cuyano Bajo. El dibujo tiene poco contraste (grabado reproducido en las Figuras 46A y 46B). Engraved rock from El Cuyano Bajo station (block $N^{o} 1$ ). It represents a large masked personage. The figure has little contrast (rock art from Figures $46 A$ and $46 B$ ).

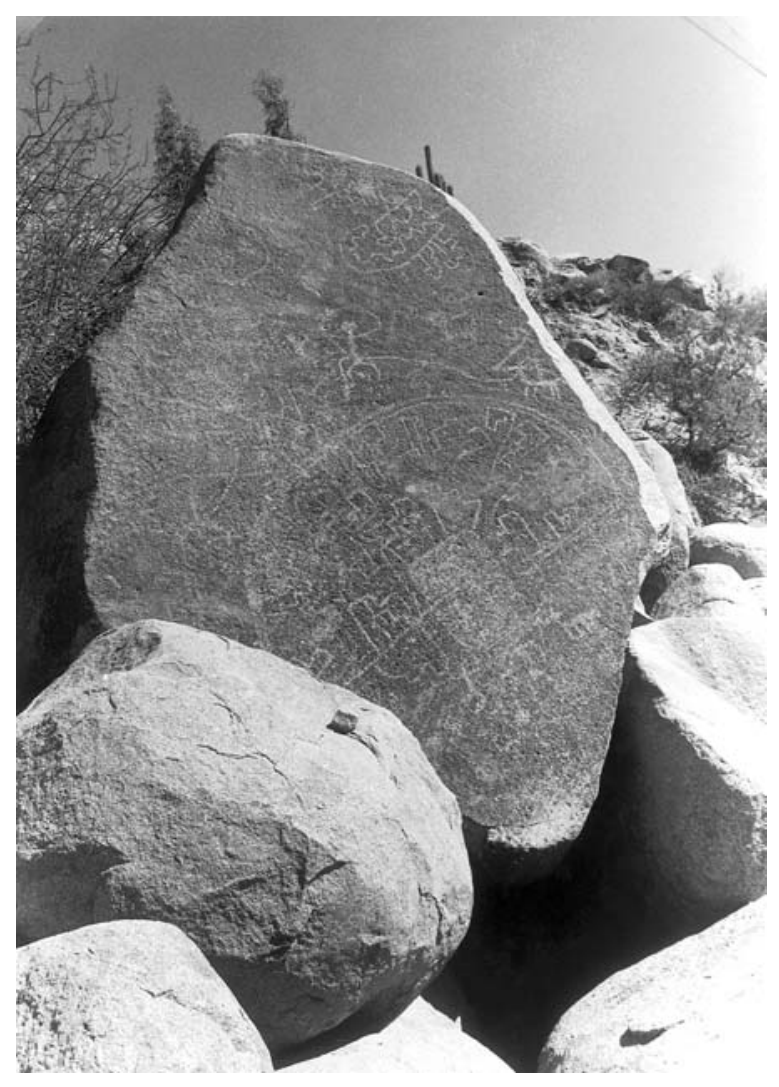




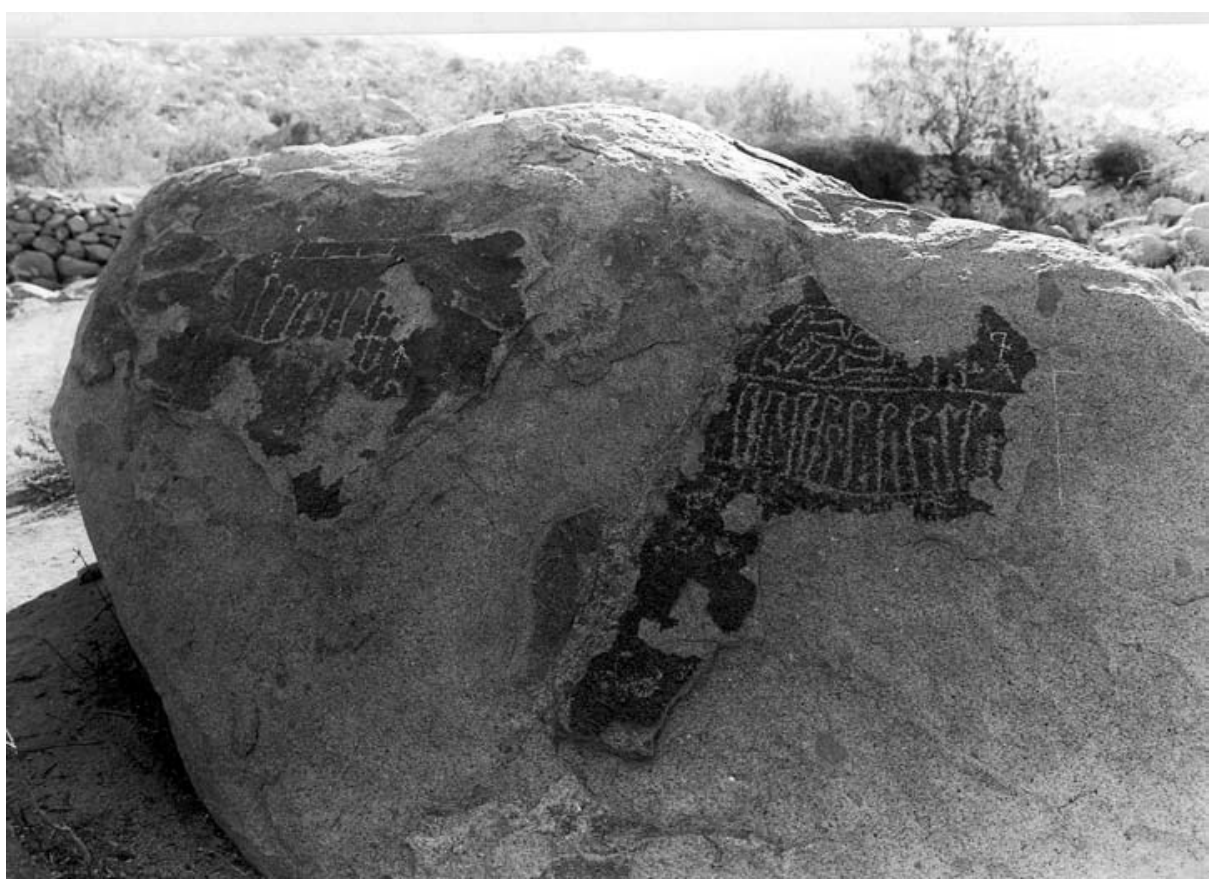

Figura 11. Roca grabada de la estación de El Cuyano Alto (bloque $\mathrm{N}^{\circ} 7$ ) de superficie erosionada por vandalismo o termofractura. Se observan restos de seres con máscaras u otro adorno cefálico (grabado reproducido en la Figura 47G).

Engraved rock of the El Cuyano Alto station (block $N^{o} 7$ ). The surface has been eroded by vandalism or natural thermofractures. The remains of figure with masks and headdress are visible (rock art from Figure 47G).

\section{Análisis del Arte Rupestre, Río Grande}

A continuación se presenta un análisis de los grabados rupestres registrados durante el proyecto río Grande. Seguimos el orden utilizado en trabajos anteriores, es decir, en primer lugar las formas humanas (máscaras y mascariformes, antropomorfos) y animales (zoomorfos) enseguida el vasto conjunto de las formas geométricas. Siguiendo el análisis morfológico, se hará un estudio estadístico, que permitirá poner en evidencia la importancia numérica de tal o cual signo rupestre.

\section{Mialqui, Mialqui Alto, Tucúquere y La Viñita (grupo de Mialqui)}

Los grabados registrados en el grupo de Mialqui están reproducidos en las Figuras 12 a 24; los que pertenecen a la estación principal de Mialqui, en las Figuras 12 a 21, 22A a 22I, 22K, 22P y 23A. Los que provienen de Mialqui Alto, en las Figuras 22J, 22L a $22 \mathrm{O}$ y $23 \mathrm{~B}$ a $23 \mathrm{H}$ (total 12 grabados). Los de Tucúquere están en las Figuras 24A y 24B, y los de La Viñita en las Figuras 24C a 24G.
Las representaciones de máscaras y mascariformes

Hemos encontrado seis mascariformes, de los cuales dos (Figuras 13D y 15H) pueden ser considerados como esbozos. Los otros son los siguientes: Figuras 13G, 16B, 20I y 23G. El primero $(13 \mathrm{G})$ es notable por la representación de una cara humana circular, identificada como tal por dos ojos vaciados, cada uno circunvalado por un círculo. Tiene un diámetro medio de 0,39 m. Dos líneas onduladas representan respectivamente la nariz y las cejas. La boca no parece marcada. El resto del rostro está ocupado por un conjunto de líneas desordenadas. Se observa, arriba de la cabeza, un pequeño rectángulo con cinco compartimientos. Este tipo de adorno de mascariforme es frecuente en el arte rupestre del Norte Chico, donde tiene formas y volúmenes variables (ver Mostny y Niemeyer 1983: Figura 65 y siguientes). Fuera de este mascariforme, el bloque está cubierto en su totalidad por una red complicada de líneas y círculos pequeños sin orden, salvo a la izquierda, donde se identifica un personaje, de 


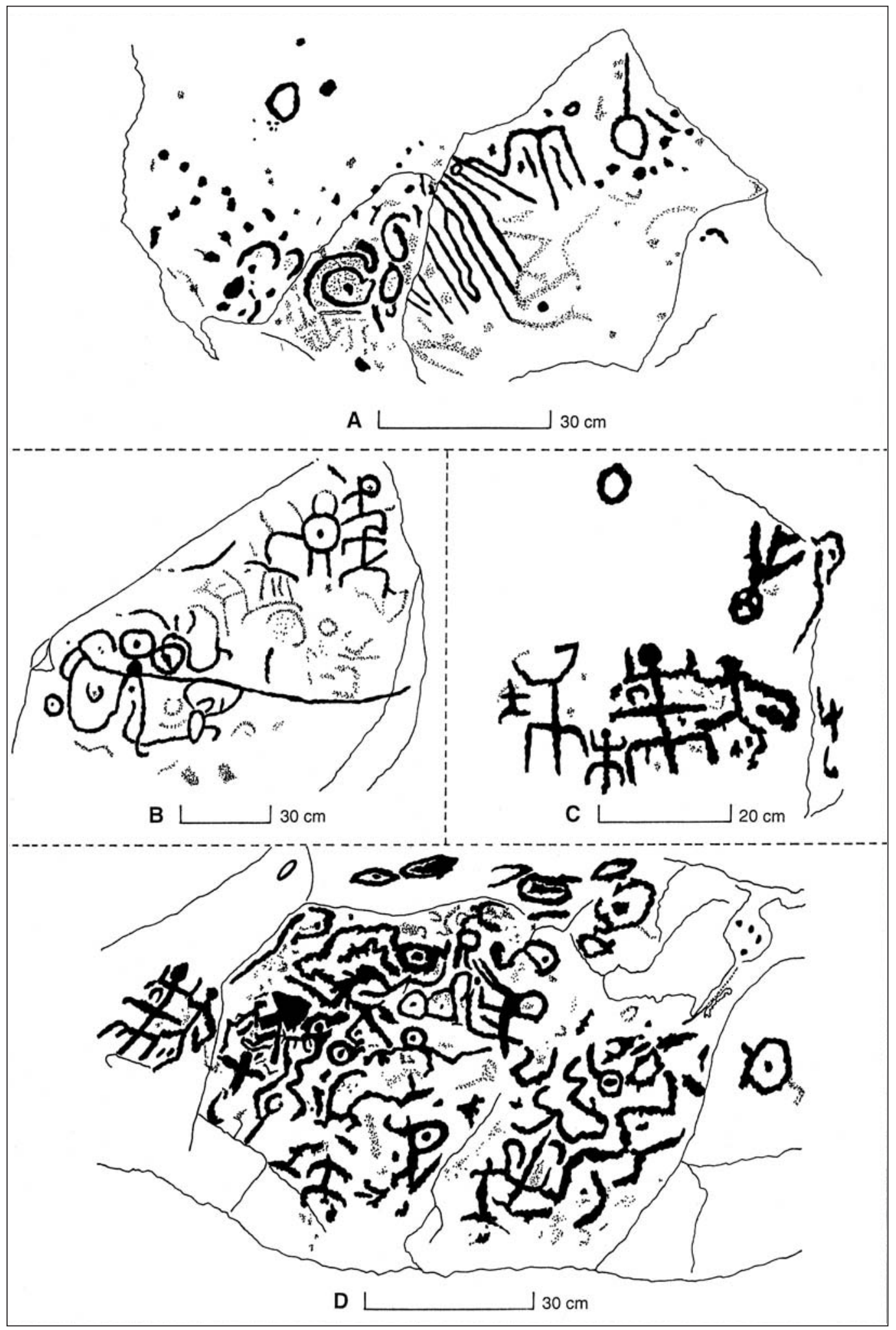

Figura 12. Conjuntos rupestres de Mialqui. Rock art clusters from Mialqui. 


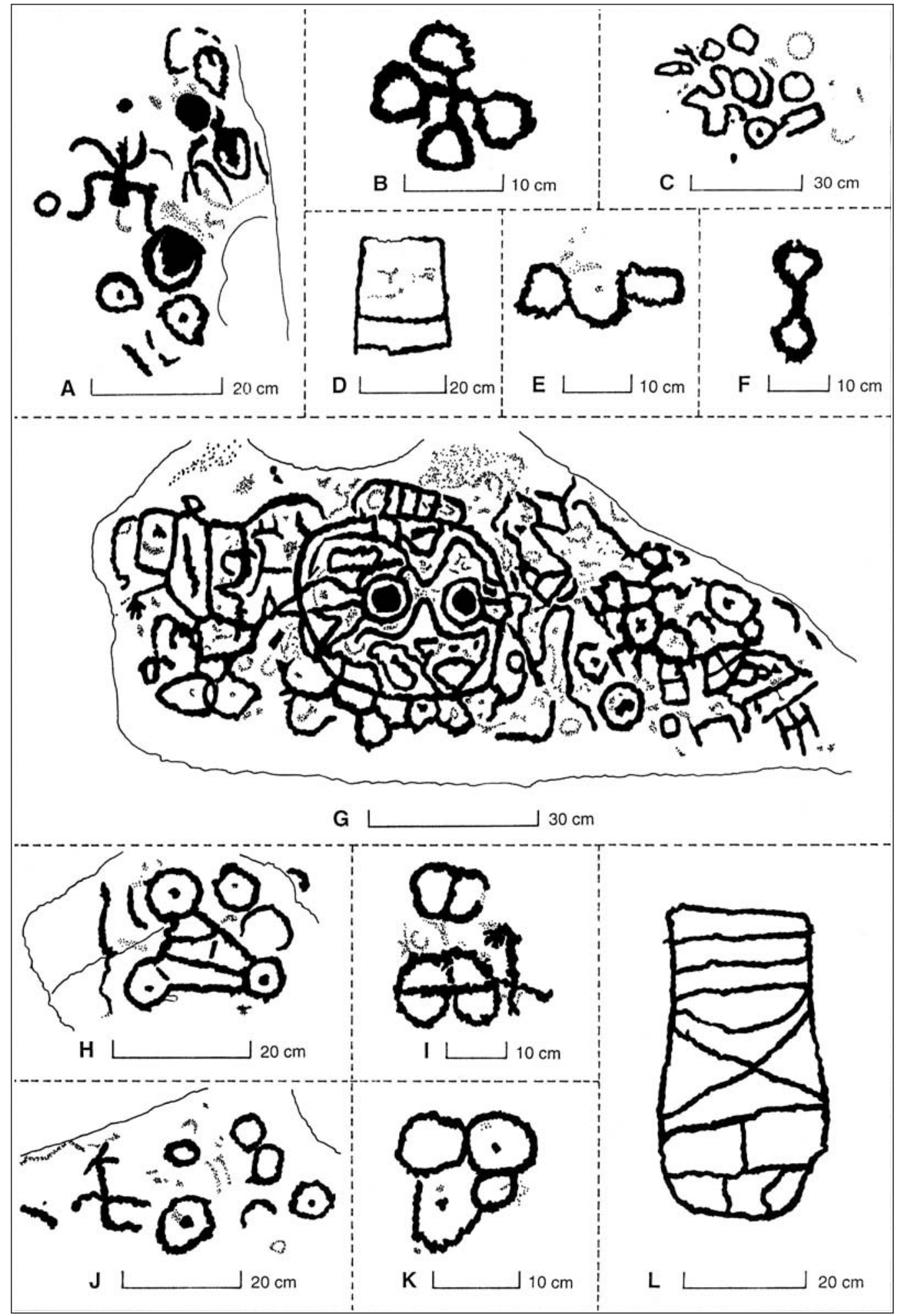

Figura 13. Conjuntos rupestres de Mialqui Rock art clusters from Mialqui. 


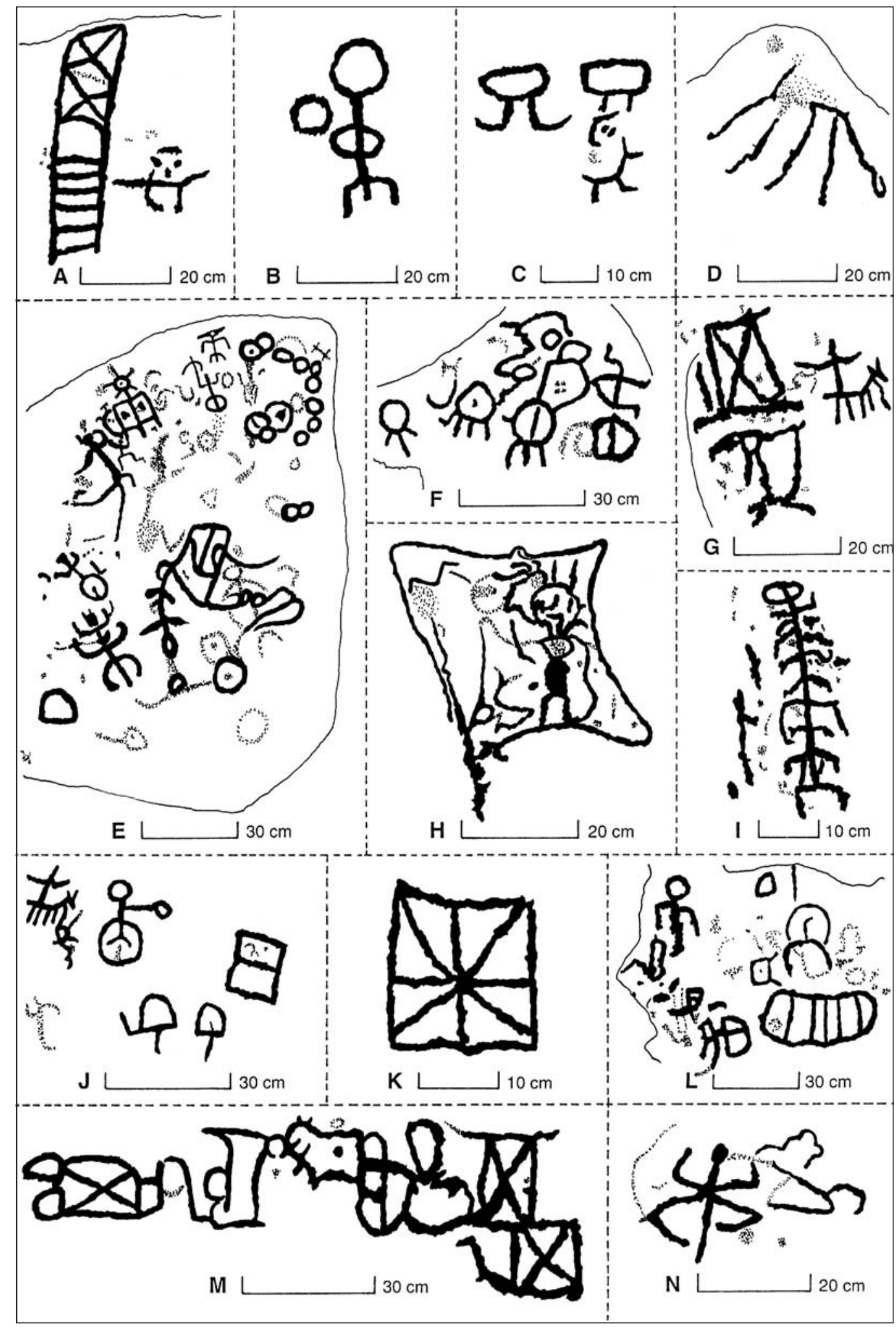

Figura 14. Conjuntos rupestres de Mialqui. Rock art clusters from Mialqui. 


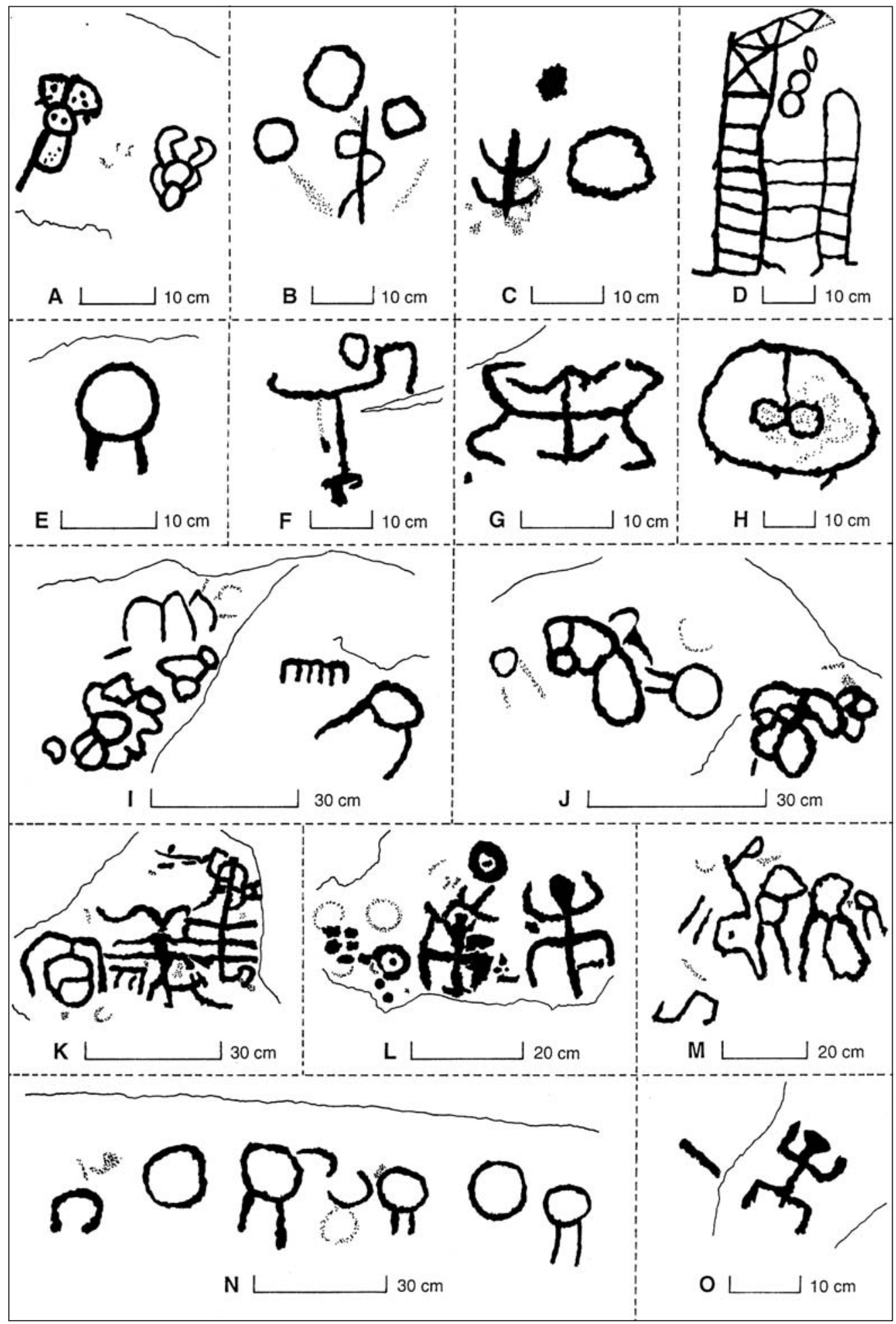

Figura 15. Conjuntos rupestres de Mialqui. Rock art clusters from Mialqui. 


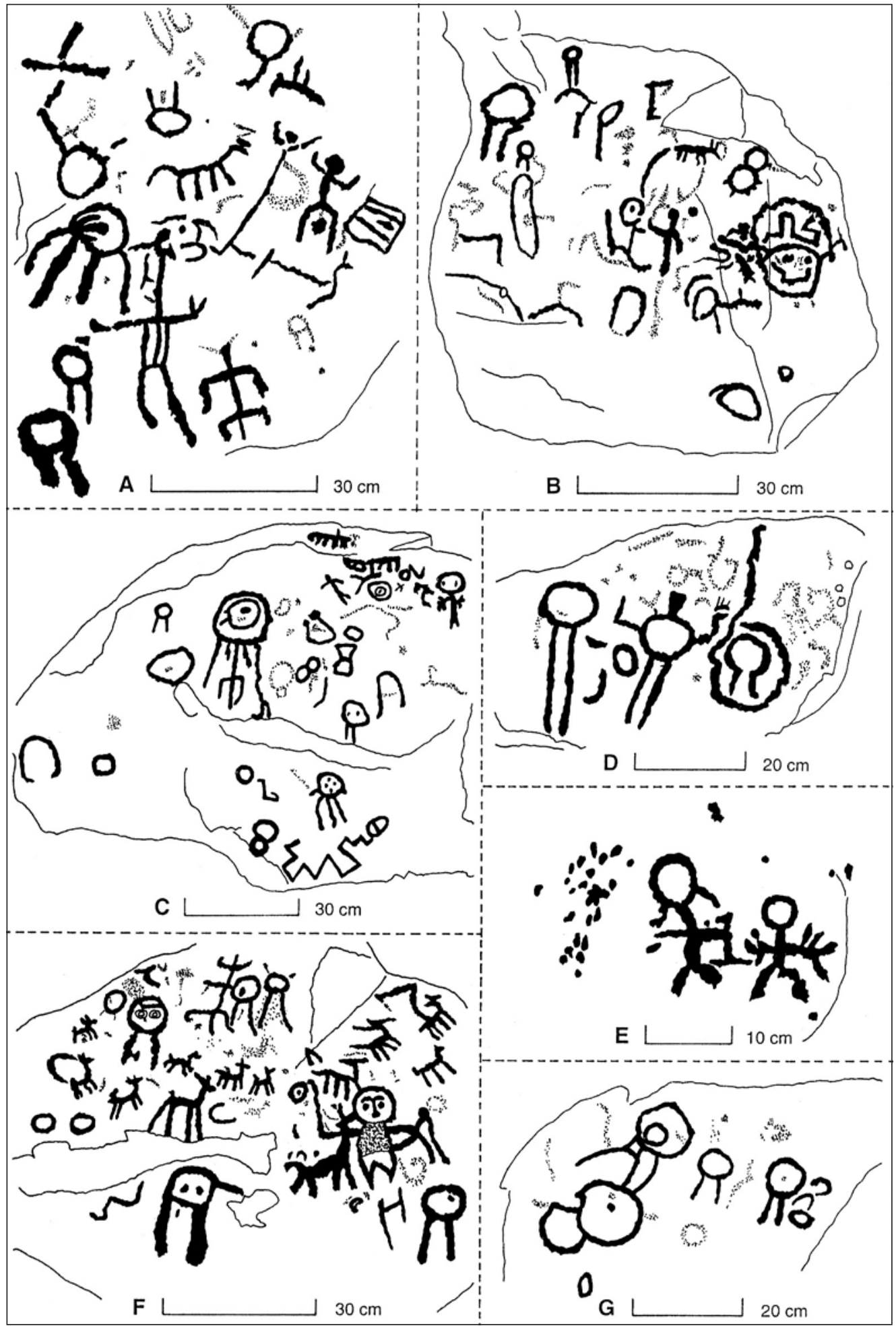

Figura 16. Conjuntos rupestres de Mialqui. Rock art clusters from Mialqui. 


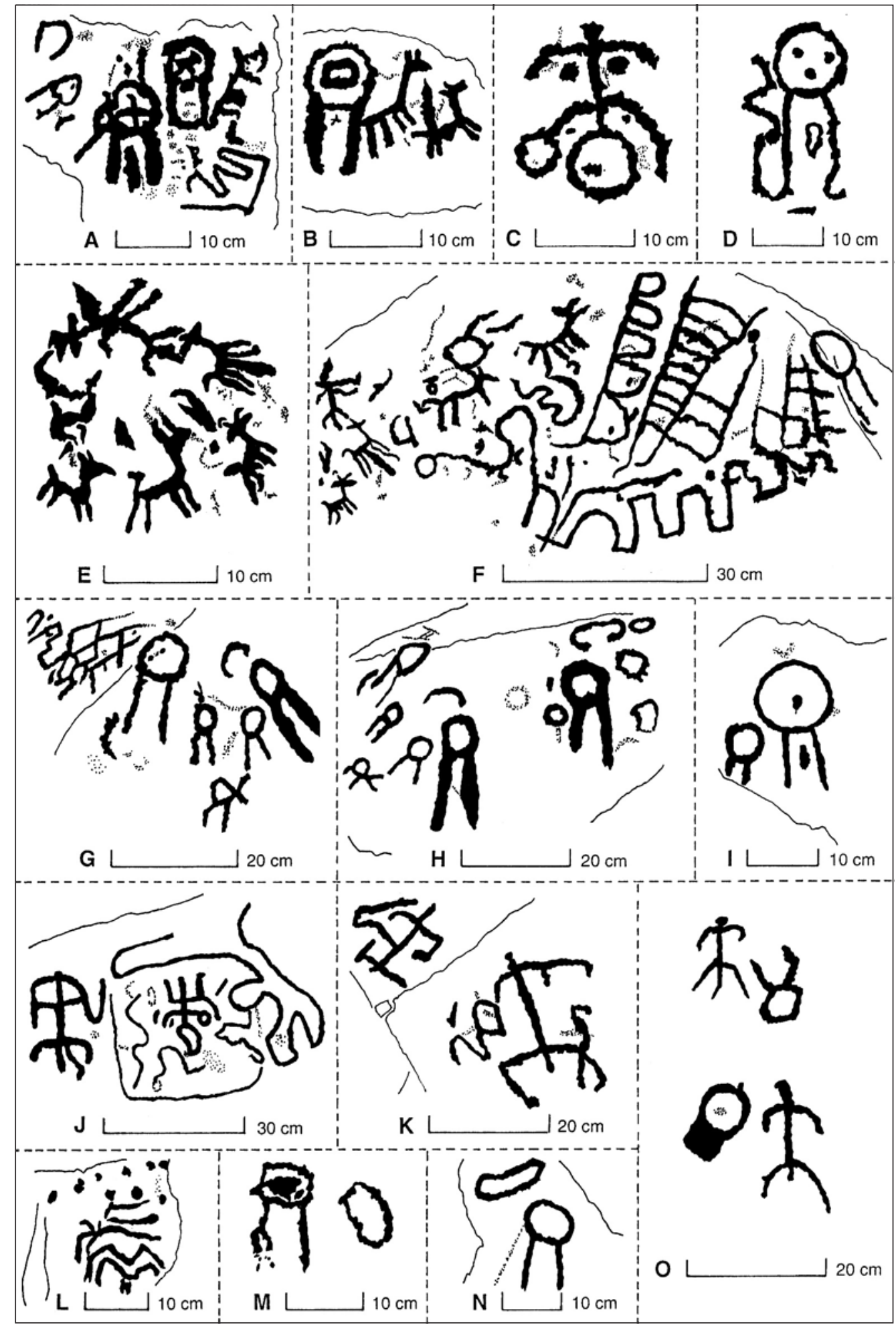

Figura 17. Conjuntos rupestres de Mialqui.

Rock art clusters from Mialqui. 


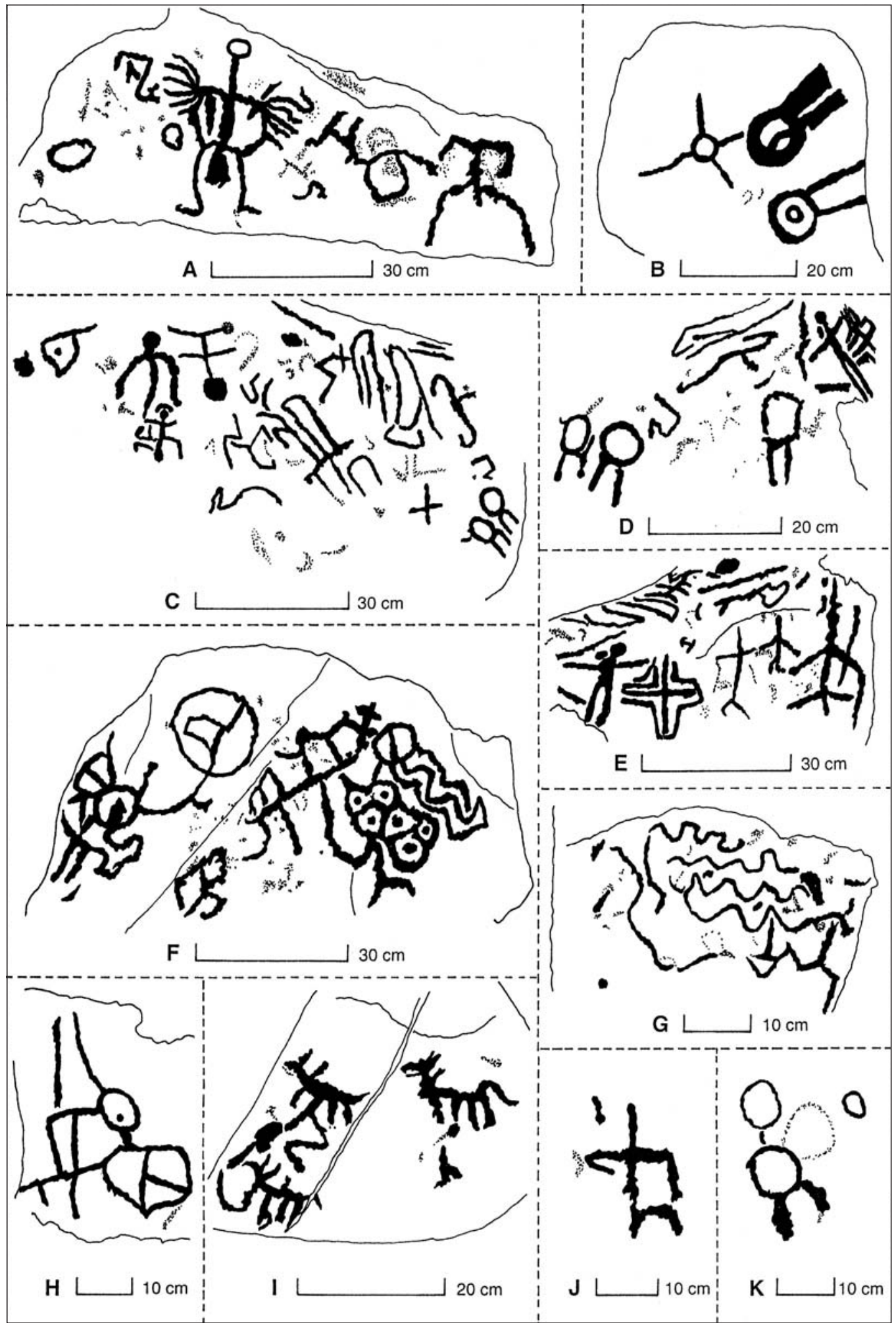

Figura 18. Conjuntos rupestres de Mialqui. Rock art clusters from Mialqui. 


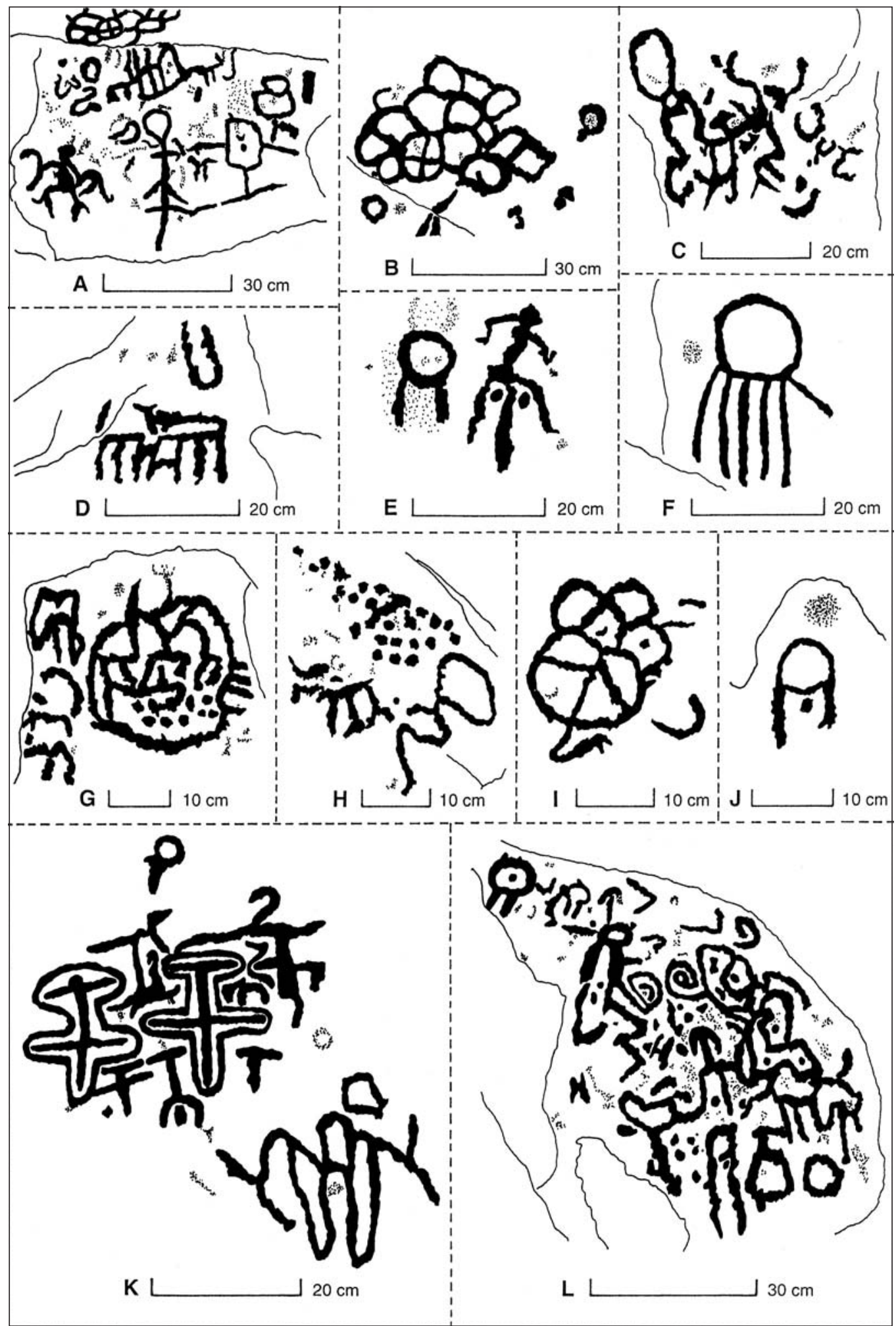

Figura 19. Conjuntos rupestres de Mialqui. Rock art clusters from Mialqui. 


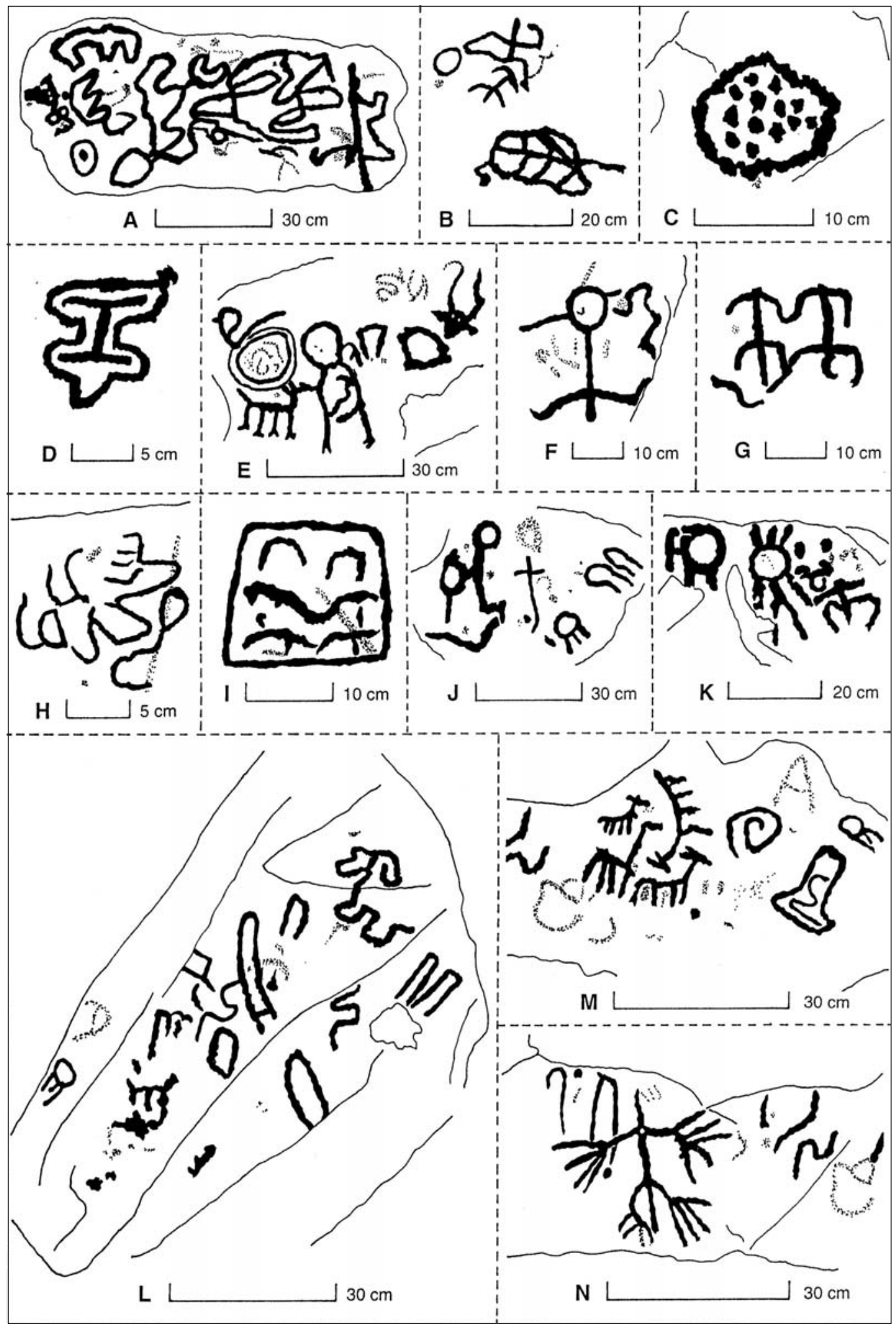

Figura 20. Conjuntos rupestres de Mialqui. Rock art clusters from Mialqui. 


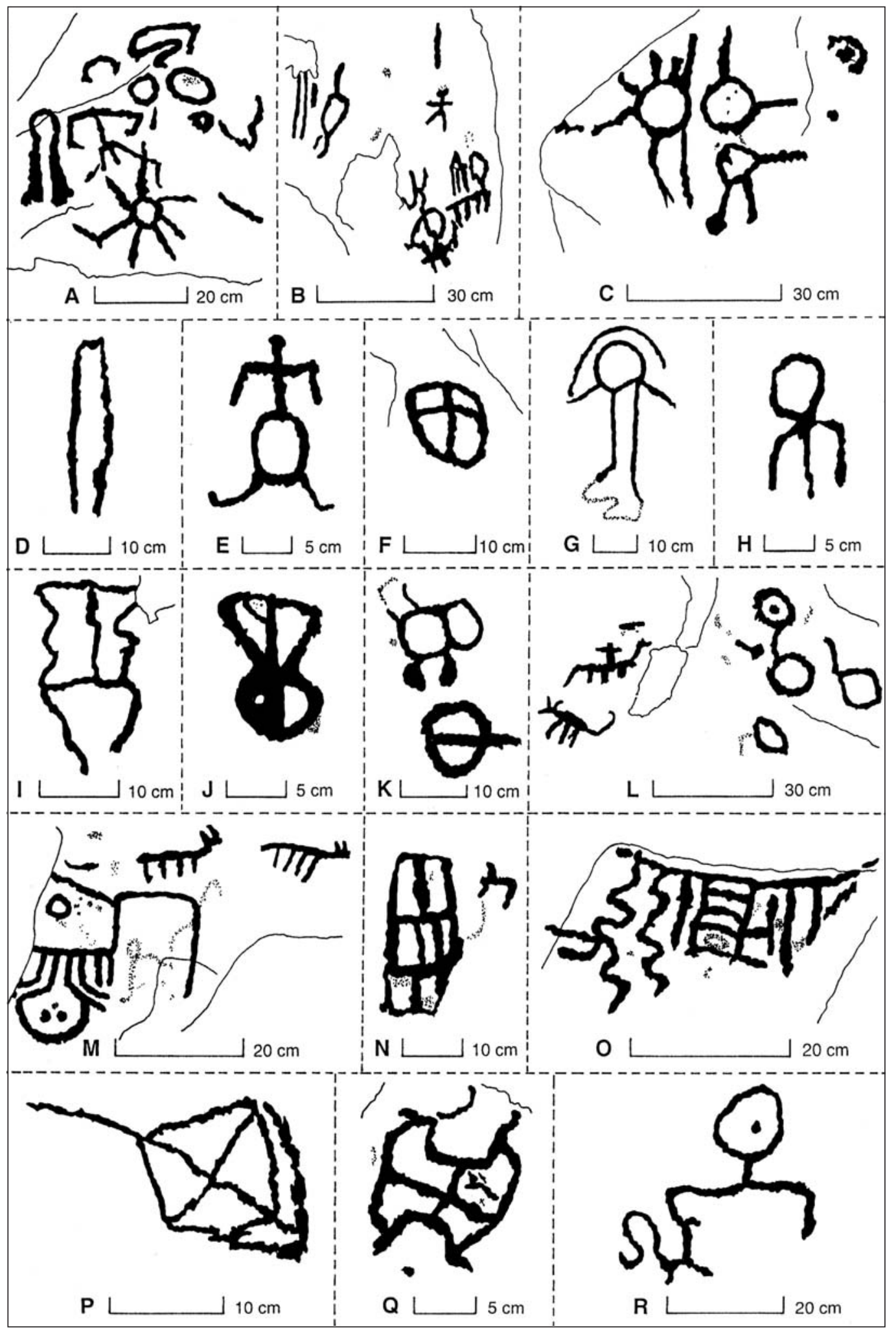

Figura 21. Conjuntos rupestres de Mialqui. Rock art clusters from Mialqui. 


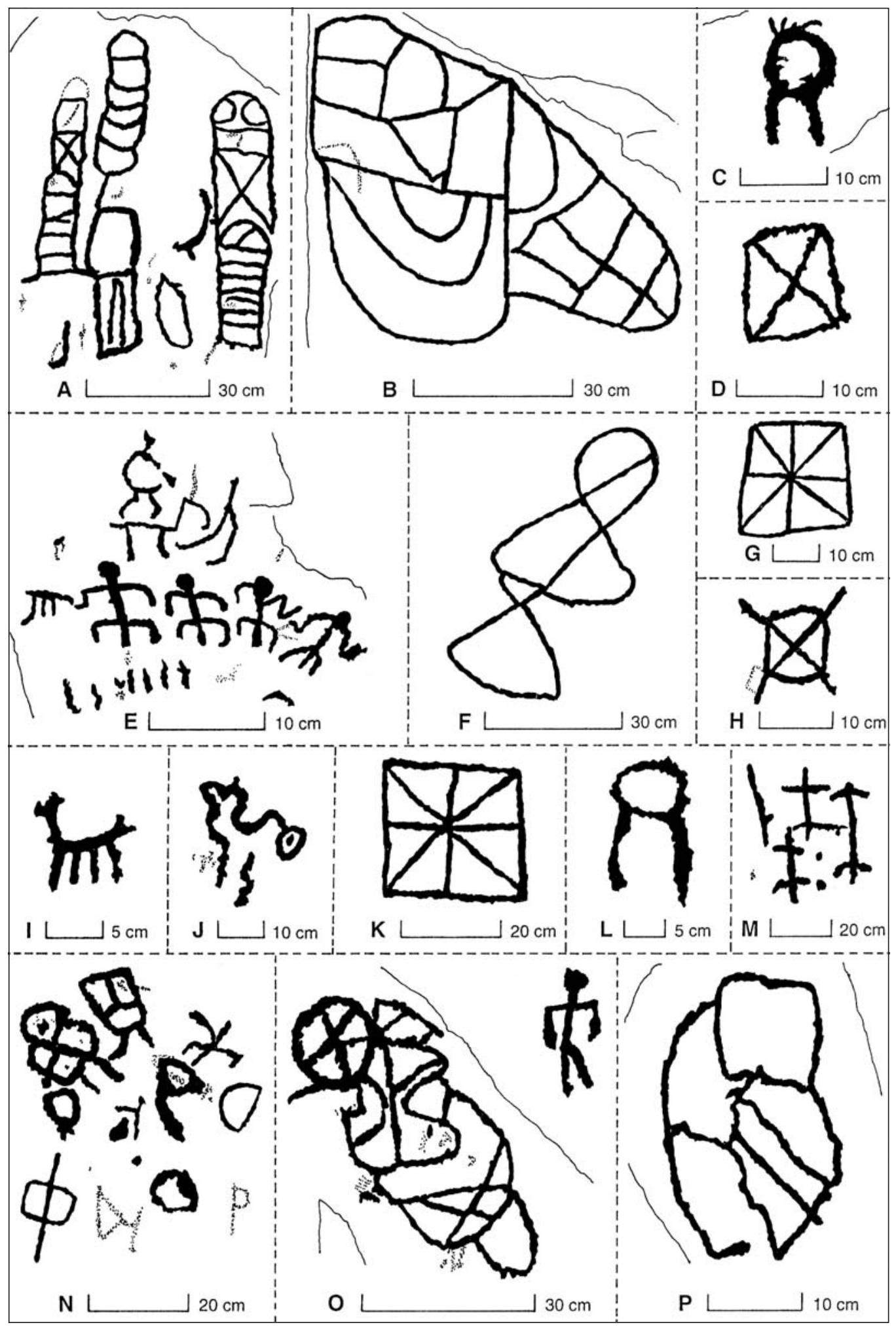

Figura 22. Conjuntos rupestres de Mialqui (A, B, C, D, E, F, G, H, I, K, P) y de Mialqui Alto (J, L, M, N, O). Rock art clusters from Mialqui ( $A, B, C, D, E, F, G, H, I, K, P)$ and Mialqui Alto $(J, L, M, N, O)$. 
58

Hans Niemeyer Fernández y Dominique Ballereau

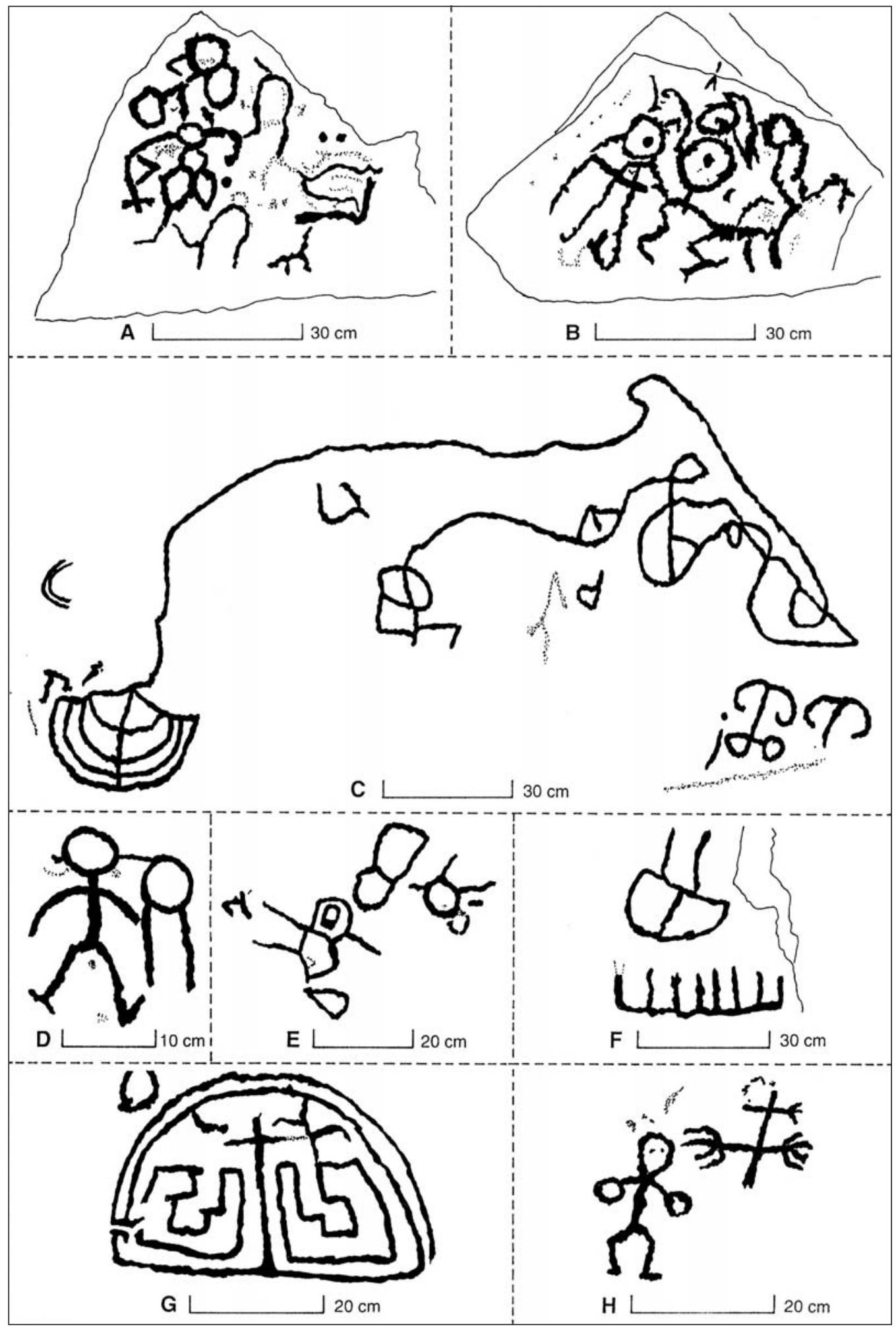

Figura 23. Conjuntos rupestres de Mialqui (A) y de Mialqui Alto (B, C, D, E, F, G, H).

Rock art clusters from Mialqui (A) and Mialqui Alto $(B, C, D, E, F, G, H)$. 


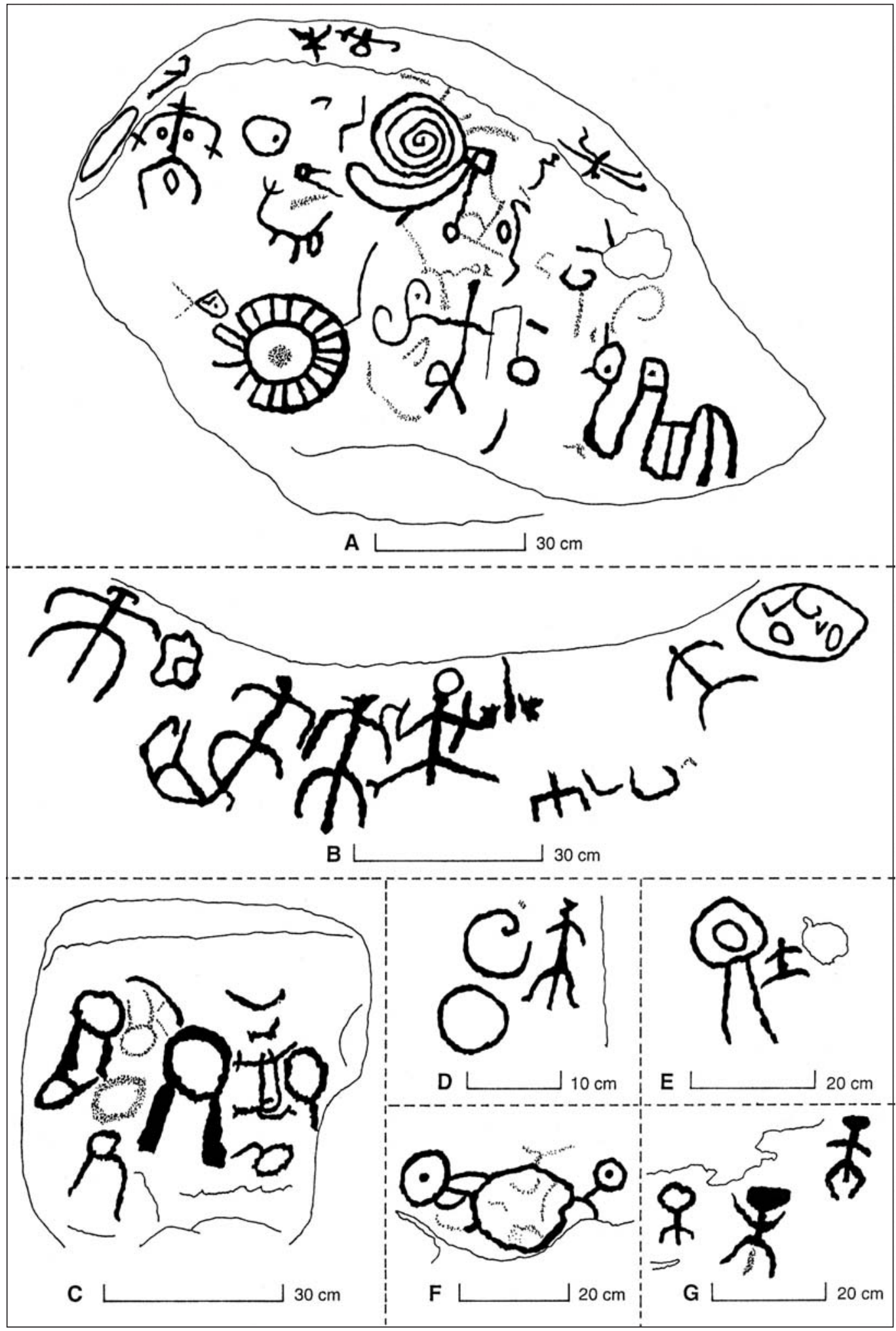

Figura 24. Conjuntos rupestres del grupo de Mialqui: Tucúquere (A, B); La Viñita (C, D, E, F, G). Rock art clusters from Mialqui: Tucúquere $(A, B)$; La Viñita $(C, D, E, F, G)$. 
tronco rectangular, y cuya pierna derecha tiene cuatro dedos.

El segundo (16B) está incluido adentro de un conjunto de signos sin contacto entre ellos. Debido a su pequeño tamaño $(18,5 \mathrm{~cm} \times 15 \mathrm{~cm})$, tiene una estructura poco evolucionada: rostro compuesto de dos ojos y una amplia boca, con adorno cefálico voluminoso que contiene una línea irregular. Esta estructura es típica de las máscaras del sitio del valle El Encanto, donde tales figuras poseen adornos desmesurados.

El tercero (20I) tiene una forma cuadrada (19 $\mathrm{cm}$ por lado), sin adorno exterior, con ojos semicirculares. Parece similar a un mascariforme del río Illapel (Ballereau y Niemeyer 1998: Figura 12). Bajo los ojos, con formas de lunas crecientes, vemos una línea ondulada que cruza todo el rostro, quizás un adorno o una nariz prolongada.

El cuarto (23G) tiene una estructura bien particular, porque no se sabe si representa una cara o un adorno cefálico. Tiene la forma de un medio círculo de $48 \mathrm{~cm}$ de diámetro. En el interior se notan dos estructuras cerradas escalonadas con eje de simetría vertical que termina en una cruz. ¿Quizás simbolizan dos ojos? Este mascariforme no parece tener equivalente en el Norte Chico.

\section{Las representaciones antropomorfas}

Las representaciones antropomorfas son numerosas en las estaciones del grupo de Mialqui, donde hemos registrado 98 unidades. Vamos a estudiar este grupo tomando en cuenta la estructura (simple o elaborada) de su cuerpo, las decoraciones asociadas, su naturaleza simbólico-abstracta, las asociaciones de antropomorfos y algunas representaciones particulares.

- Estructuras simples o lineales. El cuello, el tronco y los miembros están representados por segmentos rectos o curvilíneos. La cabeza, si existe, es un punto o un círculo. El conjunto es generalmente con simetría vertical, sin efecto de movimiento. A veces, los brazos o las piernas pueden desaparecer. La gran mayoría de las 98 representaciones son de este tipo. Ver por ejemplo las Figuras $15 \mathrm{C}, 17 \mathrm{O}$ y $22 \mathrm{O}$.

- Estructuras elaboradas. Las manos y/o los pies poseen dedos, en número variable, entre tres y cinco (Figuras 13G, 16A, 16E, 20N, 24A). El tronco tiene una estructura de superficie cerrada: rectangular, circular, irregular, a veces vaciado (Figuras 12B, 13G, 14H, 16A, 18A). Se observan anomalías de miembros desmesurados (Figura 12B). Una representación muestra obviamente los órganos sexuales, sobredimensionados (Figura 19E). La cabeza, circular o elíptica, posee un punto central, de manera parcial o completo, y los elementos de la cara (ojos, nariz, boca, Figuras 12B, 12C, 14H, $23 \mathrm{H}$ ). La cabeza puede reducirse a una cruz (Figura 24A). Ciertas representaciones humanas lineales poseen dos puntos o pequeños círculos a cada lado del tronco: ¿Quizás son imágenes simbólicas de los senos de una mujer? Se observa al mismo tiempo un círculo entre las piernas que podría simbolizar el sexo femenino (Figuras 14E, 17C, 24A).

- Estructuras decoradas. El antropomorfo posee ornamentos en ciertas partes de su cuerpo y blande uno o dos objetos, de uso desconocido, en las manos (Figuras 14J, 17J, 17K, 19A, 23H, 24A). Su tronco (o su brazo) aparece atravesado a la mitad por un palo horizontal (Figuras 12C, 14E, 16F, 18E, 24B). La cabeza está rodeada por segmentos radiales, elementos simétricos horizontales o trenza de pelo (Figuras 14H, 15K, 16E, 20F, 20K, 23D). Una figura humana de estructura simple posee, sobre su pelvis, una estructura más o menos circular (Figura 21E) que ya hemos observado en la cuenca alta del río Illapel (ver Ballereau y Niemeyer 1998: Figura 22C) y en la estación de El Llano de San Agustín, valle del río Hurtado superior (Ballereau y Niemeyer 1999: Figura 8B).

- Estructuras simbólicas y/o abstractas. Unas pocas representaciones tienen un aspecto donde se reconoce la forma humana por la presencia de ciertos detalles, tal como la cabeza (ojos), miembros. La voluntad de abstracción es evidente y resulta de una búsqueda artística. Los ejemplos que podemos citar son: Figura 12B (tronco reducido, miembros desmesurados); Figura 14I (antropomorfo con 9 pares de brazos y pies paralelos); Figura $21 \mathrm{G}$ (antropomorfo abstracto-simbólico, cuyos miembros parten de la cabeza, ésta misma siendo adornada con un semicírculo sin contacto).

- Estructuras con asociaciones de personajes. Ciertas escenas muestran personajes asociados de manera estática o en movimiento. Están alineados o dispersos, pero suficientemente cercanos, lo que 
da la impresión de una situación dinámica. En un mismo conjunto, brazos y piernas de los personajes no tienen siempre la misma disposición espacial. Damos los ejemplos más notables, con una corta descripción. Figura 12C: Cinco personajes -de los cuales dos tienen un tamaño reducido y otros dos se toman por la mano- parecen bailar. Un sexto, de cara invertida, los observa desde arriba; Figura 20G: dos personajes están en contacto por las manos y los pies; Figura 22E: cuatro bailarines, en abanico, tienen los brazos en posturas diferentes; Figura 24B: cinco personajes $-\mathrm{y}$ el esbozo de un sexto- parecen evocar un movimiento tipo danza.

- Estructuras particulares. La Figura 18A es el ejemplo de lo que podemos llamar un "hombrepájaro". Esta representación extraña nos invita a reconocer esta dualidad: la cabeza en forma de un círculo pequeño sobre un largo cuello; el cuerpo en forma de superficie cerrada cruzada por la columna vertebral; las alas cortas con cinco o seis plumas en contacto con el cuerpo; la cola larga y ancha; las extremidades inferiores con pies. Sus dimensiones son $29,1 \mathrm{~cm}$ de ancho por $34,4 \mathrm{~cm}$ de alto.

Terminamos en la Figura 14E donde siete personajes, de tamaño reducido, son de estructura muy diferentes entre ellos, y el de la Figura 14H, contenido en un cuadrilátero de lados curvilíneos, que presenta un tronco heterogéneo y una decoración de tres rayas arriba de la cabeza.

\section{Las representaciones zoomorfas}

Las representaciones zoomorfas del grupo de Mialqui son relativamente numerosas, puesto que encontramos un total de 45 . Son casi todas de tipo cuadrúpedo y de factura simple, con cabeza, lomo y patas representadas por líneas. No hay cuadrúpedo dibujado de manera elaborada, como se ve en La Silla o en el curso del río Hurtado superior. Hay dos ejemplos de un animal montado por un jinete (Figuras $14 \mathrm{G}$ y $21 \mathrm{~L}$ ). Encontramos dos representaciones que pueden ser confundidas con antropomorfos (Figuras 13A y 14N, ¿lagarto?). La Figura 17B muestra dos cuadrúpedos con cuellos largos que podrían ser camélidos. En la Figura 20M, vemos cuatro cuadrúpedos íntimamente cercanos, uno de ellos en posición vertical. Dos escenas particularmente interesantes merecen una descripción detallada:
- Figura 16F. En esta escena, aparecen dos representaciones de animales que, aparentemente por su rostro, son tucúqueres (Buho virginianus). No lejos de éstos, se ven camélidos que parecen alterados por la presencia de estas aves. El primer tucúquere se ve a la derecha de la escena, en contacto con un cuadrúpedo, con cuerpo vaciado cuya parte superior está cubierta con picoteado liviano; el segundo aparece en la parte superior izquierda, bajo el aspecto de este elemento geométrico llamado "círculo con dos apéndices (o rayos) exteriores paralelos". En la parte inferior de esta escena, parece que hay un tercer tucúquere, pero con el rostro incompleto. Estos pájaros podrían ser también imágenes del nuco (Asio flammeus), animal que actualmente tiene por costumbre atacar a animales pequeños como pollos. Los 12 cuadrúpedos de esta escena tienen estructuras simples; uno de ellos tiene las patas largas (camélido). Arriba y a la derecha, un animal posee un elemento geométrico vertical ligado a su cuerpo. Ya hemos observado tal diseño en ciertas estaciones del Norte Chico, en particular en el Potrero de la Casa de Pabellón, valle del río Hurtado superior (ver Ballereau y Niemeyer 1999: Figura 41A). A la izquierda, un cuadrúpedo parece asociado con una luna creciente.

- Figura 17E. Este dibujo muestra seis cuadrúpedos (uno mal definido) que aparecen en un ruedo (o ronda) dinámico, con la característica de una perspectiva volcada, donde algunos animales se abaten para dar la sensación de correr según un círculo. Esta técnica, la hemos encontrado en muy pocos lugares de Chile. Uno de ellos corresponde a una pintura del alero Tangani 3-b, cerca de Chapiquiña, sierra de Arica, donde observamos algo como 15 camélidos comprometidos que forman el ruedo y, a lo menos, media docena aparecen abatidos para dar la sensación, como se dijo, de un ruedo (Niemeyer 1972: Lámina VI).

\section{Las representaciones con caracteres geométricos}

La experiencia de las estaciones rupestres del Norte Chico previamente estudiadas, y las que son objeto de este estudio, nos enseñan que la gran mayoría de los temas rupestres queda sin interpretación inmediata. A la inversa, las formas "natura- 
listas", descritas en el párrafo precedente, permiten definir algunos aspectos sobre su naturaleza, aunque no se llegue a conocer el sentido o la simbología.

En las estaciones de La Silla (Niemeyer y Ballereau 1998), de la cuenca alta del río Illapel (Ballereau y Niemeyer 1998) y del valle del río Hurtado superior (Ballereau y Niemeyer 1999), hemos puesto en evidencia, además de las tres formas de seres vivos (mascariformes, antropomorfos y zoomorfos), unas pocas formas geométricas comunes. Entre ellas, las más notables son el círculo con dos apéndices exteriores paralelos, la cruz con contorno cruciforme y el cuadrilátero con lados cóncavos, que se encuentran también en el grupo de Mialqui.

- Círculo con apéndices exteriores paralelos. Este signo aparece muy frecuentemente en Mialqui (105 unidades). Su variedad morfológica es particularmente pronunciada e indica la importancia que se le atribuyó antaño. La forma "básica" de este signo se reduce a un círculo vacío ligado a dos apéndices exteriores generalmente paralelos y verticales (Figuras 15N, 19E). Por extensión y debido a la similitud gráfica, incluimos en esta categoría los círculos con más de dos apéndices exteriores paralelos (Figuras 14F: tres y cuatro apéndices; 16A: cuatro apéndices; 19F: cinco más un apéndice; 21C: tres apéndices). A veces, estos apéndices son voluntariamente divergentes (Figuras 15E, 17N). El círculo puede interrumpirse entre los dos apéndices, y se dice que el signo está "abierto" (Figuras 16D, 20J, 21A). También éste puede transformarse en una forma ovalada o rectangular (Figura 14C). El círculo puede contener ciertas variedades de detalles gráficos: un punto central (Figuras 12B, 17I), dos puntos (Figura 16F), tres puntos (Figura 17D), un círculo concéntrico (Figuras 16C, 17B, 18B, 24E), una cruz (Figura 17A), una línea vertical dividiendo el círculo como un diámetro (Figura $14 \mathrm{~F}$ ). Se observa, a veces, un punto o una raya sin contacto entre los dos apéndices paralelos (Figuras 17A, 17I, 19J). Ciertos motivos tienen apéndices más largos que lo normal (Figuras 16D, 17H) o están grabados con apéndices especialmente compactos (Figuras 16A, 16F, 17H, 18B, 21A).

Terminamos esta descripción con el signo de la Figura 16C, con estructura más elaborada; los tres signos de la Figura 16D, ejemplo de un conjunto diversificado en el cual se observa una figura "humanizada" y otra envuelta; y los cinco signos de la Figura 16F, entre las cuales dos (o tres) hemos anteriormente comparados con cabezas de pájaros.

- Cruz con contorno. Este signo se describe como una cruz rectangular, simple o doble, rodeada sin contacto y a distancia fija por un contorno regular. Hay cuatro ejemplos de este signo en Mialqui, que son identificados en las Figuras 18E, 19K (dos cruces) y 20D. La primera cruz es simple, aunque su contorno no se encuentra completo. Las otras tres son dobles, con tres diseños diferentes en la parte interior.

- Cuadrilátero con lados cóncavos. Esta forma particular de un cuadrilátero, ya se encuentra en varias estaciones del Norte Chico, por ejemplo, en la del Arenoso del Bolsico, en el valle del río Hurtado superior (Ballereau y Niemeyer 1999: Figura 43A), donde algunos aparecen como signos geométricos "humanizados". El único ejemplo de la estación de Mialqui se encuentra en la Figura $14 \mathrm{H}$, y pertenece al grupo de bloques $\mathrm{N}^{\circ} 15(\mathrm{Fi}-$ gura 4). El cuadrilátero es de dimensiones importantes (diagonales $55 \mathrm{~cm} \times 41 \mathrm{~cm}$ ) y contiene un personaje, ya descrito, y algunos motivos geométricos.

- Otros signos. Otros signos corrientes, que se deducen del círculo y del cuadrilátero regular están presentes: cuadrado/rectángulo con dos o cuatro diagonales (Figuras 14G, 14K), círculo con punto central (Figura 13J), círculo con diámetros perpendiculares (Figura 21F), círculos concéntricos (Figura 16G), y signos diversos tal como el signo escudo (Figura 24B), signo solar (Figura 21A), espiral (Figura 24A) y ondulado regular (Figura 18G). A esta lista tenemos que añadir signos propios al grupo de Mialqui, que a veces no se repiten en otros lugares. Presentamos una corta descripción de éstos:

- En cuatro de los bloques dispersos de la estación de Mialqui, hay un motivo escaleriforme, que aparece solo o en grupo. Estos son: Figuras $13 \mathrm{~L}$ (un motivo), 14A (un motivo), 15D (dos motivos) y 22A (cuatro motivos). Ninguno de estos ocho motivos son estrictamente similares, pero sus contenidos presentan elementos de superficie repetidos: cuadrados vacíos, cuadrados con diagonales cruzadas, rec- 
tángulos horizontales, semicírculos con decoración o vacíos, subdivisiones en células. A la derecha del motivo de la Figura 14A, hay un personaje con aspecto abstracto. En el conjunto de la Figura 15D, cuatro líneas horizontales unen los dos escaleriformes (se nota la presencia de tres círculos pequeños superiores). El motivo a la derecha de la Figura 22A tiene un aspecto "humano", con dos "ojos".

- En cada estación rupestre del Norte Chico, se encuentran petroglifos que muestran gran cantidad de signos, a menudo en el más perfecto desorden, de los cuales no se puede deducir alguna significación o interpretación. En Mialqui, como en otras estaciones vecinas se repite el mismo fenómeno, algunos de los cuales se describen a continuación. Figura 12D: larga superficie con numerosos elementos sin contacto. Se identifican formas humanas o animales, pareciendo esbozos, en medio de líneas rectas y curvas y unos 11 círculos con punto central. Figura 14M: elementos de superficies rectangulares e irregulares en contacto, alineados. Figura 20A: el grupo central de elementos de superficies en contacto tiene otros elementos sin contacto en sus dos lados. Figura 22B: elemento cerrado compuesto de tres partes, cada una compartimentada de manera diferente a la otra. Figura 23C: largo motivo, principalmente formado con líneas irregulares; a la izquierda, un signo de tipo abanico con cuatro semicírculos concéntricos. Figura 24A (longitud total del dibujo 1,39 m): se interpreta que este grupo de signos tiene un "orden", del cual podemos preguntarnos: ¿Qué tiene el personaje central en sus manos? ¿Qué representa esta rueda con rayos divergentes? ¿Cuál es la función de esta línea ondulada, de esta espiral, de este personaje femenino que ya hemos descrito? Quizás todos estos elementos diversos están ligados a una perspectiva simbólica de ámbito religioso.

\section{Panguecillo Bajo, Panguecillo Alto 1 y Panguecillo Alto 2 (Grupo de Panguecillo)}

Los petroglifos de la zona de Panguecillo se ilustran en las figuras de la manera siguiente:

- Panguecillo Bajo: Figura 25, Figuras 26A a 26D, Figura 26F.
- Panguecillo Alto 1: Figura 26E, Figuras 26G a 26J, Figuras 27 a 30, Figuras 31A y 31B.

- Panguecillo Alto 2: Figura 31C, Figuras 32 a 34.

Cuando dos caras de un bloque forman un ángulo y están cubiertas de manera continua con signos, reproducimos en las figuras una parte en común:

- La Figura 26A está ubicada sobre la cara izquierda de la $25 \mathrm{~A}$.

- La Figura 26B es la continuación de la 25B, en su izquierda.

- La Figura 26D está en la parte superior de la 25B.

- Las Figuras 27D y 27E tienen una parte común.

- La Figura 29B proviene de la parte superior de la 29A.

- La Figura 32A es un detalle de la Figura 31C.

- La Figura 34G es un detalle de la Figura 34B.

\section{Grandes estructuras grabadas}

Breves comentarios sobre los petroglifos notables por su longitud y altura.

La Figura 25A (longitud 1,13 $\mathrm{m} \times$ altura 1,04 $\mathrm{m})$ ofrece su cara adornada orientada al sudeste, con pátina negra descascarada en ciertas partes. $\mathrm{Al}$ extremo derecho, casi al nivel del suelo, lleva una tacita cupuliforme de $10 \mathrm{~cm}$ de diámetro. El bloque se encuentra partido en su extremo izquierdo por termofractura. La cara principal se encuentra abigarrada de signos que están raramente en contacto. La fracción del bloque separada por termofractura muestra dos veces la figura cruciforme doble (Figura 26A). La densidad de los signos es alta, y ninguna parte aparece libre de dibujo, y esta es la particularidad de un cierto tipo de representación grabada en el Norte Chico. Aquí los personajes aparecen casi escondidos, en un flujo caótico de líneas meándricas.

La Figura 25B $(1,92 \mathrm{~m} \times 1,00 \mathrm{~m})$, de cara al sur, parece similar a la anterior, pero con una densidad de signos un poco menos elevada, aunque los espacios libres son escasos. Aquí también observamos, a la derecha, una tacita cupuliforme de $8 \mathrm{~cm}$ de diámetro de boca. Ninguna de estas dos caras muestra figuras zoomorfas.

El gran panel dibujado en la Figura 27A (1,71 $\mathrm{m} \times 1,24 \mathrm{~m}$ ) es uno de los más extensos del grupo 


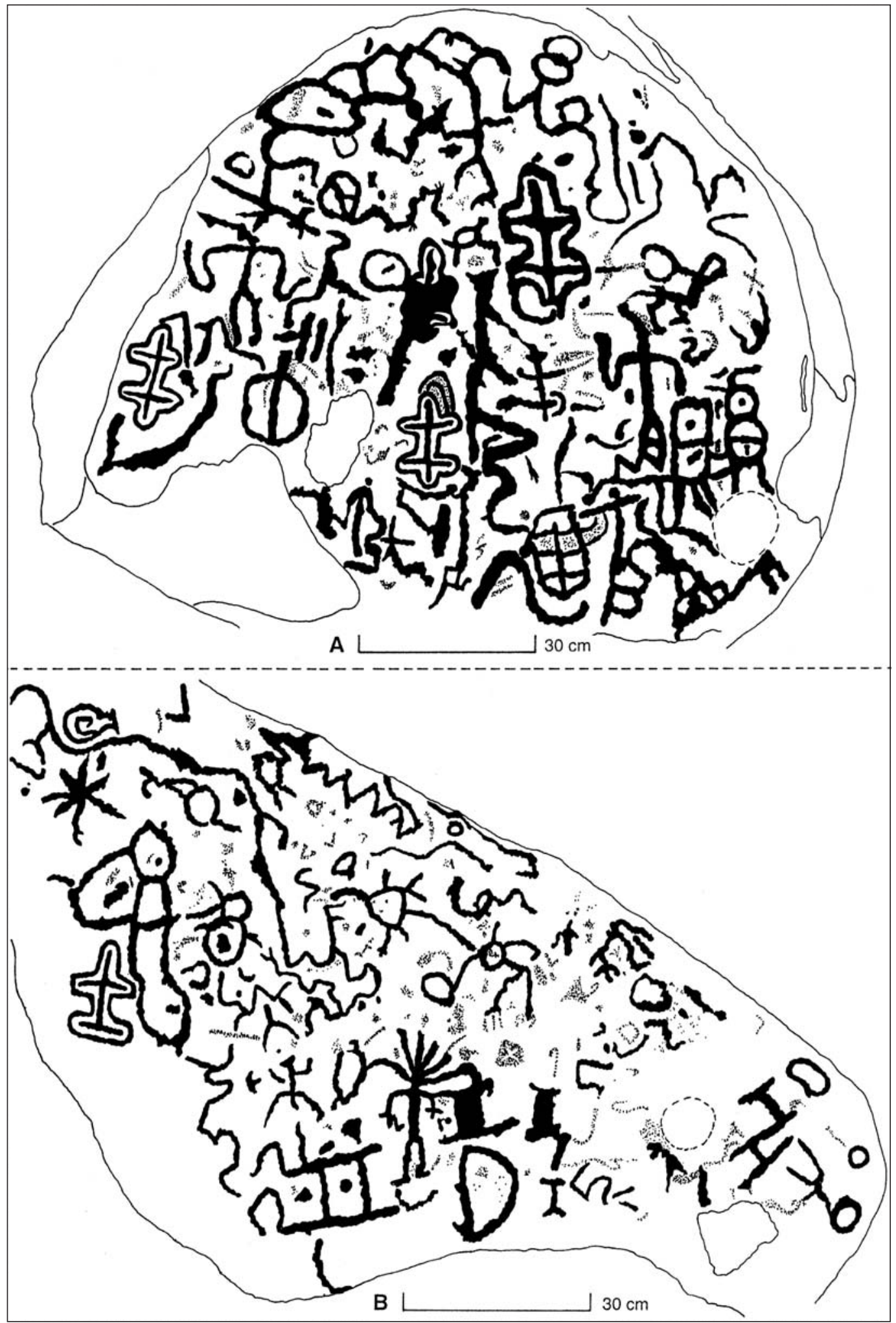

Figura 25. Conjuntos rupestres de Panguecillo Bajo.

Rock art clusters from Panguecillo Bajo. 


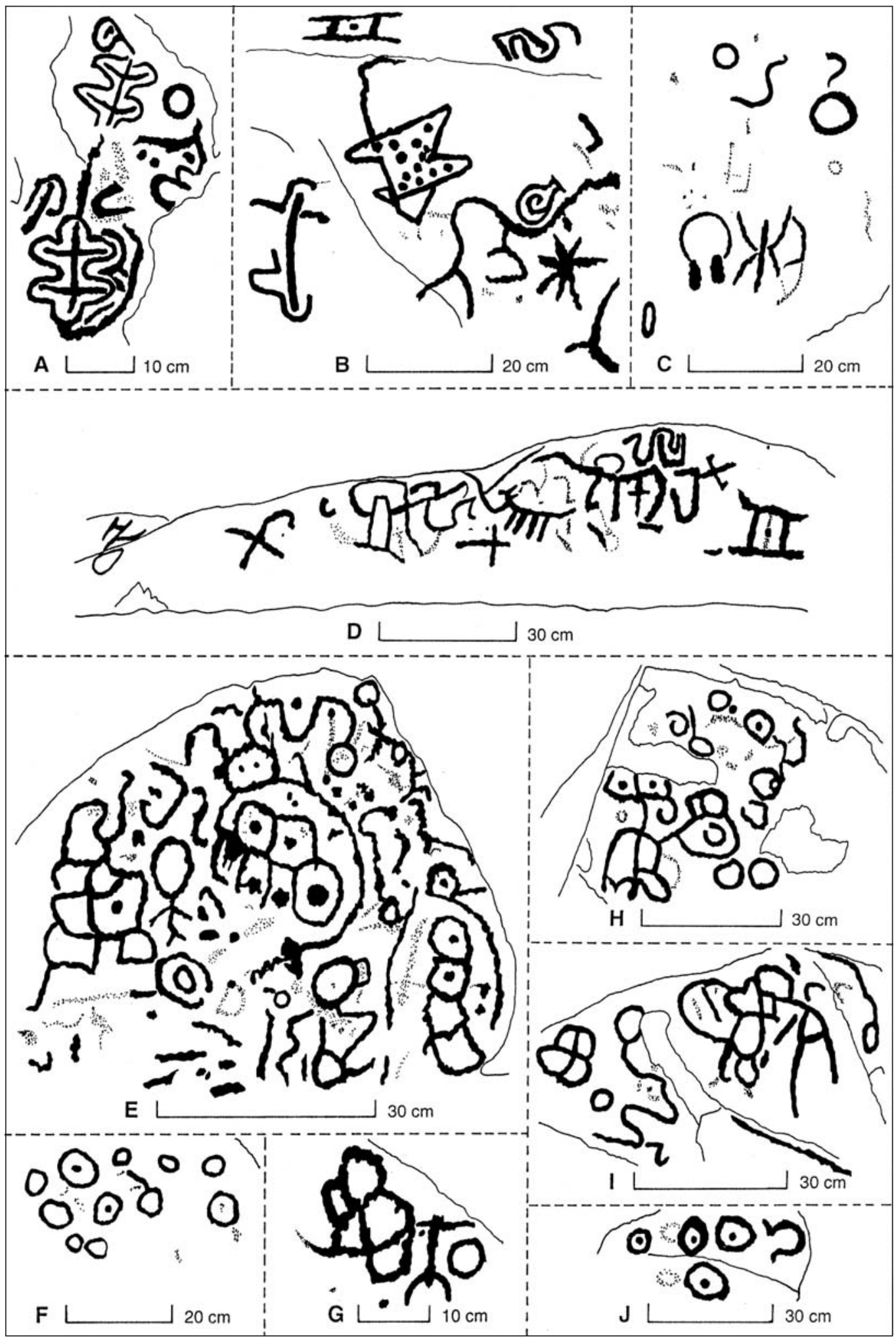

Figura 26. Conjuntos rupestres de Panguecillo Bajo (A, B, C, D, F) y de Panguecillo Alto 1 (E, G, H, I, J). Rock art clusters from Panguecillo Bajo $(A, B, C, D, F)$ and Panguecillo Alto $1(E, G, H, I, J)$. 


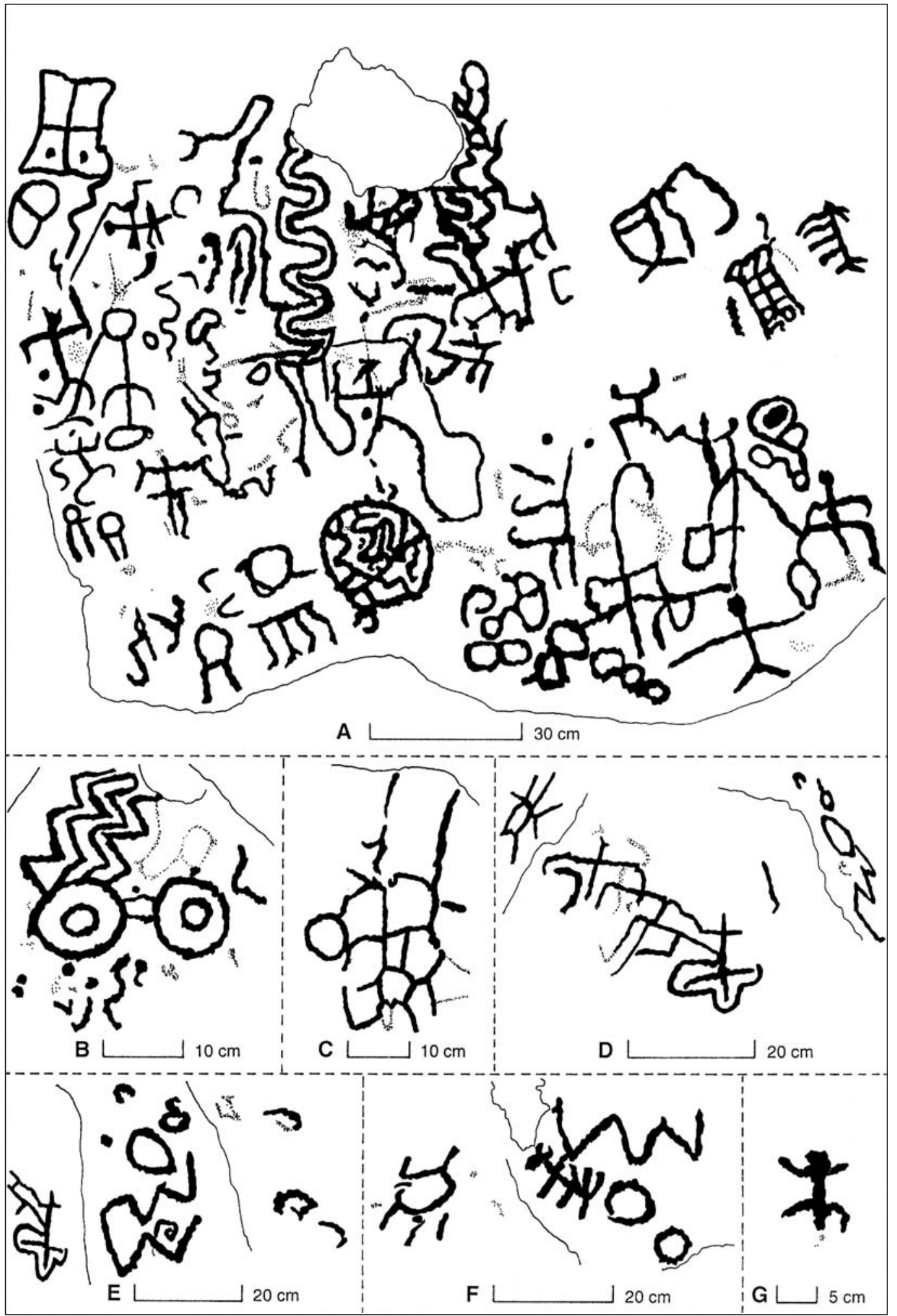

Figura 27. Conjuntos rupestres de Panguecillo Alto 1. Rock art clusters from Panguecillo Alto 1. 


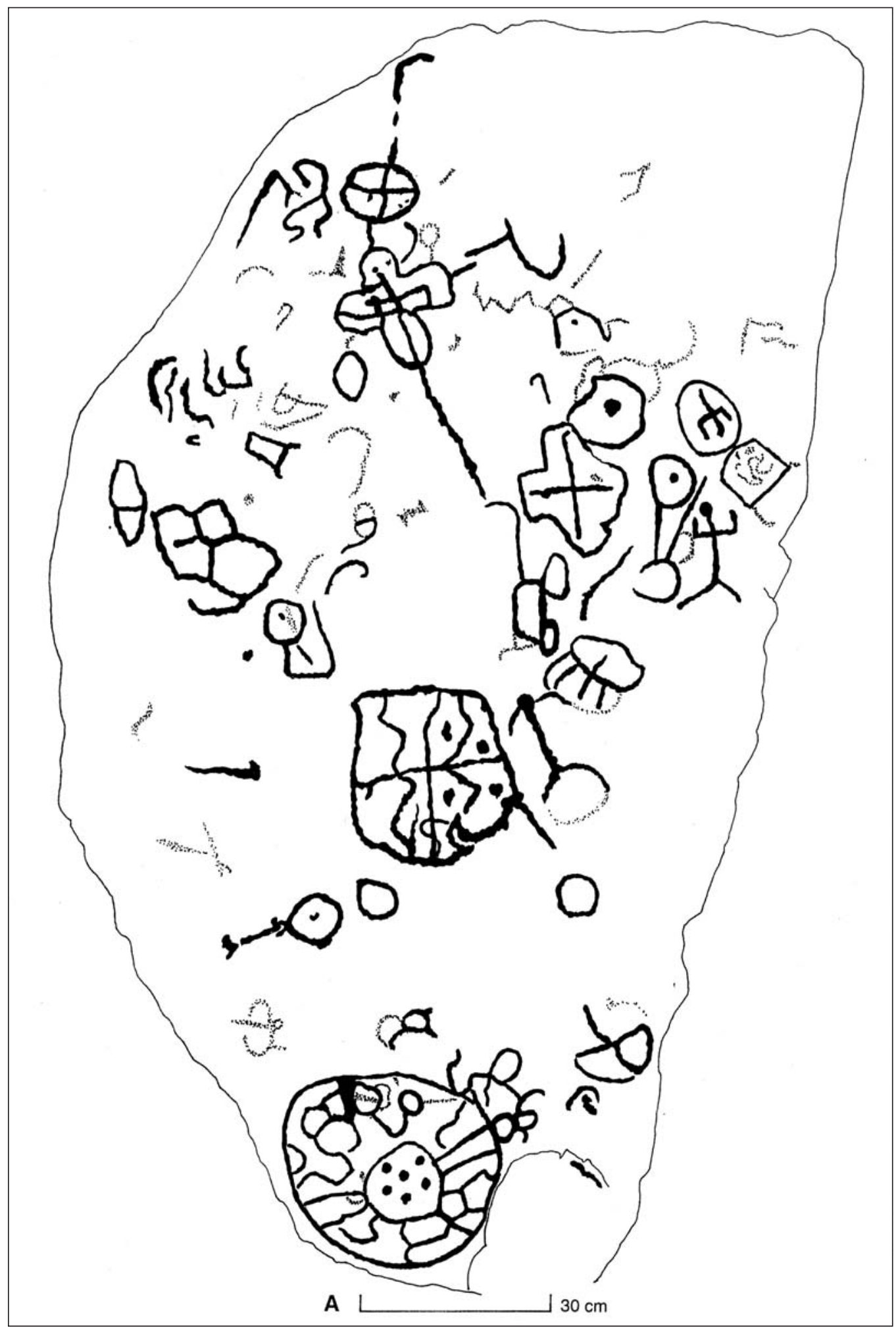

Figura 28. Conjunto rupestre de Panguecillo Alto 1. Rock art clusters from Panguecillo Alto 1. 


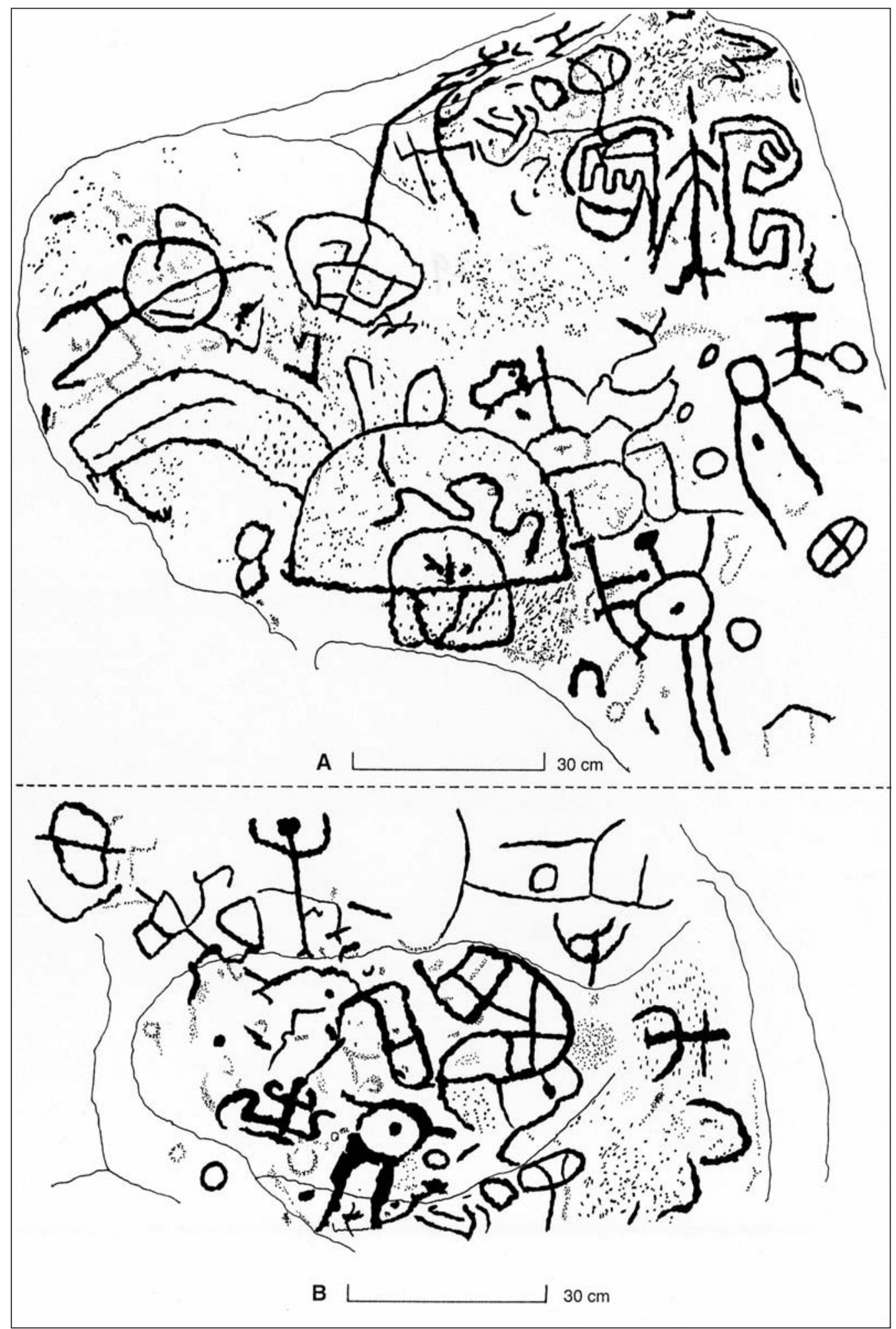

Figura 29. Conjuntos rupestres de Panguecillo Alto 1.

Rock art clusters from Panguecillo Alto 1. 


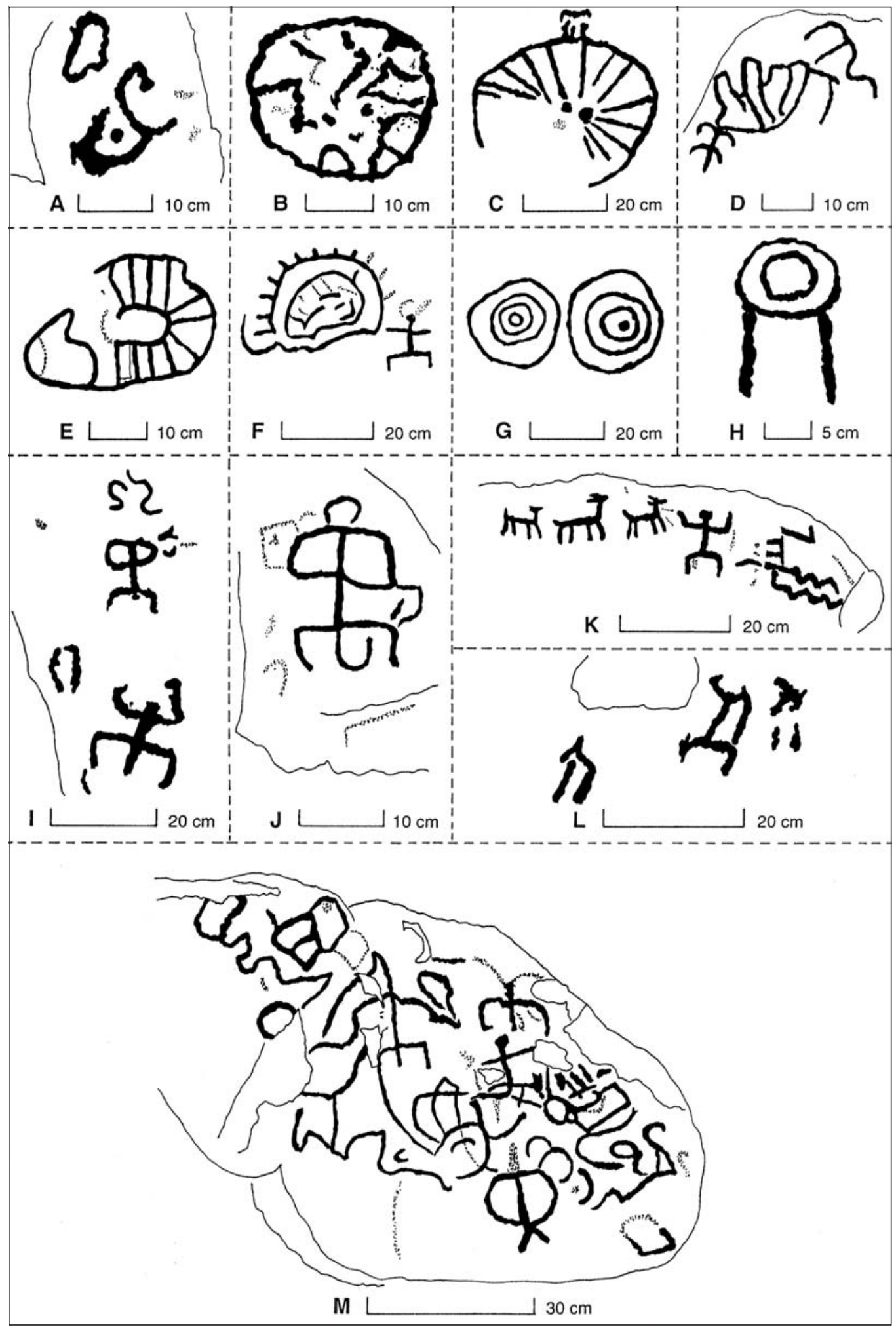

Figura 30. Conjuntos rupestres de Panguecillo Alto 1.

Rock art clusters from Panguecillo Alto 1. 


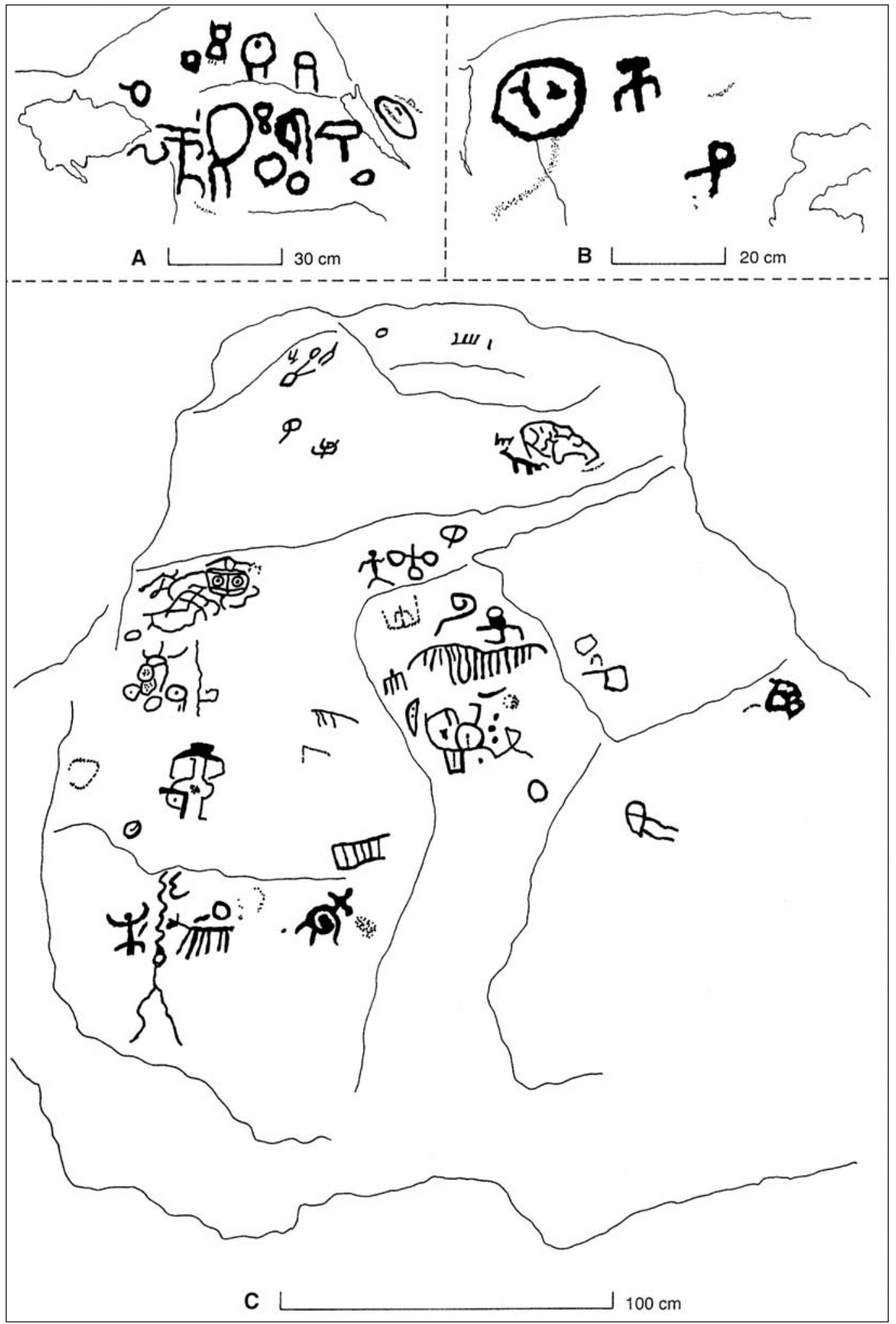

Figura 31. Conjuntos rupestres de Panguecillo Alto 1 (A, B) y de Panguecillo Alto 2 (C). Rock art clusters from Panguecillo Alto $1(A, B)$ and Panguecillo Alto $2(C)$. 


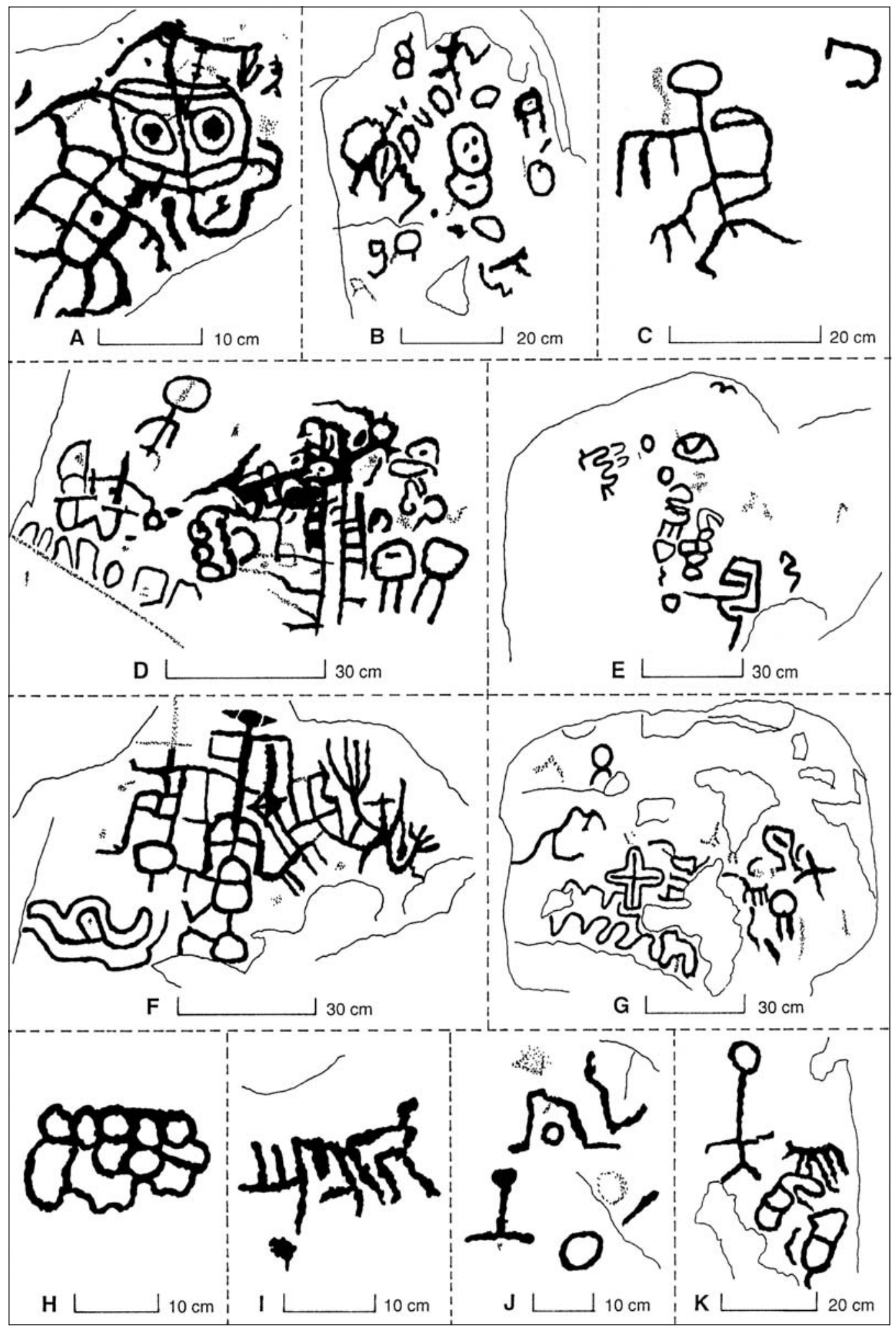

Figura 32. Conjuntos rupestres de Panguecillo Alto 2. Rock art clusters from Panguecillo Alto 2. 


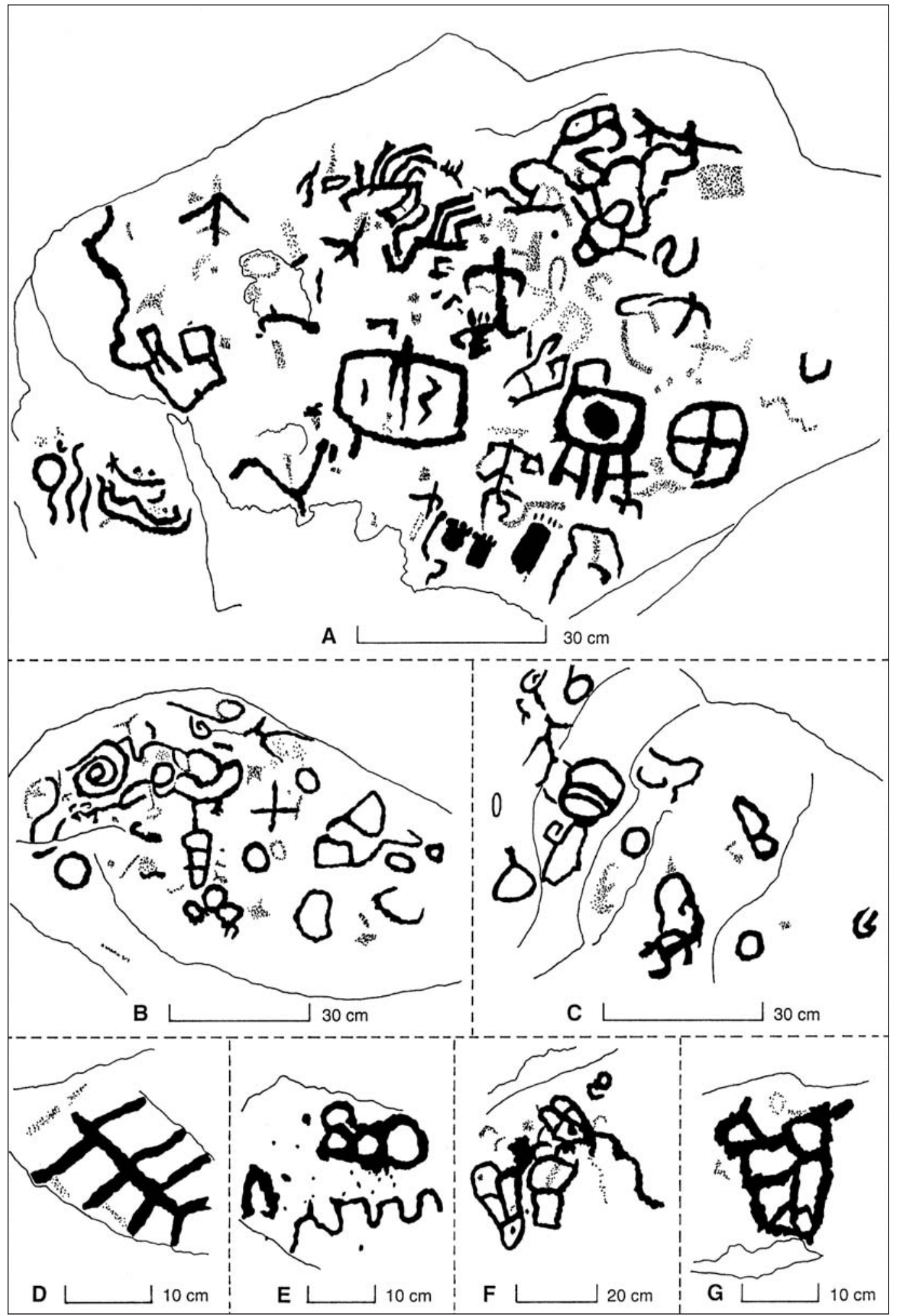

Figura 33. Conjuntos rupestres de Panguecillo Alto 2. Rock art clusters from Panguecillo Alto 2. 


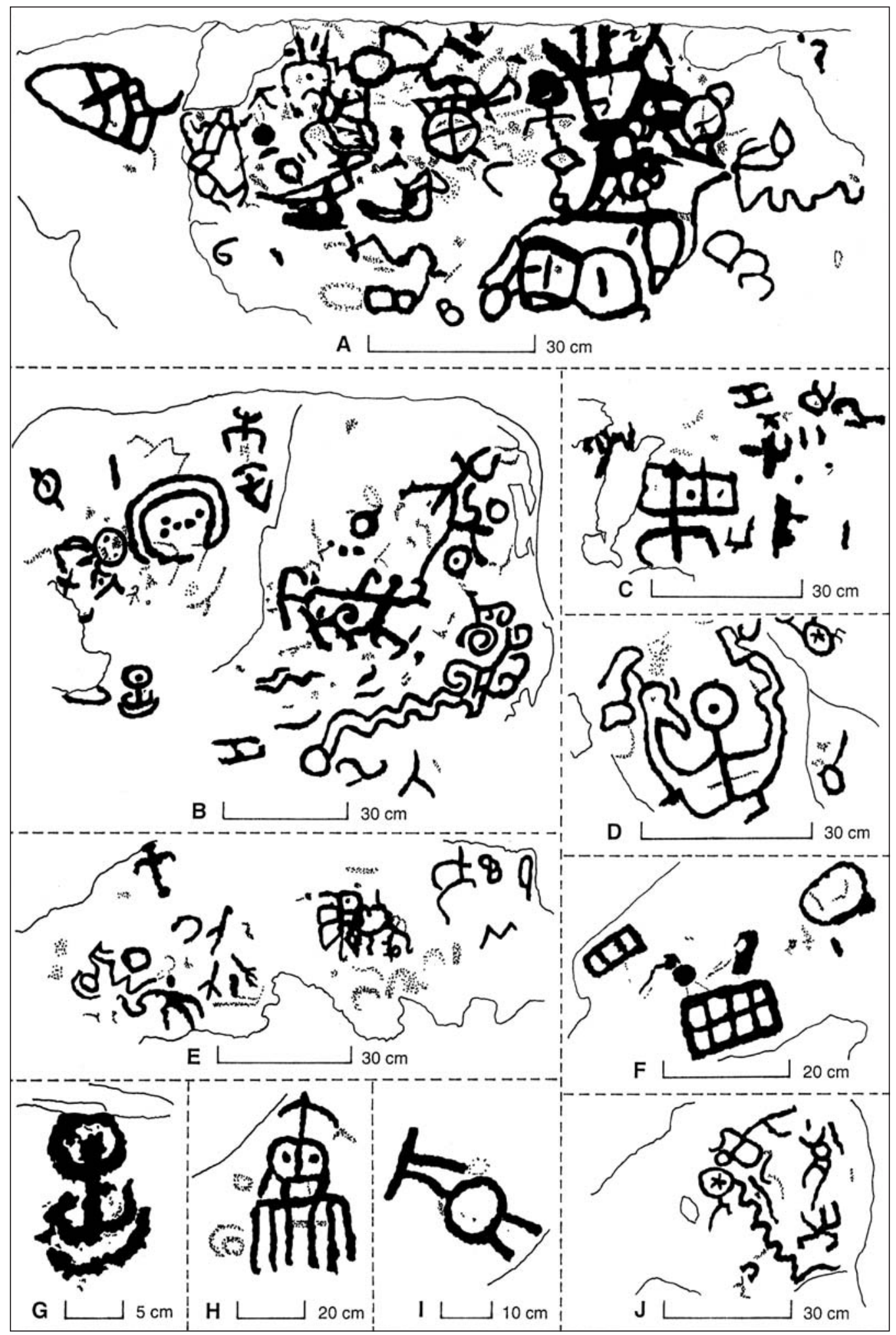

Figura 34. Conjuntos rupestres de Panguecillo Alto 2.

Rock art clusters from Panguecillo Alto 2. 
de Panguecillo. Su cara cuadrangular está orientada al sureste. Está literalmente llena de signos con gran complejidad de interdependencia (o interacción), particularmente en la parte central superior. Aquí también, los personajes aparecen escondidos, de manera muy efectiva. Sin embargo, al contrario de los dos grabados precedentes, hay aquí una parte de la superficie que resulta libre de signos.

El bloque que lleva la Figura 28A (1,90 m $\times 1,07 \mathrm{~m}$ ) es de forma medio prismática con una cara subrectangular elongada, en posición casi horizontal. Se puede decir que $50 \%$ de la superficie está ocupada por los signos que, de esta manera, parecen más aislados.

Las Figuras 29A $(1,27 \mathrm{~m} \times 1,17 \mathrm{~m})$ y $29 \mathrm{~B}$ $(1,08 \mathrm{~m} \times 0,64 \mathrm{~m})$, provienen de caras grabadas perteneciendo al mismo bloque. La primera cara aparece vertical (mirando al este, y de superficie muy irregular) y la secunda horizontal. Contienen signos espacialmente bien arreglados, que podrían constituir una escena organizada. Anotamos el uso de un picoteado ligero, que cubre casi todo el espacio, dibujado o no.

La Figura $31 \mathrm{C}(2,20 \mathrm{~m} \times 2,14 \mathrm{~m})$, que muestra pocos grabados, sobre todo en la mitad inferior, proviene de una alta piedra con cara vertical. La máscara situada encima y a la izquierda del conjunto está dibujada con mejor escala en la Figura 32A. Los grabados de la cumbre de la piedra son difíciles de acceder. Aparecen también escritos modernos. Desprendido de la roca madre, hay en el suelo un trozo de roca que lleva grabados dos antropomorfos.

La Figura 33A $(1,26 \mathrm{~m} \times 0,77 \mathrm{~m})$ que tiene su cara al sur, está compuesta de signos de pequeñas dimensiones, sin contacto, a veces en superficies cerradas, salvo en la parte superior derecha donde vemos un conjunto meándrico.

Terminamos esta lista descriptiva con la Figura $34 \mathrm{~A}(1,52 \mathrm{~m} \times 0,55 \mathrm{~m})$, cuyo contenido presenta varios grupos de elementos gráficos irregulares y caóticos, unos de ellos con líneas gruesas.

\section{Las representaciones de máscaras y mascariformes}

Se encuentran tres mascariformes en las estaciones del grupo de Panguecillo, que están representados en las Figuras 28A, 29A y 31C (este último con mejor escala en 32A).El primero (Figura
28A), de dimensiones $0,29 \mathrm{~m} \times 0,27 \mathrm{~m}$, se ve al centro de esta larga piedra horizontal ya descrita. Su contorno cuadrangular tiene tres lados rectos, y el cuarto es irregular; el interior se ve dividido en dos partes iguales por una línea horizontal; dos onduladas regulares parecen simbolizar las cejas y la boca; se ven dos pares de ojos, y no hay decoraciones exteriores. Este mascariforme se ve asociado con un antropomorfo en su límite superior.

El segundo (Figura 29A) está cerca del centro de un amplio grabado, ya descrito. De dimensiones $0,46 \mathrm{~m} \times 0,45 \mathrm{~m}$, está compuesto de dos partes: a) una superficie más o menos cuadrada, con tres lados redondeados que simboliza el rostro, y b) un vasto atavío cefálico en forma de semicírculo que corta el rostro en su mitad. En la parte superior del rostro, se ven los ojos y la nariz, muy cercanos, y en la parte inferior, tres líneas oblicuas. El atavío contiene una ondulación irregular y tiene en su cumbre un adorno vertical en forma ovalada. Se ve también un adorno exterior tipo "gancho". Cuatro otras líneas exteriores tocan este adorno (una es la pierna de un antropomorfo).

El tercero (Figuras 31C y 32A) se reconoce como un mascariforme por sus dos ojos vaciados rodeados por un círculo, y está incorporado a una superficie reticulada. El mascariforme tiene una forma cuadrada irregular, con un eje central vertical que se prolonga arriba hasta un elemento en forma de ángulo, y abajo hasta una ondulación que se cierra sobre el mascariforme.

Entre estos tres mascariformes, el primero se acerca a los que se encuentran en el curso del río Hurtado superior, donde hemos visto que $47 \%$ entre ellos tienen una separación horizontal mediana, y $70 \%$ tienen una cara estilizada. El segundo es de estilo El Encanto (ver Mostny y Niemeyer 1983: Figura 68). El tercero es de estilo figurativo-abstracto y puede ser comparado a ciertas figuras mascariformes de la cuenca alta del río Illapel.

\section{Las representaciones antropomorfas}

Hemos registrado 65 figuras humanas en las tres estaciones del grupo de Panguecillo, que se incluyen en los cinco tipos de estructuras previamente definidas para las estaciones de Mialqui:

- Estructuras sencillas o lineales. Buenos ejemplos son: Figura 26E (larga cabeza ovalada), 
Figura 26G (personaje sin cabeza), Figura 28A (dos personajes, con y sin cabeza).

- Estructuras elaboradas. El personaje de la Figura 25A, a la derecha, blande un objeto lineal en su mano derecha. Posee un adorno oblicuo en su cabeza; sus piernas parecen plegadas. Al extremo izquierdo de la Figura 27A, vemos un antropomorfo en la posición del corredor; de su mano izquierda, lleva por arriba un palo. Arriba y a la derecha de la Figura 29A, observamos una figura antropomorfa con largo tronco y dos pares de brazos; no tiene cabeza; a sus dos lados están dos estructuras con seudosimetría vertical, que incluyen dos onduladas. En la Figura 29B, vemos a la izquierda un antropomorfo con miembros sinuosos. El personaje de la Figura 30J muestra brazos en jarra. Abajo y a la izquierda de la Figura $31 \mathrm{C}$, están dos personajes, uno con cuerpo espiralado. El antropomorfo de la Figura 32C se ve adornado con varios elementos lineales.

- Estructuras decoradas. El personaje de la Figura 25A, a la izquierda, tiene una decoración cefálica, recta e inclinada, que podría ser una pluma de adorno. Sus brazos están prolongados por elementos ondulados, simétricos. El de la Figura 25B es seguramente el más notable de Panguecillo. De su cuerpo, se ven manos con tres dedos y sus pies están marcados. Su cabeza soporta un adorno cefálico en abanico con seis elementos. El de la derecha toca un rectángulo vaciado, del cual dos lados se prolongan horizontalmente.

- Estructuras simbólicas y/o abstractas. Al centro derecha de la Figura 34A, se ve un personaje con cabeza vaciada, un par de brazos horizontales y la base del tronco bajo la forma de un óvalo horizontal. El pequeño antropomorfo de la Figura 34G simboliza un ser humano que parece destacado del suelo. Está envuelto por abajo por una línea curva. El de la Figura 34H se deduce del signo "círculo con dos apéndices exteriores paralelos", al cual se superpone una barra horizontal con cuatro nuevos apéndices verticales. Anotamos que, arriba de la cabeza, se ve el mismo adorno que en la máscara de la Figura 32A.

- Estructuras con asociaciones de personajes. A la derecha de la Figura 27A, vemos la asociación de tres (o cinco) personajes lineales, en contacto por los miembros, que parecen estar en un movimiento común. Están asociados con motivos circulares. El conjunto de la Figura 32F es excepcional. Los tres antropomorfos están en contacto estrecho con un sistema geométrico semirregular. El personaje central, de constitución corporal simple, tiene dos adornos agudos a cada lado de su cabeza; el de la izquierda tiene una estructura más abstracta; el de la derecha se reconoce por estas dos manos con cuatro dedos, la cabeza se adivina por una cruz. A la derecha de la Figura 34B, vemos un conjunto de tres antropomorfos que se tocan por los brazos y los pies. El de abajo tiene sus miembros en forma de ganchos. El conjunto está acompañado por figuras geométricas onduladas y circulares.

\section{Las representaciones zoomorfas}

Las estaciones de Panguecillo poseen un total de 12 representaciones zoomorfas. Es un número relativamente pequeño, en comparación con las del grupo de Mialqui. Los ejemplos más notables se describen a continuación: Figura 26C: ¿lagarto? Figura 26D: cuadrúpedo con una cuerda al cuello; Figura 27A: a la derecha un cuadrúpedo con dos cabezas; Figura 27F: cuadrúpedo con seis patas en proyección vertical; Figura 30K: personaje enfrenta a "rebaño" de tres animales; Figura 31C: "cuadrúpedo" con seis patas.

\section{Las representaciones con caracteres geométricos}

- Círculo con apéndices exteriores paralelos. Hemos estudiado 37 de estos símbolos en esta zona, de los cuales la mitad tiene una estructura simple, sin adorno ni extensión (ver Figura 27A, tres signos). Figura 25A: a la derecha de este panel grabado, se ven dos signos, constituidos por dos células superpuestas cuadradas a la izquierda, circulares a la derecha, con puntos centrales (o un rayo horizontal); el signo de la izquierda tiene tres apéndices, el de derecha dos. Figura 26C: el contorno está interrumpido entre los dos apéndices verticales. Figura 28A, al centro derecha: signo con su superficie achatada con cuatro apéndices. Figura 29A, muestra tres signos de este tipo: el de derecha tiene largos apéndices y se ve un punto entre ellos; este signo está situado muy cerca de un antropomorfo con cabeza lineal horizontal; a la izquierda de este paramento, se ve el segundo signo, de gran 
tamaño $(0,16 \mathrm{~m} \times 0,33 \mathrm{~m})$ y tocado o cruzado por varias líneas; el tercero, abajo y a la derecha de la escena, se ve "humanizado" por una cabeza encima de un largo cuello y dos brazos; el personaje blande un objeto curvo con dos o tres rayas perpendiculares, y parece amenazar al mascariforme vecino. La Figura 29B contiene un signo con apéndices espejos, un punto central y dos rayas superiores opuestas. Este signo hace la relación con el panel grabado de la Figura 29A. La Figura 30H posee dos círculos concéntricos. Los dos signos de la Figura 32D parecen cuadrados. Figura 33A: signo con contorno cuadrado y punto central vaciado, que posee 4 apéndices, unidos dos por dos. A la izquierda, quizás el esbozo de otro signo parecido. Figura 34B, a la izquierda: un signo con dos puntos adentro: ¿dos ojos? y apéndices exteriores divergentes. Está en contacto con un elemento de círculo con doble contorno. Figura 34I: un signo en contacto con otro en forma de $\pi$.

- Cruz con contorno. De las diez cruces con contorno del grupo de Panguecillo, siete están sobre las diferentes caras de las piedras dibujadas en las Figuras 25A y 25B (con extensiones en Figuras 26A y 26B). Salvo la de la Figura 26B, que es un esbozo, las otras seis tienen doble cruz con envoltura completa (casi completa con la de la Figura 28A). En la Figura 27D, hay otra cruz incompleta, ligada con una red geométrica. En la Figura 28A, la envoltura de la cruz simple está un poco alejada, en un concepto geométrico nuevo. La última, en la Figura $32 \mathrm{G}$, tiene el perfil ideal de una cruz simple.

- Cuadrilátero con lados cóncavos. Un solo dibujo de este signo existe en el grupo de Panguecillo; está representado en la Figura 27A (lado superior izquierdo) y muestra adentro dos ejes rectangulares, con un punto dentro de las dos superficies inferiores.

- Otros signos. No hay cuadrados/rectángulos concéntricos, ni cuadrado/rectángulo con diagonales. Hay círculos con punto central (37), círculos con diámetros perpendiculares (4), círculos concéntricos (6), signos escudos (4, ver prototipo en Figura 25A, abajo), un signo solar, nueve espirales y 26 onduladas regulares. La Figura 33A posee las tres únicas huellas de paso de la zona de Panguecillo; dos parecen ser de animal, la tercera de un antropomorfo.
Terminamos con breves comentarios sobre signos/conjuntos muy particulares, sin clasificación posible. Figura 26B: forma geométrica con 13 puntos en su interior. Figura 26E: vasto conjunto de formas cerradas, circulares o no (total de 23), alineadas o en grupo compacto. Figura 27A, abajo: círculo conteniendo una red geométrica muy densa. Figura 28A, abajo: otro círculo con numerosos elementos geométricos adentro, cuyo pequeño círculo central contiene seis puntos. Figura 28A, arriba: una figura cruciforme, prolongada hacia abajo por una línea $i$ antropomorfo estilizado? Figura 34D: ¿antropomorfo estilizado o animal imaginario?

\section{La Rinconada de Carretón}

Los petroglifos de la estación La Rinconada de Carretón están reproducidos en las Figuras 35 a 38. La estación se ve dominada por la presencia de un enorme bloque de varios metros de largo y de altura media de un metro y medio. Le hemos dado el número 1. Sus numerosas caras laterales portan petroglifos, en escenas o con signos aislados. La cumbre del bloque, más o menos llana y horizontal, presenta algunos signos, pero son escasos y borrados por la erosión. Sólo fueron reproducidos aquí los del perímetro, cuyas reproducciones ocupan la Figura 35. Los otros bloques portadores de grabados tienen tamaños que no superan los dos metros. A menudo, como en otros lugares, un bloque tiene varias caras ocupadas por grabados y los dibujos pueden mostrar partes comunes. Así se ve en las Figuras 36F y 36H, 37F, 38A y 38B.

\section{Las representaciones de máscaras, mascariformes, antropomorfos y zoomorfos}

El mascariforme de la Figura 35B se ve con un alto grado de estilización. Se adivina, gracias a una red de seis adornos en forma de ángulos rectos, que miran por mitades a la derecha y a la izquierda, y dos círculos que simbolizan los ojos. El segundo y último mascariforme es el de la Figura $37 \mathrm{G}$. Tiene ojos y boca marcados y está tocado a la derecha por un adorno externo. Se podría discutir el carácter apócrifo de esta figura.

En la estación La Rinconada de Carretón se registran 36 figuras antropomorfas. Dos escenas con varios personajes atraen nuestra atención. La primera, en la Figura 35C, muestra cinco 


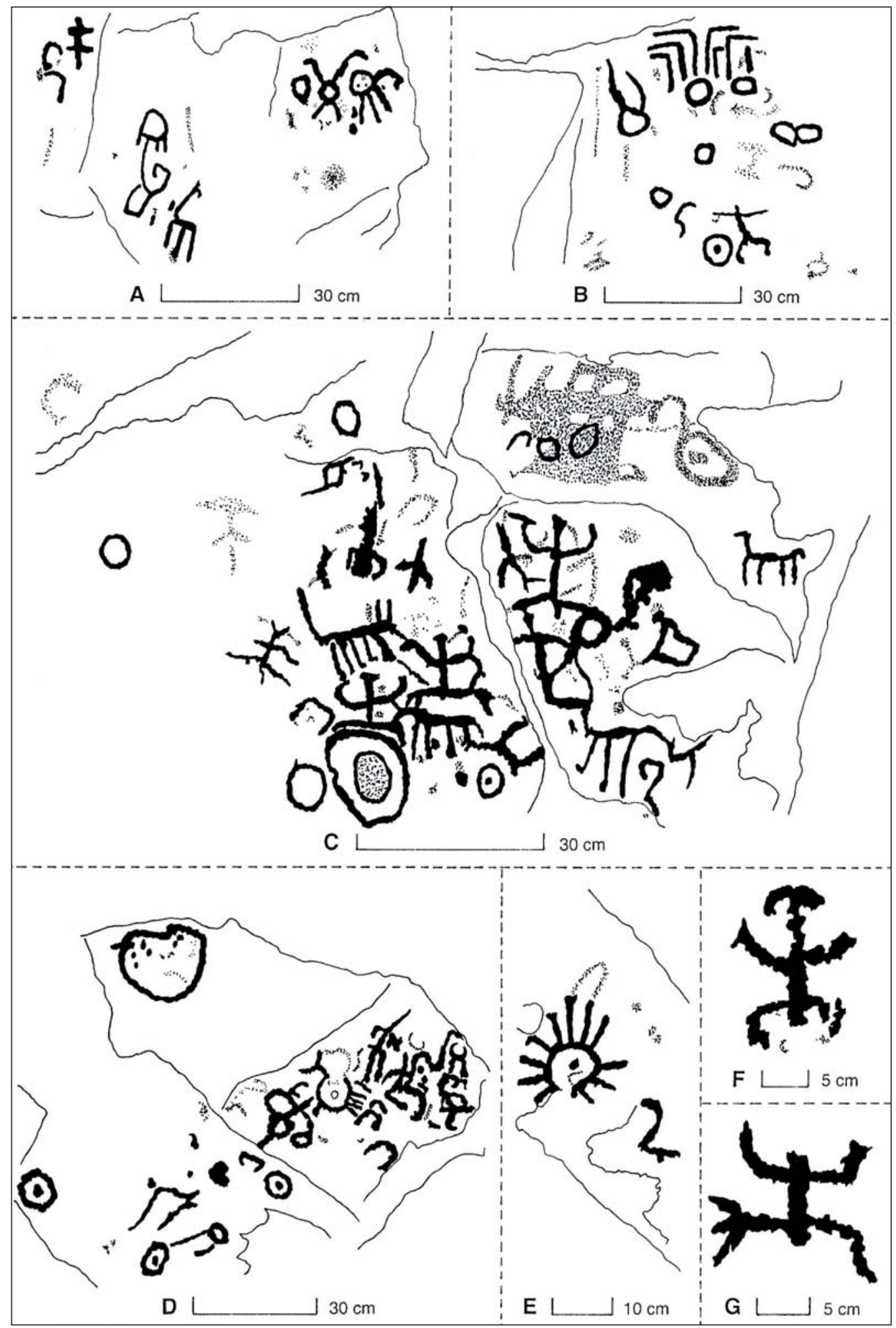

Figura 35. Conjuntos rupestres de La Rinconada de Carretón. Rock art clusters from La Rinconada de Carretón. 


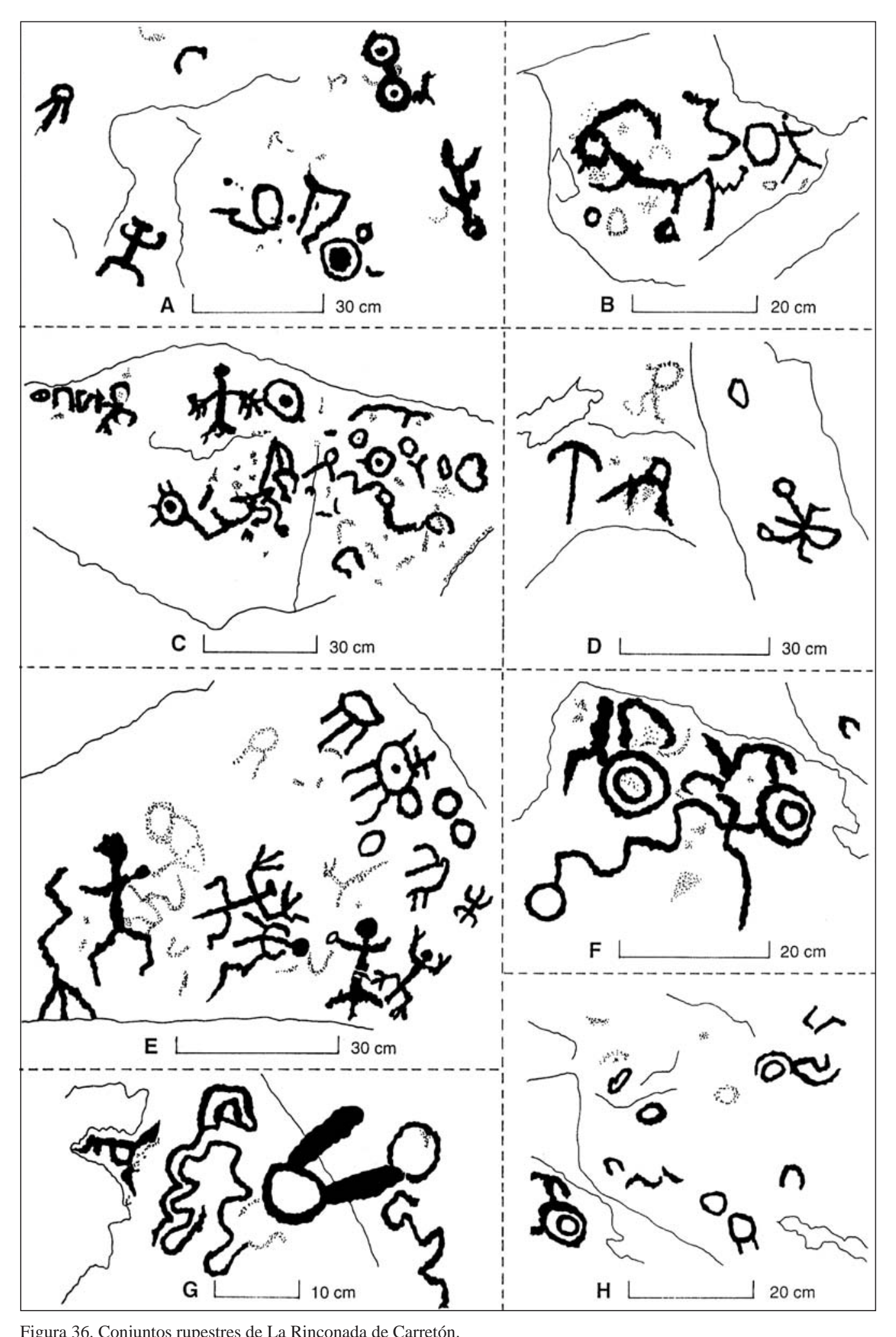




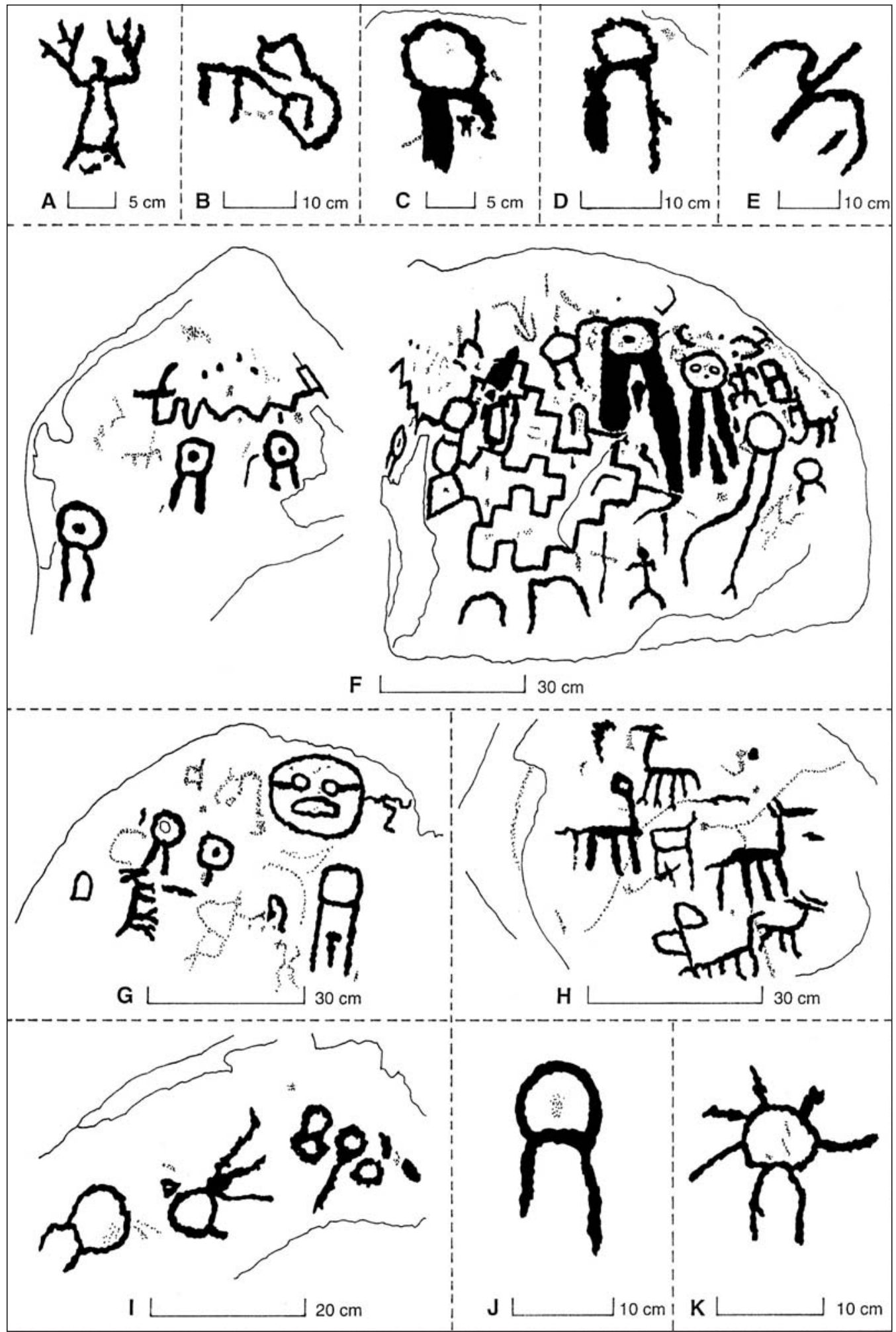

Figura 37. Conjuntos rupestres de La Rinconada de Carretón. Rock art clusters from La Rinconada de Carretón. 


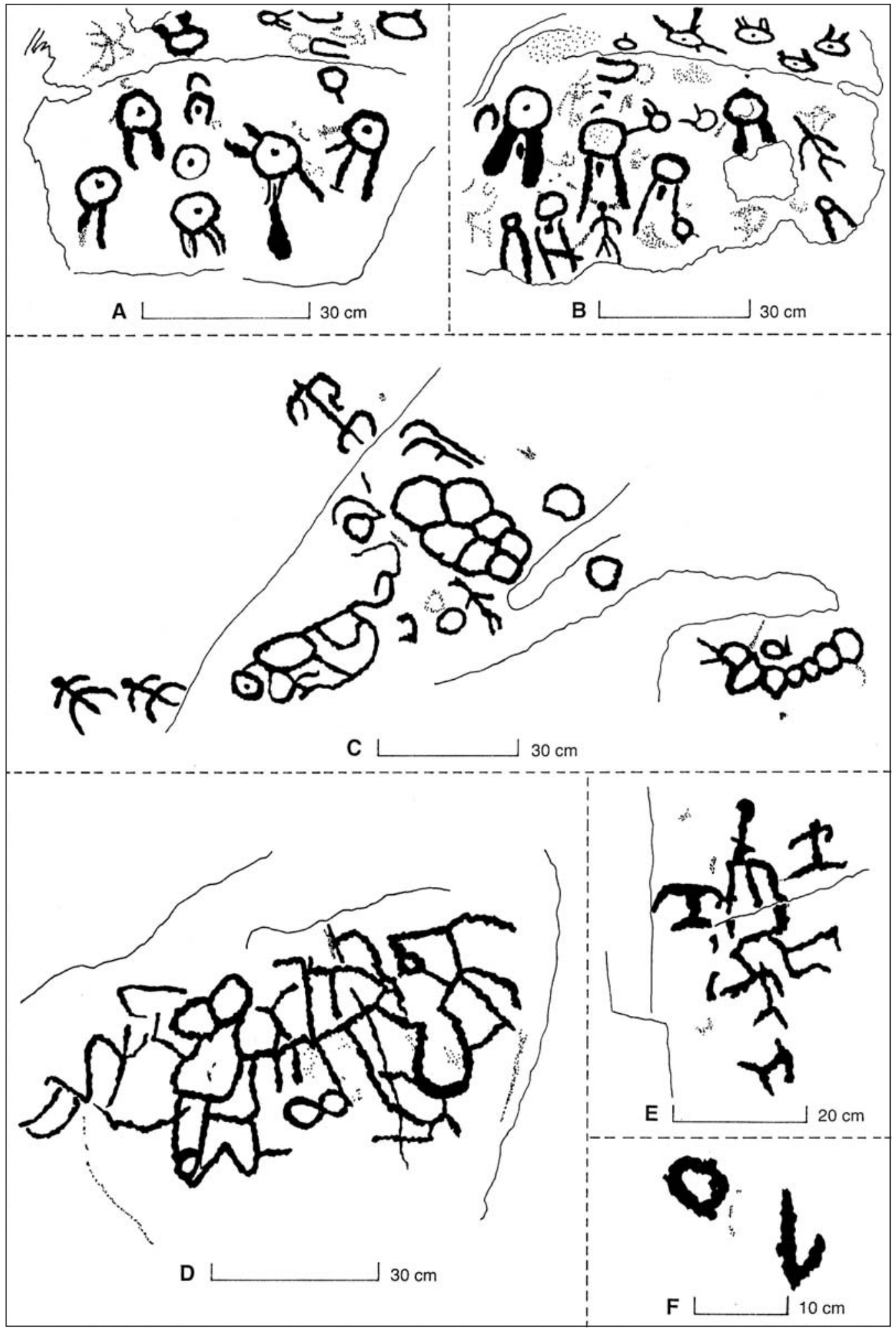

Figura 38. Conjuntos rupestres de La Rinconada de Carretón. Rock art clusters from La Rinconada de Carretón. 
antropomorfos, de formas simples. Tres de ellos de mayor tamaño y se encuentran alineados en el centro, según la dirección SW-NE. El de arriba tiene una cabeza ligeramente triangular y blande un palito en su mano derecha. Por sus piernas está al contacto de una estructura geométrica compleja, que comprende un círculo. El del centro parece llevar un adorno oblicuo en su pequeña cabeza circular. Su mano derecha (con una cuerda) y su pie derecho, cada uno, tocan un cuadrúpedo. El tercer antropomorfo, abajo, está sentado sobre una estructura con dos círculos concéntricos, se codea también con los dos cuadrúpedos de manera muy próxima. Aquí, la simbiosis hombre/animal aparece fuerte.

La segunda escena, Figura 36E, revela seis personajes más o menos alineados de izquierda a derecha, en la parte inferior del dibujo, aparentemente entrenados en un movimiento general. Sus morfologías de estructuras simples aparecen, sin embargo, diferenciadas y tienen tamaños variables: el de izquierda mide $29 \mathrm{~cm}$ de alto, el de derecha $8,6 \mathrm{~cm}$. Cinco de los seis poseen una cabeza en forma de punto o de círculo y tienen -o no tienendedos en los pies y en las manos. El personaje central tiene una estructura abstracta, que se parece al "círculo con dos apéndices exteriores". El cuarto, desde la izquierda, posee un círculo pequeño en la mano derecha y un adorno en su tronco.

Otras representaciones de antropomorfos de esta estación merecen una corta descripción. El personaje de la Figura 35F, de estructura simple, tiene una decoración cefálica en arco de círculo. El de la Figura 35G no tiene cabeza, pero su pie derecho tiene tres dedos. El antropomorfo de la Figura 36B se apodera de un círculo. El de la Figura $36 \mathrm{C}$, que tiene dedos en las manos, toca un círculo con punto central. El de la Figura 37A tiene piernas cortas, su cuerpo presenta una superficie y tiene dedos en sus dos manos. En la Figura 38E (arriba), un personaje aparece en la posición de un corredor, que se dirige hacia una estructura geométrica compleja.

De los zoomorfos, hemos registrado 11 ejemplares. Son todos cuadrúpedos de formas simples. Ya hemos descrito la escena 35C, donde aparecen tres zoomorfos. El de la izquierda tiene cinco patas -sería la pata de atrás un palo blandido por el personaje de abajo-, dos orejas y una cola vertical casi tan larga como el cuerpo. El cuadrúpedo de la Figura $37 \mathrm{G}$ está en posición vertical y algunas de sus patas son bífidas. El roza con su hocico un “círculo con dos apéndices exteriores". En la Figura $37 \mathrm{H}$, vemos un rebaño de cinco cuadrúpedos; cuatro miran a la derecha, uno a la izquierda; un animal tiene un círculo pequeño en lugar de la cabeza; las formas de las cabezas cambian de un animal al otro.

\section{Las representaciones con caracteres geométricos}

El signo geométrico que aparece con más frecuencia en la estación de La Rinconada de Carretón es, lejos, el círculo con apéndices exteriores. Se puede decir que es "la" estación madre de este símbolo, porque se encuentra en variedades geométricas que no existen en otros lugares. El total es de 46 signos, y como hay 33 petroglifos, quiere decir que hay 1,4 signos por petroglifo. Podemos dar la lista de los detalles morfológicos que en una representación puede manifestar la personalidad de cada signo:

- Forma del contorno cerrado. Generalmente, es un círculo (Figura 37C), pero puede aparecer como un óvalo (Figura 36E) o una superficie cuadrada (Figura 37G).

- Contenido del contorno cerrado. A menudo se ven un punto central (Figuras 37F izquierda, 38A), dos ojos y una nariz (Figura 37F, derecha).

- Número de los apéndices exteriores. Generalmente, el signo tiene dos apéndices (Figura 37D), pero puede aparecer con tres (Figura 36E) o cuatro (Figuras 35A, 38A).

- Paralelismo de los apéndices. Estos apéndices aparecen generalmente paralelos (Figuras 37D, $37 \mathrm{G}$ ), pero se observa de vez en cuando, estas dos líneas que forman un ángulo ligeramente abierto (Figuras 36G, 38B). Con tres o cuatro apéndices, se puede observar una estructura en abanico (Figuras 35A derecha, 38A derecha). - Longitud, separación, desigualdad de longitud de los apéndices. Un signo tiene, por término medio, un diámetro igual a la longitud de los apéndices (Figura 38A). Aquí encontramos ejemplos con apéndices muy largos (Figuras 36G, 37F derecha). La distancia entre los apéndices es menos que el diámetro del elemento circular cerrado (Figura 37G izquierda), pero puede ser igual (Figuras 37D, 37G derecha). Observamos ciertos signos con apéndices voluntariamente desiguales (Figuras 37F derecha, 37J). 
- Adornos exteriores. El signo puede presentar adornos pegados al círculo cerrado (Figuras 36E: cruz, círculo pequeño; 37F derecha: extremidad inferior bífida; 38A: dos rayas).

- Presencia/ausencia de un punto o una raya sin contacto entre los apéndices (Figuras 37F, 37G: forma de un clavo; 38B: tres ejemplares).

- Espesor de las líneas del dibujo. Varios signos aparecen con líneas obviamente trazadas con contorno y apéndices exagerados en anchura: Figuras 36G, 37C, 37F derecha, 38B izquierda.

Terminamos con las otras formas geométricas particulares, tal como los círculos con punto central (28), círculos concéntricos (5), signos solares (2), onduladas regulares (4), construcciones celulares (Figura 38C, más de 15 células) y el petroglifo 38D de concepción totalmente abstracta.

\section{Las Chupallas}

Los petroglifos de la estación de Las Chupallas están representados en las Figuras 39 a 45. La Figura 40E es una ampliación de la escena que se encuentra abajo de la Figura 40D. Las Figuras 40F y 40G están sobre dos caras llanas formando un ángulo del mismo peñasco y muestran una parte común.

\section{Grandes estructuras}

Antes de que empecemos la descripción de las principales categorías de los signos más comunes, vamos a describir brevemente los conjuntos más notables por sus tamaños y contenidos artísticos.

Figura 39A. Este bloque de forma cúbica, que se encuentra a la entrada de la estación, tiene una naturaleza granítica y mide $2,30 \mathrm{~m}$ de largo por $1,80 \mathrm{~m}$ de alto. Su cara grabada está orientada al este. Priman aquí los círculos de pequeño diámetro así como elementos de superficie irregulares -de un total de 57-, que se ven repartidos en toda la cara, muchos con punto central y algunos en asociaciones aglomeradas de dos, tres y hasta cinco unidades. Algunos llevan apéndices ciliados como líneas quebradas.

- Figuras 40F y 40G. Este conjunto, que se extiende entre las dos caras en ángulo de un mismo bloque, mide $1,20 \mathrm{~m}$ de longitud por 1,00 $\mathrm{m}$ de altura. Se pueden ver elementos sobre todo circulares y algunas cruces con contorno. - Figura 41A. La roca, sobre la cual admiramos este extraordinario conjunto, da al sur, y su plano se presenta suavemente inclinado, lo que mejora las condiciones de su estudio. La escena grabada mide $1,14 \mathrm{~m}$ de longitud sobre 1,28 $m$ de alto, y presenta un contraste un poco débil con la roca madre. Los signos representados llenan totalmente la cara, hasta una quebradura que vemos abajo y a la derecha de la figura. Casi todas las unidades gráficas están en contacto con los signos vecinos y la identificación resulta más intuitiva. Sin embargo, podemos discriminar figuras que llamamos "invariables". Así, esta cara contiene cuatro mascariformes, nueve antropomorfos, 39 círculos con apéndices exteriores y siete círculos con punto central. Para una clara identificación de las unidades gráficas, hemos construido un sistema de coordenadas [ $\mathrm{x}, \mathrm{y}$ ], que sirve también para identificar los signos de la Figura 41B. Los signos básicos de esta escena, así como de la siguiente, serán descritos en los párrafos siguientes.

- Figura 41B. Esta escena es del mismo tipo que la precedente, pero con tamaño de dibujo reducido $(1,20 \mathrm{~m} \times 0,68 \mathrm{~m})$. Se puede observar un mascariforme, tres antropomorfos, siete círculos con apéndices exteriores, cuatro círculos con punto central y una cruz con contorno. Esta piedra grabada se ve en la Figura 8.

- Figura 42D. Este bloque grabado tiene su cara orientada al oeste. Mide 1,17 m×0,93 m. Presenta un conjunto variado de personajes mezclados con elementos geométricos diversos, entre ellos círculos con punto central.

\section{Las representaciones de máscaras y mascariformes}

Se encuentran nueve figuras mascariformes en Las Chupallas, que están presentes en las Figuras 40E (2), 41A (4), 41B (1), 43B (1) y 44A (1).

- Figura 40E, máscara de izquierda: la cara ovalada contiene dos ojos, la nariz, la boca y dos elementos horizontales en su mitad. Arriba se ve un elemento rectangular vertical, entre dos adornos simétricos en semicírculo. Este complejo cefálico es típico del estilo Limarí y se ve casi igual en otra representación situada 


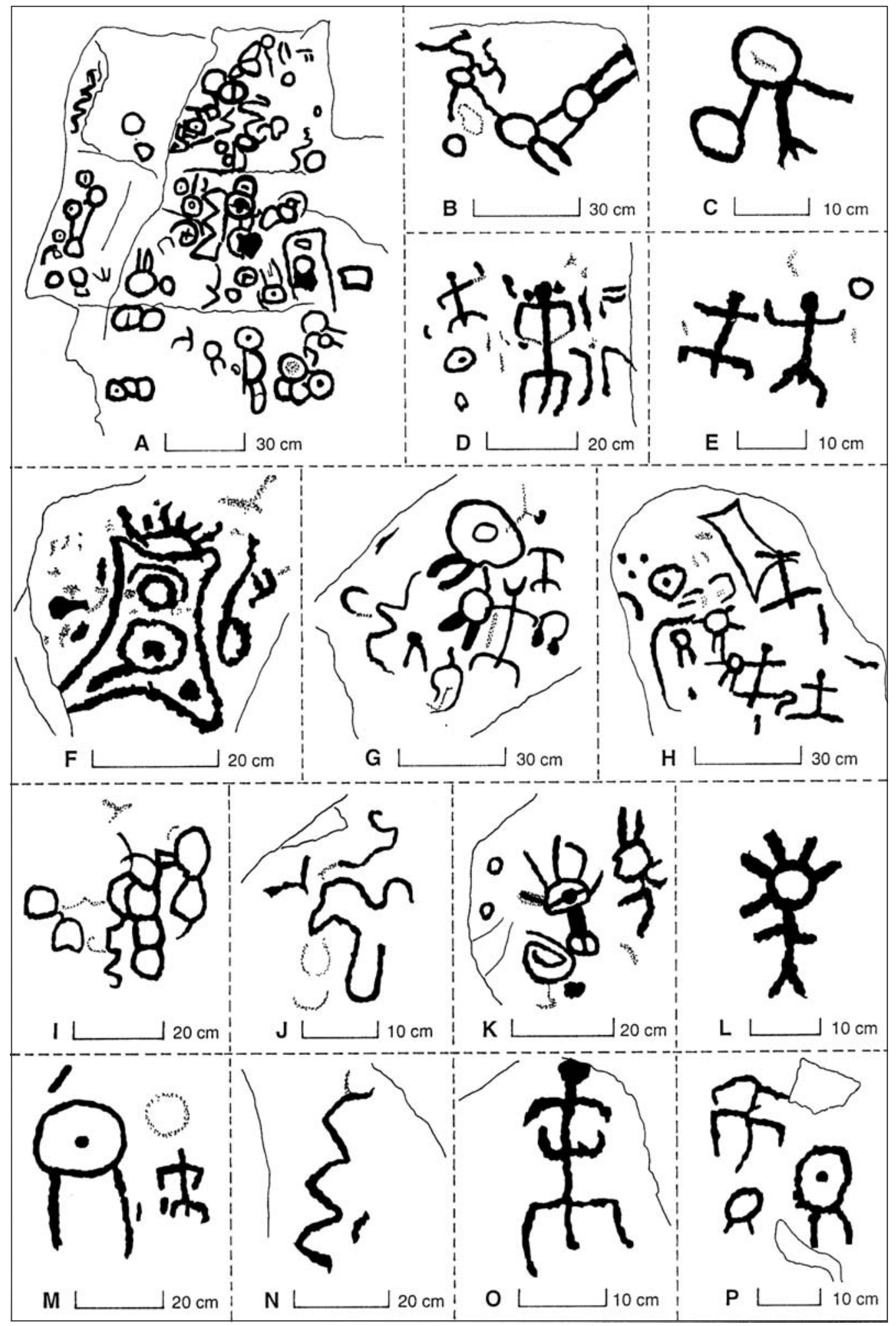

Figura 39. Conjuntos rupestres de Las Chupallas. Rock art clusters from Las Chupallas. 


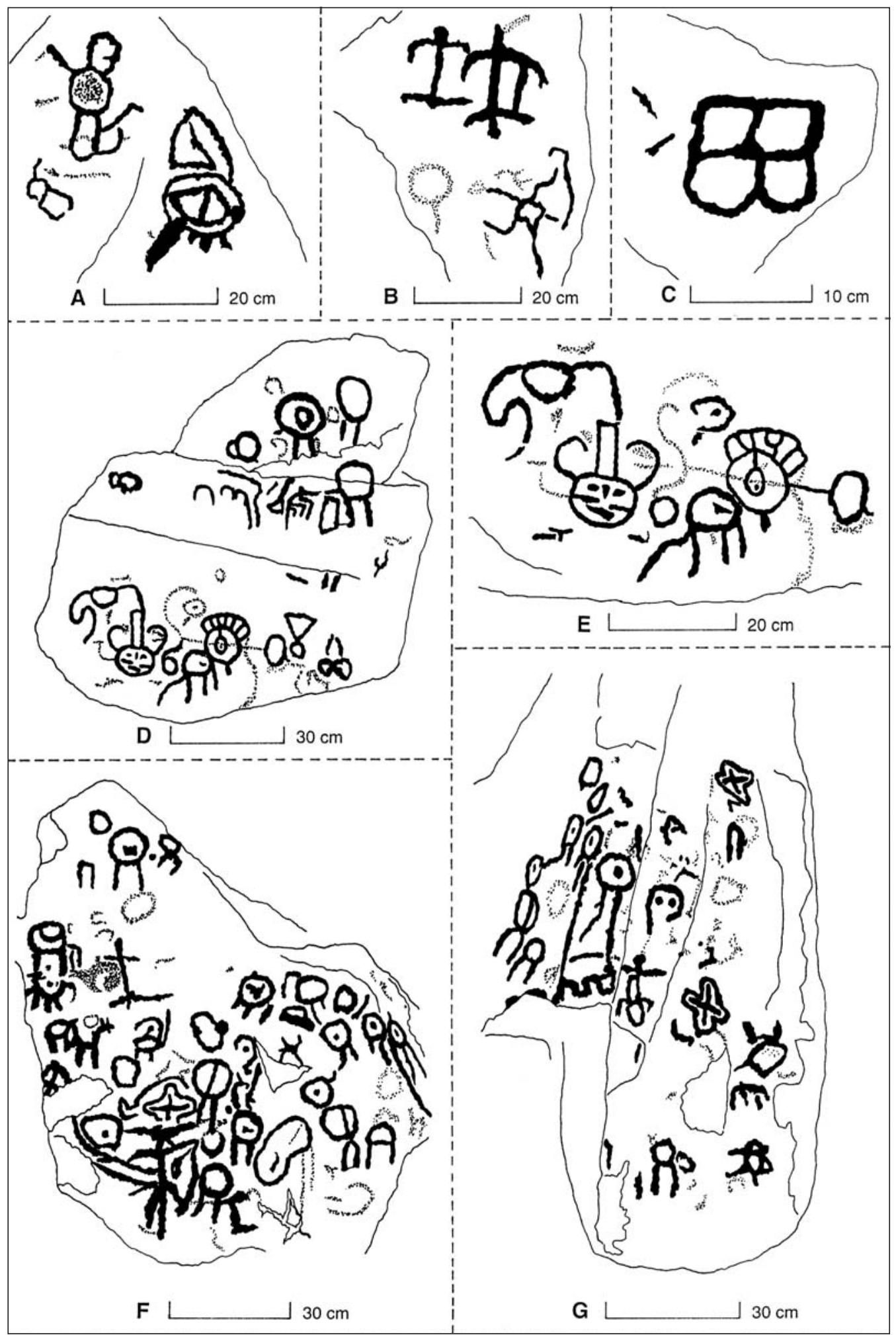

Figura 40. Conjuntos rupestres de Las Chupallas. Rock art clusters from Las Chupallas. 


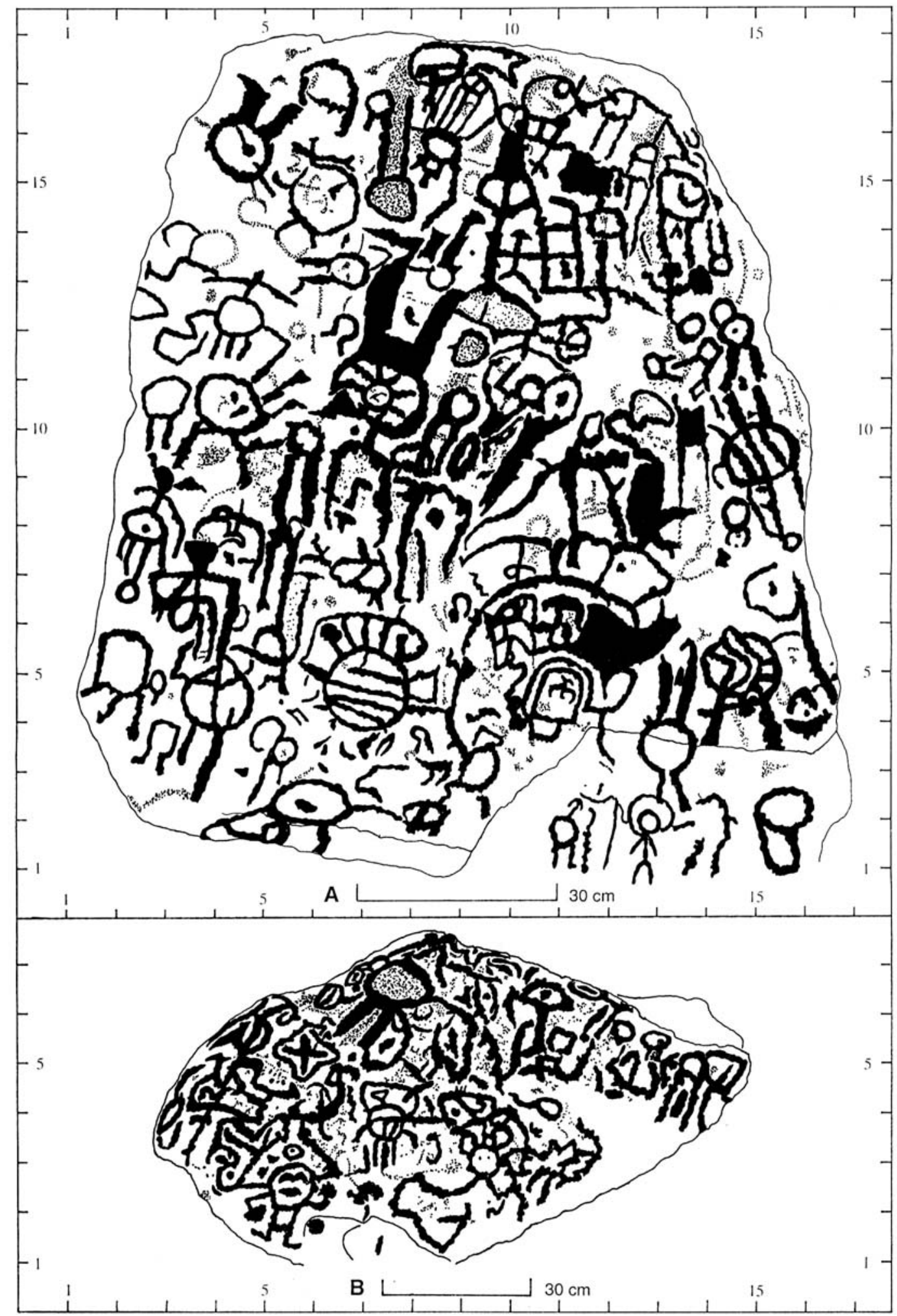

Figura 41. Conjuntos rupestres de Las Chupallas.

Rock art clusters from Las Chupallas. 


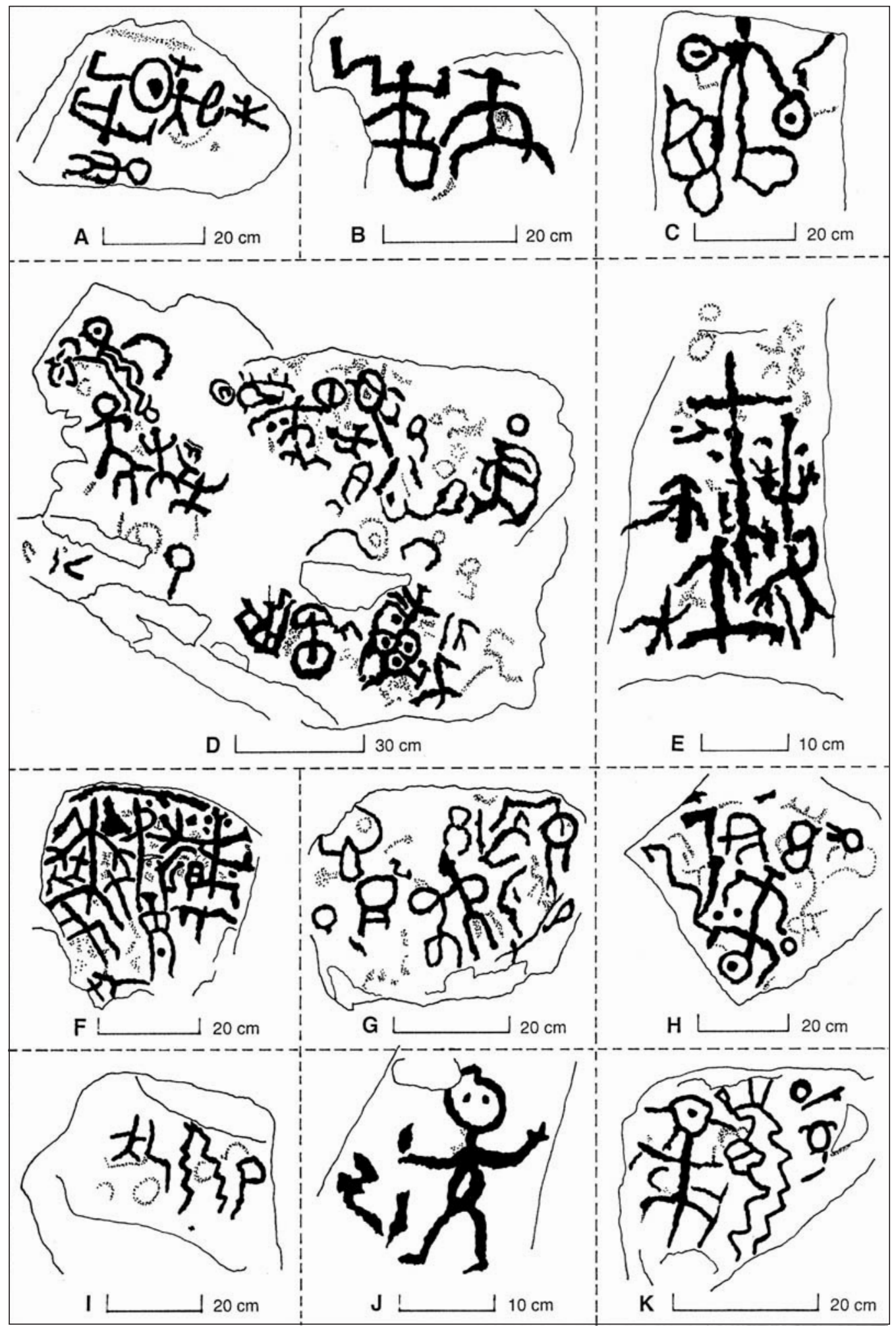

Figura 42. Conjuntos rupestres de Las Chupallas. Rock art clusters from Las Chupallas. 


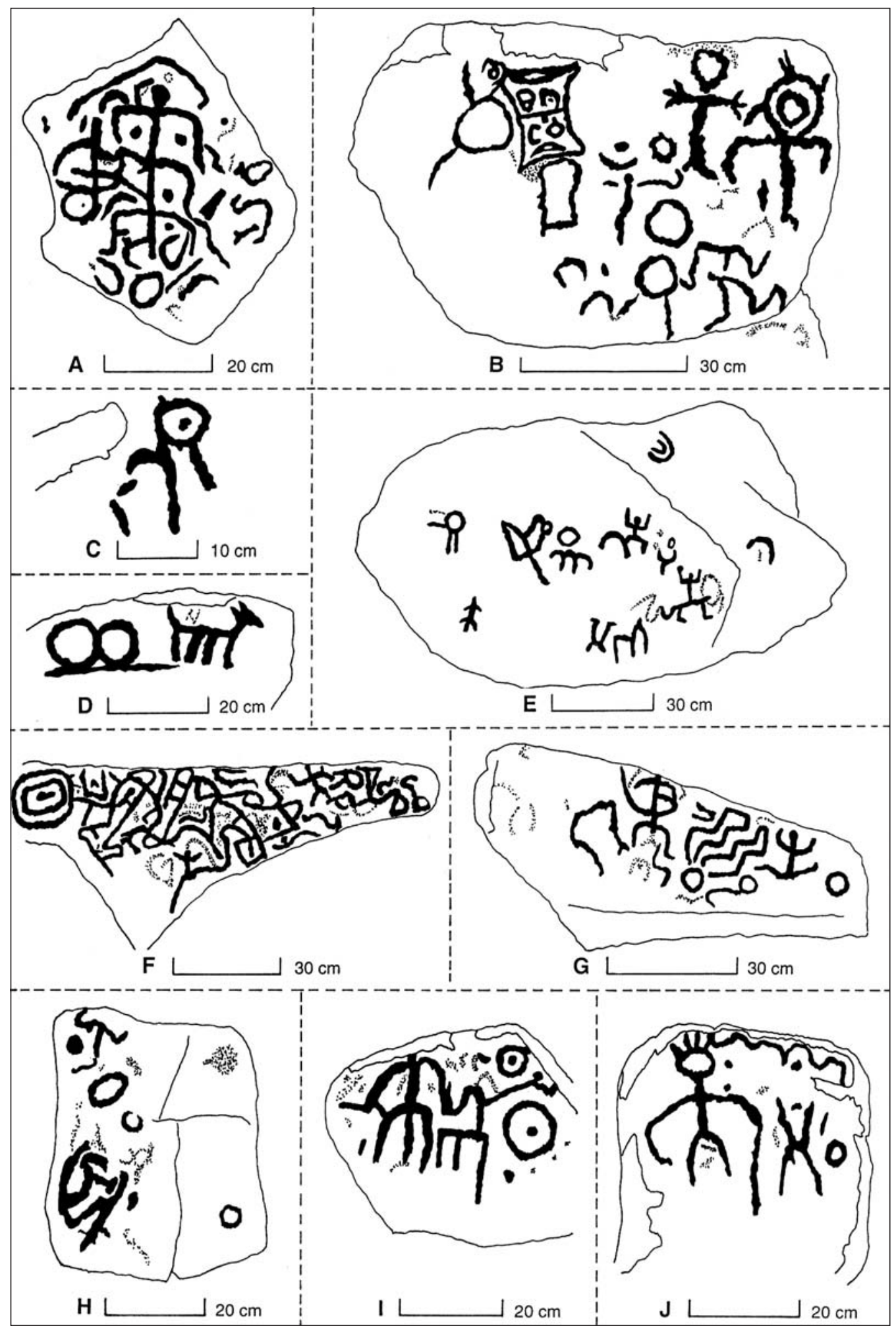

Figura 43. Conjuntos rupestres de Las Chupallas. Rock art clusters from Las Chupallas. 


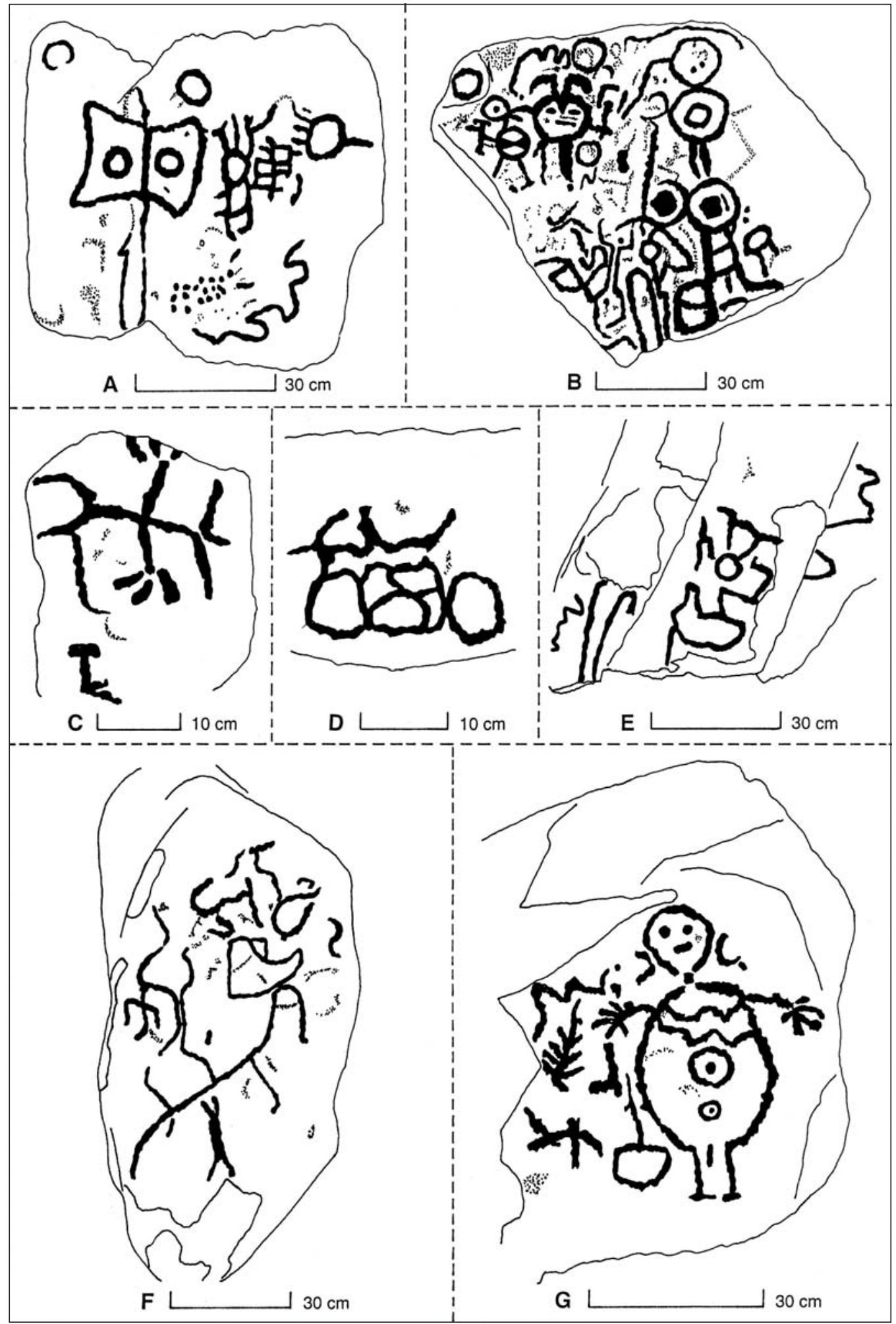

Figura 44. Conjuntos rupestres de Las Chupallas. Rock art clusters from Las Chupallas. 


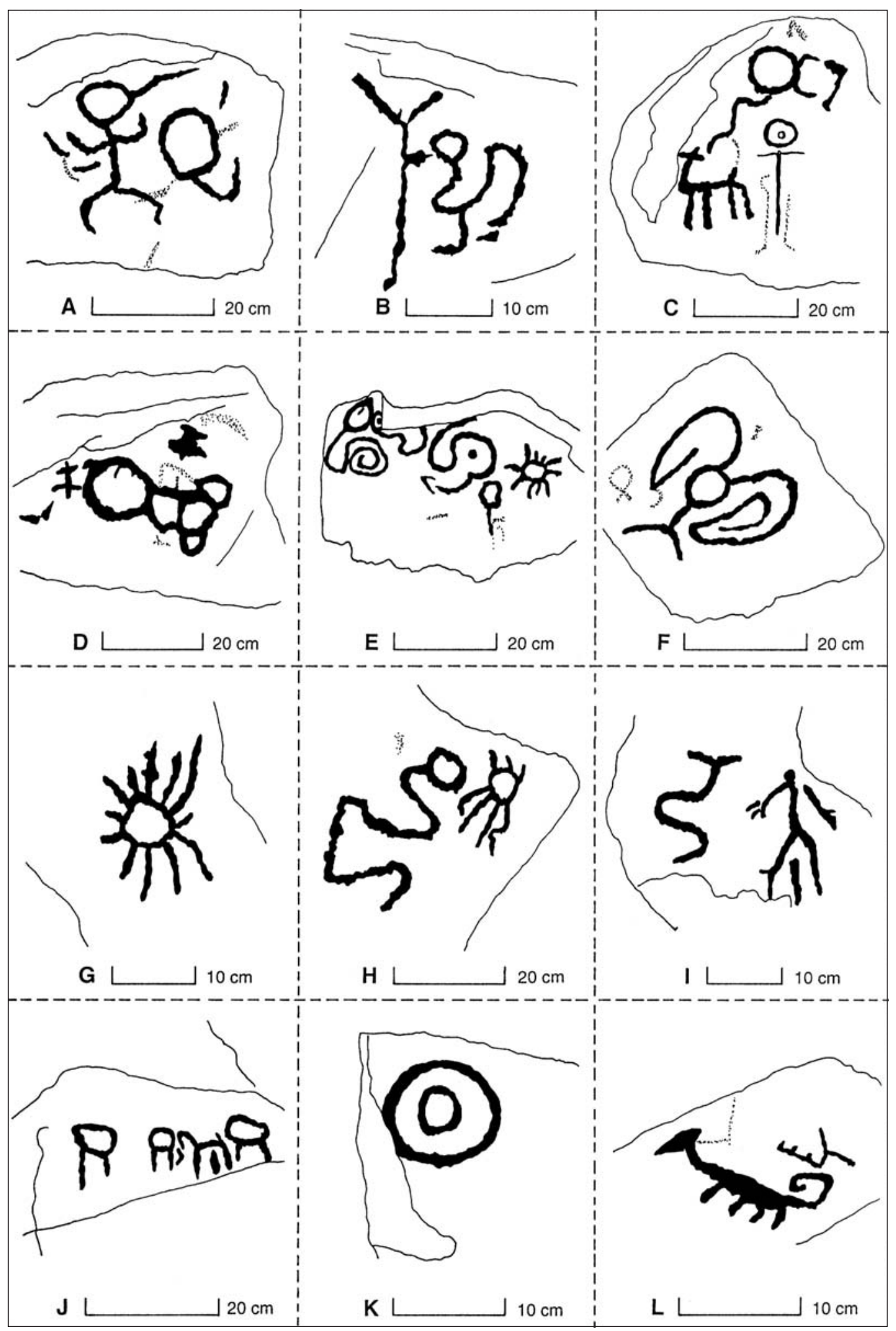

Figura 45. Conjuntos rupestres de Las Chupallas. Rock art clusters from Las Chupallas. 
arriba del cerro Buitre y publicada por Mostny y Niemeyer (1983: Figura 65).

- Figura 40E, máscara de derecha: al centro de esta cara se ve un círculo con punto central; el adorno cefálico se presenta como una alineación de seis elementos celulares formando un arco de círculo. La cara está en contacto con una línea adherida a un círculo.

- Figura 41A, las cuatro máscaras, cuyas coordenadas se indican, son:

Mascariforme 1 [7, 5]: la cara es circular, cruzada al interior por cuatro barras paralelas. Arriba se ve un adorno en tres células y dos trazos cortos, uno de los cuales tiene un punto. A los lados, otros trazos horizontales y un elemento de cuadrilátero.

Mascariforme 2 [11, 5]: la cabeza aparece como una superficie aislada, con el lado superior semicircular y adherido abajo con un cuadrito. Adentro se ve un signo trífido, que puede simbolizar los ojos y la nariz. El gran tocado que la cubre es de forma semicircular, con una organización gráfica muy caótica. Se puede ver adentro una red abigarrada de pequeñas células, cerca de una importante superficie de roca vacía, de forma irregular. Arriba del tocado, hay un adorno que ya hemos visto en otros mascariformes. Se trata aquí de dos células cuadradas y pegadas.

Mascariforme 3 [15, 10]: este mascariforme tiene una forma circular y está cruzado por tres líneas paralelas. Las dos de izquierda se juntan más abajo a un círculo pequeño. Su decoración cefálica se compone de tres rayos divergentes. Visto de revés, este signo puede ser interpretado como un círculo con tres apéndices exteriores.

Mascariforme 4 [9, 16]: la cara, vacía de grabado, se prolonga hacia abajo por un cuadrito, seguido por un trazo corto. Arriba se ve un atavío cefálico con tres líneas verticales adentro, que se prolongan por un circulito cortado por un diámetro vertical.

- Figura 41B [6, 3]: un personaje posee un adorno cefálico de forma triangular, prolongado hacia arriba por un cuadrito. Adentro del adorno, un círculo pequeño con punto central y dos manchas puntuales.

- Figura 43B: se ve una máscara grabada dentro de un rectángulo vertical con lados cóncavos; tiene una separación horizontal que le corta en dos partes iguales: arriba, dos ojos; abajo, una pequeña nariz, pegada a la línea de separación, una boca, dos pequeños círculos (uno incompleto); el lado superior del rectángulo aparece desdoblado; casi pegado al motivo central, un rectángulo vertical y un círculo.

- Figura 44A: mascariforme incluido en un rectángulo horizontal con tres lados cóncavos y uno convexo. Está cortado en dos partes iguales por un eje vertical y los ojos se presentan como dos pequeños círculos.

\section{Las representaciones antropomorfas}

El número de antropomorfos en la estación de Las Chupallas alcanza a 80 unidades, lo que la coloca entre el grupo de Mialqui (98) y el grupo de Panguecillo (65). Damos aquí la descripción de las estructuras más representativas, con la metodología previamente empleada.

- Estructuras simples o lineales. Los ejemplos siguientes pertenecen a esta categoría: Figura 39E (dos personajes), Figura 39M (sin cabeza).

- Estructuras elaboradas. Figura 40G: cuerpo rectangular; Figura 42H: posible representación de una mujer, con los senos (dos puntos) y el sexo (circulito con punto); Figura 42J: cuerpo ovalado, cabeza con ojos; Figura 43A: otra representación femenina (senos y sexo); Figura 43B: dos personajes con cabezas en círculos.

- Estructuras decoradas. Figura 39D (derecha): adornos a cada lado de la cabeza; Figura 39L: cabeza decorada con rayos radiales; Figura 39O: decoración arqueada a la mitad del cuerpo; Figura 42A: un personaje tiene un objeto circular en la mano derecha y uno espiralado en la izquierda; Figura 42C: un círculo con punto central en cada mano del personaje; Figura 42G: un antropomorfo con cabeza marcada sostiene en su mano derecha lo que parece ser una cuerda; Figura 43J: personaje con cabeza decorada, con un palo en una mano; Figura 45F: amplias decoraciones espiraladas en cada lado de la cabeza de un personaje sin brazos; Figura 45I: antropomorfo con una forma recta y vertical entre sus piernas (que se observa en ciertos círculos con apéndices exteriores, ver La Rinconada de Carretón). 
- Estructuras simbólicas y/o abstractas. Figura 39G: cabeza en forma de luna creciente; Figura 39K: personaje sin brazos ni pies, de cuerpo vaciado, con un solo punto sobre su cara, cortado por una línea horizontal; Figura 40F: antropomorfo íntimamente mezclado con formas geométricas, con una cabeza simbolizada por dos líneas horizontales; Figura 44B: un antropomorfo toma el aspecto de un "círculo con dos apéndices exteriores", donde se ven dos ojos, una nariz y una boca; el brazo derecho parece blandir un palo. Arriba de su cabeza se ven dos adornos en "ángulo recto", que ya observamos en la cuenca alta del río Illapel (ver Ballereau y Niemeyer 1998: Figura 18D).

- Estructuras con asociaciones de personajes. Figura 42A: tres personajes con actitudes diferentes; Figura 42B: dos figuras simples en posturas diferentes; Figura 42D: a la izquierda, grupo de tres personajes en movimiento; Figura 42E: seis antropomorfos íntimamente cercanos en posturas estáticas; Figura 42F: cinco (o seis) antropomorfos están íntimamente mezclados, cada uno con morfología diferente a la otra (uno tiene un punto entre las piernas).

- Estructura particular. El personaje de la Figura 44G parece ser apócrifo.

- Los nueve antropomorfos de la Figura 41A. Aquí damos sus coordenadas y una breve descripción:

- Antropomorfo $1[13,2]$ : forma lineal, cabeza circular envuelta en otro círculo.

- Antropomorfo 2 [14, 13]: forma simple, dos brazos, sin pies, tiene un objeto rectangular con su mano izquierda, ligado a un círculo por el tronco.

- Antropomorfo 3 [10, 14]: personaje extraño, con cabeza cortada verticalmente en dos partes y coronada por un atavío rectangular vaciado; no tiene brazos ni pies; abajo, está en contacto con una superficie ovalada.

- Antropomorfo $4[10,13]$ : personaje de forma lineal, con brazos y pies, cuya cabeza es de forma triangular.

- Antropomorfo $5[11,16]$ : pequeño personaje lineal, con cabeza en forma de punto, al contacto con el Antropomorfo 3.

- Antropomorfo 6 [4, 12]: antropomorfo formado a partir de un círculo con tres apéndices exteriores; arriba, tiene dos brazos extendidos; a cada lado del círculo, dos líneas quebradas.

- Antropomorfo 7 [8, 11]: este signo está formado en su centro por un círculo con rayos y círculo pequeño central; arriba se ve una estructura vaciada en tres partes; abajo el cuerpo del personaje se reduce a un tronco corto y dos piernas paralelas.

- Antropomorfo 8 [3, 8]: personaje del mismo tipo que el Antropomorfo 6, pero con cuatro apéndices ligados al círculo y una cabeza circular vaciada adornada con dos estructuras rectas; uno de los apéndices está en contacto con un pequeño círculo, otro toca el Antropomorfo 9 .

- Antropomorfo 9 [4, 7]: antropomorfo de estilo abstracto; la cabeza se ve como un triángulo vaciado; el brazo izquierdo se prolonga hasta un círculo con dos apéndices exteriores; el tronco desaparece en una estructura geométrica compleja.

- Los tres antropomorfos de la Figura $41 B$ :

- Antropomorfo 1 [6, 2]: ya hemos descrito el atavío cefálico de este personaje; su cara circular muestra los ojos y la boca; el cuerpo se ve cuadrado y las manos, disimétricas, aparecen destacadas.

- Antropomorfo $2[8,4]$ : este antropomorfo estilizado se construye a partir de un círculo con dos apéndices, que presenta un tercer apéndice sin contacto entre las piernas; tiene una decoración cefálica donde se ve un triángulo pequeño; una línea transversal representa los brazos.

- Antropomorfo 3 [10, 3]: el elemento central de este antropomorfo estilizado es un círculo con dos ojitos; tiene un adorno cefálico complicado, con elementos celulares desordenados; las piernas se ven como líneas onduladas irregulares.

\section{Las representaciones zoomorfas}

En la estación de la quebrada de Las Chupallas, encontramos solamente cinco representaciones de zoomorfos; todos son cuadrúpedos. El más representativo es el de la Figura 43D, con orejas, cola y cuatro patas. En las Figuras 45H y 45I, se pueden adivinar unos ofidiomorfos. 
Las representaciones con caracteres geométricos

Como en la estación de La Rinconada de Carretón, se encuentra aquí gran cantidad de signos en forma de círculo con apéndices exteriores paralelos (o poco divergentes). La clasificación morfológica, que ya hicimos en esta estación, es válida aquí. Sin embargo, la diversidad de las formas es mucho más baja. Hay un total de 125 ejemplos de este signo y los más significativos son:

- Forma del contorno cerrado: generalmente un círculo, a veces un poco ovalado (Figura 39M).

- Contenido del contorno cerrado: un punto (Figura 39P), un círculo (Figura 39G).

- Número de los apéndices exteriores: dos, a veces tres o cuatro (Figura 39H).

- Paralelismo de los apéndices: paralelos (Figura 39M) o divergentes (Figura 39G).

- Longitud, separación, desigualdad de longitud de los apéndices: generalmente cortos, raramente más largo que el diámetro (Figura 39B); pocos casos de desigualdad (Figura 43C).

- Adornos exteriores: una pierna con tres dedos, un circulito (Figura 39C).

- Presencia/ausencia de un punto o una raya sin contacto entre los apéndices: Figura 44B.

- Espesor de las líneas del dibujo: un ejemplo de línea espesa, con la Figura 39G.

De los 39 signos de tipo "círculo con apéndices exteriores (CCAE)", que hemos identificado en el grabado de la Figura 41A, podemos extraer algunos que merecen una corta descripción; señalamos sus coordenadas:

- CCAE $1[13,4]$ : de un lado se ven dos apéndices divergentes con espacio abierto entre ellos; del otro lado, dos apéndices espesos.

- CCAE $2[15,5]$ : el interior del círculo aparece lleno de elementos gráficos curvos; dos apéndices espesos que forman ángulo.

- CCAE $3[8,15]$ : diseño con dos apéndices muy largos, paralelo y espacio picoteado.

- CCAE $4[5,16]$ : signo con punto central y trazos espesos.

- CCAE $5[4,4]$ : signo con dos apéndices paralelos y de longitudes desiguales; está cortado por el Antropomorfo 9.

De los 7 signos "CCAE" de la Figura 41B, describimos los dos siguientes:
- CCAE $1[14,5]$ : signo con adorno entre los apéndices, sin contacto.

- CCAE $2[8,6]$ : este signo es una superposición sobre el diseño primitivo, que se ve bien en la fotografía de la Figura 8. El contenido del círculo es un picoteado liviano; tiene un adorno entre los apéndices de poco contraste.

Hay escenas que muestran gran número del signo "círculo con apéndices exteriores". El bloque que muestra los grabados representados en las Figuras 40F y 40G cuenta 19 signos, algunos con pequeñas variaciones de forma. La escena $44 \mathrm{~B}$ es la más interesante, porque contiene varios signos que parecen todos diferentes entre ellos.

La cruz con contorno se encuentra en cuatro ejemplares en la estación de Las Chupallas y todas son cruces simples: Figura 40F (cortada abajo por un antropomorfo), Figura 40G (dos unidades) y 41B (contorno casi rectangular).

El cuadrilátero con lados cóncavos cuenta con cuatro unidades: Figura 39F, que aparece como un cuadrilátero "humanizado" por la presencia de una pequeña cabeza con adornos cefálicos; en su interior, dos círculos y otros adornos; Figura $39 \mathrm{H}$, totalmente vacía, en contacto con un antropomorfo; los cuadriláteros de las Figuras 43B y 44A ya fueron descritos como figuras mascariformes. Finalmente, señalamos la presencia de un signo llamado "cuadrados concéntricos" (Figura 43F), de 53 círculos con punto central, de seis figuras llamadas "círculos concéntricos", de dos signos solares, seis espirales y 15 líneas onduladas regulares.

\section{El Cuyano Bajo y El Cuyano Alto (Grupo de El Cuyano)}

El único petroglifo de El Cuyano Bajo es este mascariforme de gran tamaño, que se encuentra en las Figuras 46A y 46B (Figura 10), Iribarren (1975) publicó su dibujo. La piedra portadora está casi vertical y mide $2,50 \mathrm{~m}$ de ancho x 2,50 m de alto y su cara mira al sudeste. Hace parte de un grupo caótico de piedras de grandes dimensiones (Figura 10). Su color es gris claro, lo que disminuye el contraste entre el grabado y la roca madre.

Este mascariforme mide 1,57 m de largo (extremos del semicírculo) y $0,94 \mathrm{~m}$ de altura (abajo de la cara hasta la cumbre del atavío). Está compuesto de dos partes: un rectángulo vertical, con ángulos redondeados, de $0,33 \mathrm{~m}$ longitud y 


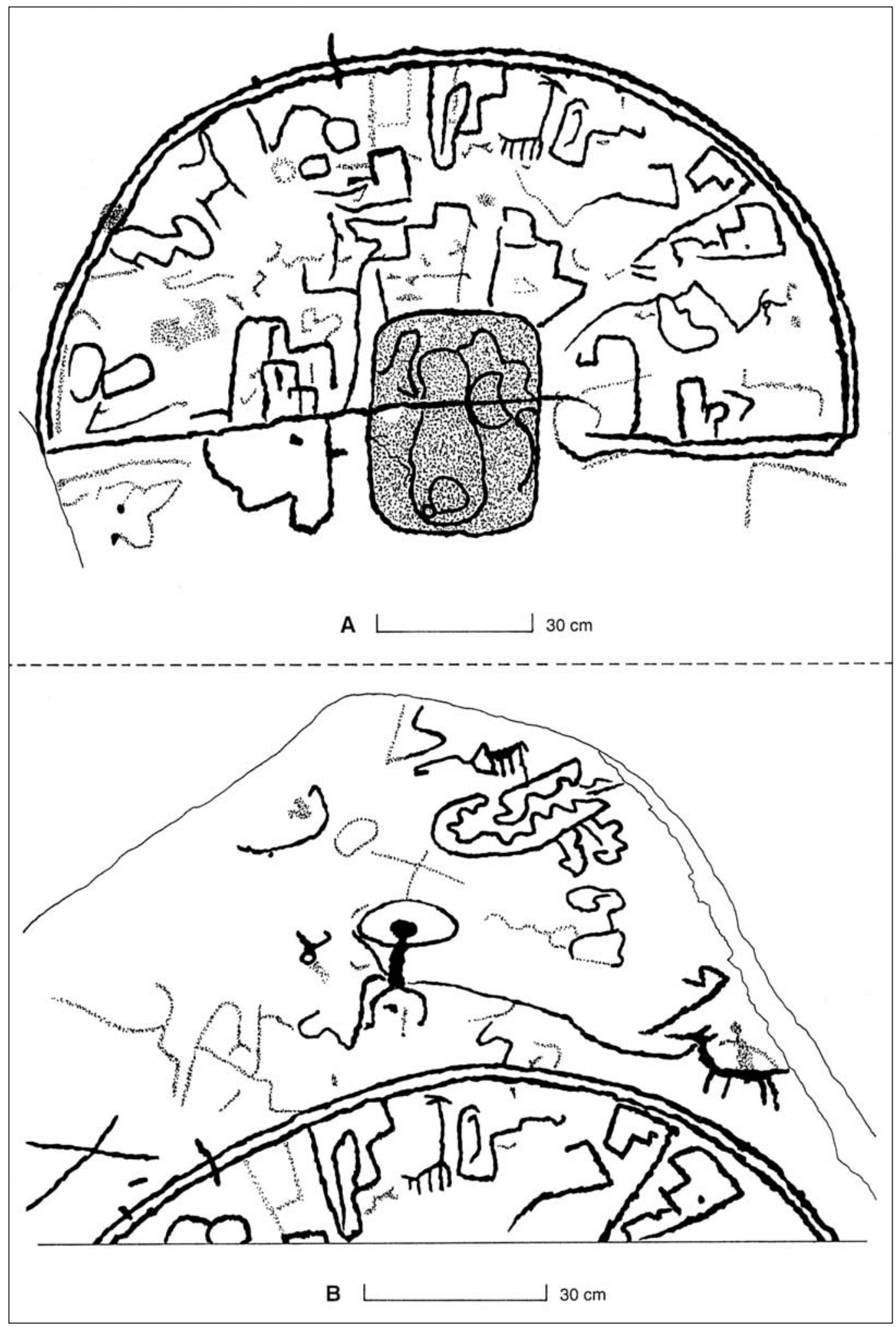

Figura 46. Conjuntos rupestres de El Cuyano Bajo.

Rock art clusters from El Cuyano Bajo. 
de $0,44 \mathrm{~m}$ de altura y un semicírculo que corta el rectángulo poco arriba de su centro. El rectángulo vertical, que simboliza la cara de un ser humano, está cubierto con un picoteado liviano y muestra varias superficies cerradas así como líneas meándricas. Estas formas geométricas son difíciles de leer, como lo hemos dicho, por el contraste débil y también por la debilidad de los trazos. Entre éstas, se perciben tres contornos cerrados. El más grande, similar a un óvalo vertical irregular, contiene en su parte inferior un círculo irregular, al cual se adhiere un círculo pequeño. El tercer contorno, con forma de luna creciente, está pegado al primero, arriba y a la derecha. Otros elementos meándricos ocupan el espacio. El semicírculo superior tiene un contorno desdoblado, salvo a lo largo del diámetro inferior, desde el interior del gran rectángulo vertical hasta la extremidad izquierda. Se observa, por fin, un ornamento exterior al atavío, bajo el diámetro, a la izquierda.

El ornamento interior del atavío cefálico es de orden geométrico abstracto. Sólo se reconoce un camélido en su parte superior. El dibujo general no presenta un orden, ninguna simetría -salvo dos motivos escalonados en el centro-, como se ve con otros mascariformes del Norte Chico, de estilo Limarí. Sin embargo, se puede decir que el desgaste del tiempo ha marcado esta roca y que varios motivos han desaparecido o se han borrado parcialmente.

La parte superior de esta piedra está ocupada por un dibujo reproducido en la Figura 46B. Ésta da una visión ligeramente oblicua de la escena, porque la disposición del terreno impide tomar una fotografía perpendicular al plano de la roca. Se ve un antropomorfo que, con una cuerda, atrapa un cuadrúpedo, aparentemente montado por un jinete. Más arriba se observa otro cuadrúpedo, mal definido, sobre un extraño motivo geométrico con cuatro superficies parcialmente cerradas por líneas onduladas. En la Figura 10, abajo del mascariforme, se ven un antropomorfo y un cuadrúpedo. En total, hay un mascariforme, dos antropomorfos y cuatro zoomorfos en El Cuyano Bajo.

Los grabados de la estación de El Cuyano Alto están reproducidos en la Figura 47. Se cuentan dos mascariformes, 14 antropomorfos y un zoomorfo. Los mascariformes son:

- Figura 47A: la cara, en forma de círculo ligeramente estirado, se presenta totalmente va- cía. El gran atavío que la cubre es de forma semicircular y contiene dos largas onduladas verticales similares.

- Figura 47D: el dibujo a la izquierda puede interpretarse como una figura mascariforme estilizada. El rostro, de forma triangular pero con un vértice redondeado, se ve ocupado por una cruz vertical. Al contacto de la parte superior, siete tracitos verticales y un pequeño círculo lateral constituyen el adorno de la cabeza.

Los antropomorfos están presentes en:

- Figura 47B: personaje simple con cuerda ligada en su tronco.

- Figura 47D: 4 antropomorfos simples diseminados entre otros signos; las formas y las actitudes son diferentes.

- Figura 47E: un antropomorfo estilizado tiene su tronco cortado por un eje vertical; tiene dos piernas pero no brazos.

- Figura 47I: personaje simple, cerca de un óvalo.

- Figura 47J: grupo vertical de seis personajes en posición estática; algunos tienen estructuras evolucionadas, o con decoraciones: seis miembros (brazos o piernas), cabeza circular, dedos en las manos.

Los círculos con apéndices exteriores están en gran número en la estación El Cuyano Alto y alcanzan 13 unidades. Se pueden observar en:

- Figura 47D: dos abiertos, uno con cinco apéndices, uno con decoración cefálica.

- Figura 47E: un curioso signo rectangular que aparece con siete "miembros".

- Figura 47H: dos signos simples, cerca de un esbozo de antropomorfo.

- Figura 47J: dos signos con uno y dos apéndices.

Algunas figuras con carácter geométrico deben ser descritas:

- Figura 47C: en este grande conjunto grabado, donde aparece un único zoomorfo (tres patas), se ve a la izquierda un círculo totalmente lleno con signos meándricos.

- Figura 47F: línea ondulada casi cerrada, semejante a la que se ve en la Figura 46B.

- Figura 47G: es la parte no destruida de la roca que se ve en la Figura 11. Se ven signos en for- 


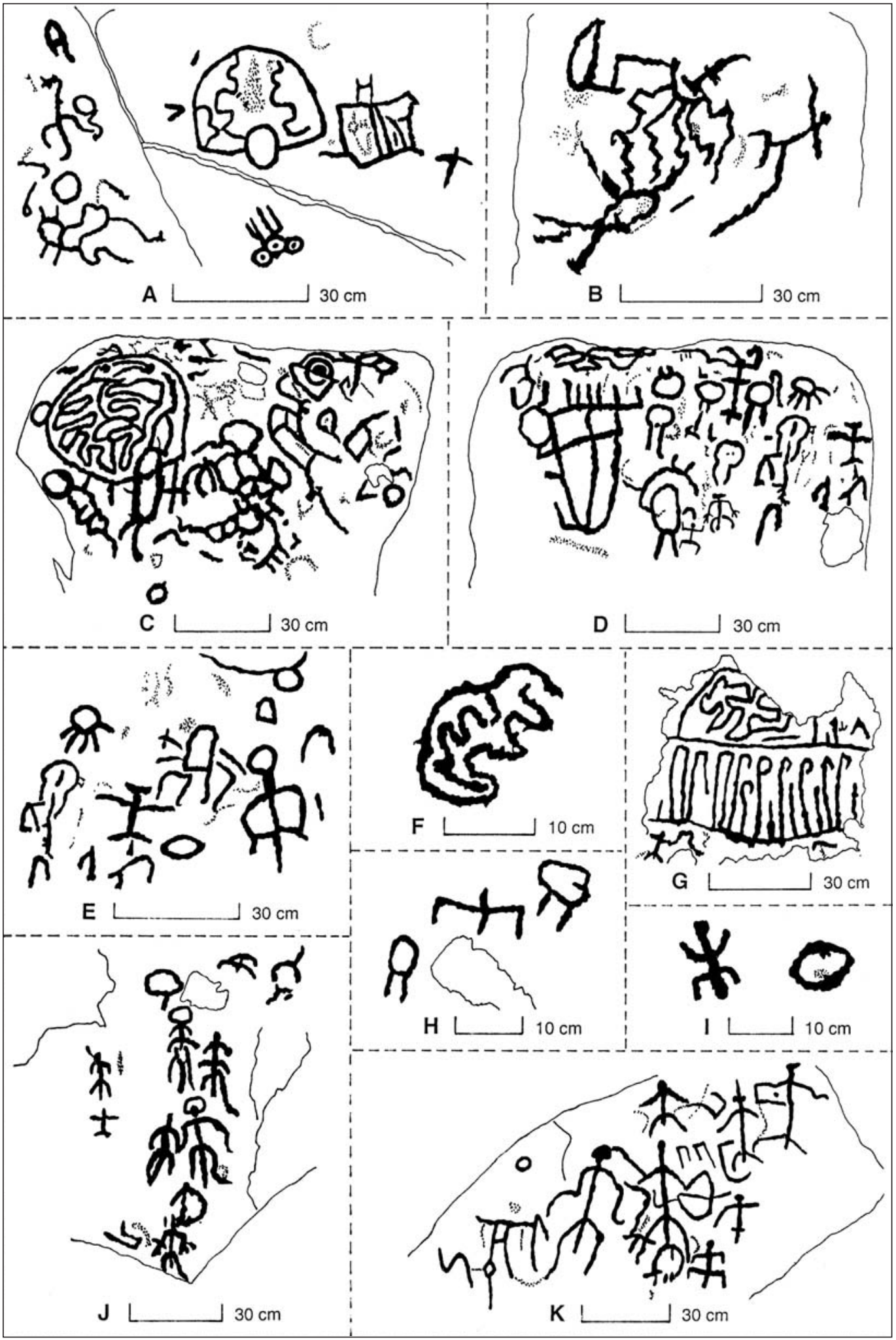

Figura 47. Conjuntos rupestres de El Cuyano Alto (A, B, C, D, E, F, G, H, I, J) y de El Macano. Rock art clusters from El Cuyano Alto $(A, B, C, D, E, F, G, H, I, J)$ and El Macano. 
ma de gancho y, arriba, líneas meándricas cerradas. El petroglifo original debió cubrir la roca entera, porque se ve, a la izquierda, otros elementos de dibujos rescatados del vandalismo.

\section{El Macano}

El único petroglifo de esta estación se muestra en la Figura 47K. Aparece un grupo de siete antropomorfos de tipo lineal que parecen estar en una escena de convivencia. El personaje del centro es un poco ambiguo y aparece como una figura compleja, porque tiene dos pares de piernas que podrían tener una connotación sexual.

\section{Análisis Estadístico de los Signos en las Estaciones del río Grande y Comparación con el Resto del Norte Chico}

La Tabla 2 reúne, en la primera columna, los 16 signos más representativos descritos en nuestro estudio. Cada línea da el total de signos registrados en cada estación (o grupo de estaciones), y finalmente el total por toda el área estudiada. Esta Tabla sigue el patrón de tabulaciones previas de la cuenca alta del río Illapel (Ballereau y Niemeyer 1998) y del valle del río Hurtado superior (Ballereau y Niemeyer 1999). Hemos hecho algunos cambios menores en el orden de los signos y añadido dos signos, el cuadrado/rectángulo con diagonales y el signo solar. Es interesante estudiar la frecuencia y la repartición geográfica de los signos más representativos en esta parte del río Grande y compararlo con otras áreas ya estudiadas en el Norte Chico. Ballereau y Niemeyer (1999) han desarrollado la noción de "densidad" de un signo, equivalente al cociente entre el número total de un signo en la estación (o en un área más amplia) por el número total de petroglifos grabados de la estación (o área). Es obvio que el uso de este parámetro matemático, neutro y objetivo, debe ser utilizado solamente cuando una estación ha sido totalmente registrada. La última línea de la Tabla 2 da el número total de grabados en cada estación (o grupo de estaciones) y nos permite calcular las densidades previamente definidas.

Los tres primeros signos (máscaras y/o mascariformes, antropomorfos y zoomorfos), corresponden a seres vivos, mientras los otros 13 se refieren a signos geométricos y ciertas representa-

Tabla 2. Frecuencia de los dieciséis principales signos rupestres del valle de río Grande, estudiados en 1997, 1998 y 1999.

Frequency of the sixteen main rock art designs found in the valley of río Grande that were studied in 1997, 1998 and 1999.

\begin{tabular}{|c|c|c|c|c|c|c|c|}
\hline Signos rupestres & $\begin{array}{c}1 \\
\text { Mialqui/ } \\
\text { Tucúquere/ } \\
\text { La Viñita }\end{array}$ & $\begin{array}{c}2 \\
\text { Panguecillo } \\
\text { Bajo, } \\
1 \text { y } 2\end{array}$ & $\begin{array}{c}3 \\
\text { La Rinconada } \\
\text { de Carretón }\end{array}$ & $\begin{array}{c}4 \\
\text { Quebrada } \\
\text { de Las } \\
\text { Chupallas }\end{array}$ & $\begin{array}{c}5 \\
\text { El Cuyano } \\
\text { Bajo y Alto }\end{array}$ & $\begin{array}{c}6 \\
\text { El Macano }\end{array}$ & Total \\
\hline Máscara y/o mascariforme & 6 & 3 & 2 & 9 & 3 & & 23 \\
\hline Antropomorfo & 98 & 65 & 33 & 80 & 16 & 7 & 299 \\
\hline Zoomorfo & 45 & 12 & 11 & 5 & 5 & & 78 \\
\hline Cruz con contorno & 4 & 10 & & 4 & & & 18 \\
\hline Cuadrilátero con lados cóncavos & 1 & 1 & & 4 & & & 6 \\
\hline Cuadrados/rectángulos concéntricos & & & & 1 & & & 1 \\
\hline Cuadrado/rectángulo con diagonales & 10 & & & & & & 10 \\
\hline Círculo con punto central & 62 & 37 & 28 & 53 & 3 & & 183 \\
\hline Círculo con diámetros perpendiculares & 4 & 4 & & & & & 8 \\
\hline Círculos concéntricos & 7 & 6 & 5 & 6 & & & 24 \\
\hline Círculo con apéndices exteriores & 105 & 37 & 46 & 125 & 13 & & 326 \\
\hline Signo escudo & 3 & 4 & & & & & 7 \\
\hline Signo solar & 3 & 1 & 2 & 2 & & & 8 \\
\hline Mano/pie & & 3 & & & & & 3 \\
\hline Espiral & 4 & 9 & & 6 & & & 19 \\
\hline Ondulada regular & 24 & 26 & 4 & 15 & 4 & 1 & 74 \\
\hline Número de grabados de la estación & 166 & 66 & 33 & 65 & 11 & 1 & 342 \\
\hline
\end{tabular}


ciones "humanizadas". Entre los signos geométricos, ya hemos señalado que tres entre ellos -la cruz con contorno, el cuadrilátero con lados cóncavos y el círculo con apéndices exteriores- parecen poseer una función especial, en razón de sus formas a la vez simples y específicas, así como sus frecuencias de aparición particularmente elevadas.

La Tabla 3 presenta los seis signos invariables que estimamos más importantes para cinco de las seis estaciones (o grupos de estaciones) del valle del río Grande (eliminamos El Macano). Las cinco columnas se refieren a las estaciones con más de diez grabados, aunque, en el grupo de El Cuyano, la muestra -11 grabados- nos parezca demasiado reducida para tomar en cuenta sus resultados. Cada columna muestra a) el número de signos, proveniente de la Tabla 2, y b) la densidad calculada. Para cada signo, subrayamos la densidad más alta.

Aparece de inmediato que el sitio de la quebrada de Las Chupallas, con un total de 65 grabados, posee las densidades más altas para cuatro de los seis invariables, una de ellas superando un (antropomorfo) y otra acercándose a dos (círculo con apéndices exteriores). Solamente el zoomorfo y la cruz con contorno alcanzan una densidad máxima en La Rinconada de Carretón y el grupo de Panguecillo. Tenemos aquí, con este cálculo simple, la confirmación de nuestra estimación sobre el carácter especial de la estación de Las Chupallas que, quizás, desempeñó un papel importante de centro ceremonial en los tiempos precolombinos. Este sentimiento es confirmado por el tamaño reducido de la estación y la ausencia total de grabados aislados fuera de sus límites. El número muy bajo de zoomorfos en Las Chupallas (5) es notable. Este signo, como lo hemos visto en La Silla, pertenece a zonas con grabados que tuvieron en el pasado una función de pastoreo. Aquí, esta función parece ser atribuida al grupo de Mialqui y La Rinconada de Carretón (densidades 0,27 y 0,33 zoomorfo por grabado), cuyos terrenos, llanos y terrosos, parecen más adecuados para esta actividad.

La Tabla 4 resume la presencia y la densidad de los seis principales invariables en las tres zonas estudiadas por los autores hasta ahora: Hurtado, río Grande e Illapel, ordenadas geográficamente del norte al sur. Las conclusiones que podemos extraer son las siguientes:

- Las máscaras y mascariformes están presentes sobre todo en el río Hurtado superior, con más de un signo por dos grabados.

- Los antropomorfos se encuentran con densidad elevada en el río Grande, casi con una razón de uno; siguen las zonas de Hurtado e Illapel, con razones semejantes de un signo por dos petroglifos. Estos personajes tienen morfologías muy diversificadas, que van del signo sencillo -tronco y miembros lineales, cabeza puntiforme- hasta las representaciones sofisticadas, con atavíos, vestidos y joyas, ver con carácter abstracto.

- Los zoomorfos -en su mayoría camélidos-se ven en la cuenca alta del río Illapel, con más de un animal por grabado. Hemos señalado que esta alta densidad puede relacionarse con una tradición pastoril, testimoniados por los rebaños del arte rupestre.

Tabla 3. Frecuencia y densidad de los seis principales signos rupestres estudiados en el proyecto "Río Grande". Se subrayaron las densidades más altas. Frequency and clustering of the six principal rock art designs studied in the "Rio Grande" project. The highest concentrations were underlined.

\begin{tabular}{|c|c|c|c|c|c|c|c|c|c|c|}
\hline \multirow{2}{*}{$\begin{array}{l}\text { Signo rupestres } \\
\text { Máscara y mascariforme }\end{array}$} & \multicolumn{2}{|c|}{$\begin{array}{l}\text { Mialqui } \\
\text { Tucúquere } \\
\text { La Viñita }\end{array}$} & \multicolumn{2}{|c|}{$\begin{array}{c}\text { Panguecillo } \\
\text { Bajo, } 1 \text { y } 2\end{array}$} & \multicolumn{2}{|c|}{$\begin{array}{l}\text { La Rinconada } \\
\text { de Carretón }\end{array}$} & \multicolumn{2}{|c|}{$\begin{array}{c}\text { La Quebrada } \\
\text { de Las } \\
\text { Chupallas }\end{array}$} & \multicolumn{2}{|c|}{$\begin{array}{l}\text { El Cuyano } \\
\text { Bajo y Alto }\end{array}$} \\
\hline & 6 & 0.04 & 3 & 0.05 & 2 & 0.06 & 9 & $\underline{0.14}$ & 3 & 0.27 \\
\hline Antropomorfo & 98 & 0.59 & 65 & 0.98 & 33 & 1.00 & 80 & $\underline{1.23}$ & 16 & 1.45 \\
\hline Zoomorfo & 45 & 0.27 & 12 & 0.18 & 11 & $\underline{0.33}$ & 5 & $\overline{0.08}$ & 5 & 0.45 \\
\hline Cruz con contorno & 4 & 0.02 & 10 & $\underline{0.15}$ & & - & 4 & 0.06 & & - \\
\hline Cuadrilátero con lados cóncavos & 1 & 0.01 & 1 & $\overline{0.01}$ & & - & 4 & $\underline{0.06}$ & & - \\
\hline Círculos con apéndices exteriores & 105 & 0.63 & 37 & 0.56 & 46 & 1.39 & 125 & $\underline{1.92}$ & 13 & 1.18 \\
\hline
\end{tabular}


Tabla 4. Frecuencia y densidad de los seis principales signos rupestres en tres áreas del Norte Chico. Se subrayaron las densidades más altas.

Frequency and clustering of the six principal rock art signs in three areas of the Norte Chico. The highest concentrations were underlined.

\begin{tabular}{|c|c|c|c|c|c|c|}
\hline Signos rupestres & \multicolumn{2}{|c|}{ Hurtado } & \multicolumn{2}{|c|}{ Río Grande } & \multicolumn{2}{|c|}{ Illapel } \\
\hline Máscara y mascariforme & 81 & $\underline{0.58}$ & 23 & 0.07 & 47 & 0.23 \\
\hline Antropomorfo & 80 & 0.57 & 299 & $\underline{0.87}$ & 120 & 0.59 \\
\hline Zoomorfo & 93 & 0.66 & 78 & 0.23 & 212 & $\underline{1.04}$ \\
\hline Cruz con contorno & 5 & 0.04 & 18 & $\underline{0.05}$ & 4 & $\overline{0.02}$ \\
\hline Cuadrilátero con lados cóncavos & 7 & 0.05 & 6 & 0.02 & 14 & $\underline{0.07}$ \\
\hline Círculo con apéndices exteriores & 5 & 0.04 & 326 & $\underline{0.95}$ & 82 & $\overline{0.40}$ \\
\hline Número total de grabados & \multicolumn{2}{|c|}{140} & \multicolumn{2}{|c|}{342} & \multicolumn{2}{|c|}{204} \\
\hline
\end{tabular}

- Los dos primeros signos geométricos de la Tabla 4 (cruz con contorno y cuadrilátero con lados cóncavos) presentan baja densidad. Mientras en río Hurtado la presencia del círculo con apéndices es casi nula, la densidad alcanza 0,40 signo por grabado en Illapel y tiende a uno en río Grande. Hemos visto que, en ciertas representaciones del río Grande, este signo aparece "humanizado" o "animalizado", en este último caso con un ave (búho). Las numerosas representaciones de La Rinconada de Carretón y su diversidad morfológica hacen del círculo con apéndices exteriores el más extraño de los símbolos del Norte Chico. Su uso en arte rupestre nos parece totalmente desconocido.

- Si miramos las densidades afectadas a los tres primeros signos de la Tabla 4 (signos "vivos"), vemos que las más elevadas están repartidas sucesivamente a cada una de las tres áreas, ríos Hurtado, Grande e Illapel. Lejos de extrañarnos, este resultado debe convencernos que, más allá de la unidad de los estilos rupestres, podemos reconocer cierta diversidad cultural entre poblaciones divididas entre las diferentes cuencas del Norte Chico, como se observa también hoy día en el Chile moderno.

\section{Análisis Estadístico de las Máscaras y Mascariformes en las Estaciones del Río Grande}

La Tabla 2 nos indica que un total de 23 máscaras y mascariformes fueron registrados en la seis estaciones y grupos de estaciones del valle del río Grande, con un subtotal máximo de nueve en la estación de Las Chupallas (con solamente seis en el grupo de Mialqui). A lo largo de las descripciones y análisis, hemos puesto en relieve la gran similitud de estas figuras con las del estilo Limarí definido por Mostny y Niemeyer (1983) y Castillo (1985).

En el valle del río Hurtado superior, este signo aparece 81 veces, como ya lo hemos señalado. En un artículo anterior (Ballereau y Niemeyer 1999), los autores han desarrollado un método de análisis de este signo en dos partes: definición de un antropomorfo y de una representación del rostro humano por criterios puramente morfológicos, y establecimiento de criterios descriptivos para poner de relieve las características propias de un conjunto de mascariformes en un estilo local. Nos parece importante volver a recordar aquí los cinco grupos mayores que reúnen los 18 criterios tipológicos (y sus códigos) que permitieron el análisis de los mascariformes del río Hurtado superior:

- Grupo I: carácter del mascariforme: realista (Ia), realista-estilizado (I-b) y estilizado (I-c).

- Grupo II: forma del contorno del mascariforme: recto (II-a), mixto recto-curvo (II-b) y curvo-circular (II-c).

- Grupo III: presencia o ausencia y localización de los elementos decorativos periféricos del mascariforme: sin decoración externa (III-a), con decoración superior (III-b), con decoración(es) lateral(es) (III-c), con decoración in- 
ferior (III-d), con decoración externa completa (III-e).

- Grupo IV: presencia o ausencia de una línea de separación horizontal que corta el signo en dos partes más o menos iguales (IV-a), y de los tres elementos estructurales del rostro: los ojos (IV-b), la nariz (IV-c) y la boca (IV-d).

- Grupo V: presencia y naturaleza del reticulado que, a veces, ocupa la superficie del mascariforme: reticulado cuadrangular ( $\mathrm{V}-\mathrm{a})$, cuadrangular-curvilíneo (V-b) y curvilíneo (V-c).

Si aplicamos estos criterios tipológicos a los 23 mascariformes del valle del río Grande, obtenemos los datos de la Tabla 5, semejante a su vez a los resultados de las Tablas 3-a a la 3-d de Ballereau y Niemeyer (1999). La penúltima línea da el total de los criterios positivos y la última los porcentajes. Sin embargo, debemos utilizar estos datos con precaución, dado que la muestra de los mascariformes es un poco baja para atribuir un sentido matemático a los porcentajes. Podemos extraer las conclusiones siguientes:

- Hay una mayoría de mascariformes con rostro estilizado (70\%), resultado exactamente igual al de Hurtado.

- La forma más recurrente del contorno del mascariforme es la con lados mixtos recto-curvo $(52 \%)$.

- Los mascariformes con decoración superior aparecen los más numerosos (70\%); en Hurtado, aparecen en primer lugar los mascariformes sin decoración externa (38\%), y después los con decoración superior (36\%).

- La separación lineal horizontal está presente en $43 \%$ de los signos, resultado casi similar al de Hurtado (47\%); los elementos estructurales del rostro aparecen con porcentajes muy parecidos en cantidad y orden en ambas zonas.

El resultado estadístico muestra total similitud entre los estilos locales "río Grande", "río Illapel” y "río Hurtado". La similitud se extiende a las figuras mascariformes, tanto a nivel estético como morfológico. El estilo local "río Grande" se caracteriza no solamente por la presencia de la mayoría de los invariantes ya reconocidos en otras estaciones del Norte Chico, sino también por otros signos que, por el momento, no fueron identificados en otras estaciones. Podemos citar el "motivo de la escalera", cuyos ejemplares están presentes en el grupo de Mialqui, y que no podemos interpretar ni reconocer con la ayuda de la arqueología.

\section{Definición Crono-cultural de los Grabados}

Si las técnicas nucleares permiten obtener un fechamiento de los depósitos de pinturas, por ejemplo en cuevas protegidas, ninguna se ha desarrollado con los grabados rupestres. Aquí, se ha eliminado una parte de la capa superficial por percusión, la acción del sol y de los elementos naturales (aire, lluvia, variaciones de temperatura) que producen una patina que no se puede calibrar de manera temporal como un fenómeno físico. Una manera indirecta de fechamiento consiste en comparar los sitios rupestres con los restos arqueológicos explorados alrededor. Según Castillo (1985), la mayoría de los sitios rupestres del Norte Chico serían de origen El Molle (Niemeyer et al. 1989) con un porcentaje de $20 \%$ asociados con asentamientos arqueológicos de esta cultura. El complejo El Molle se desarrolló entre 0 y 800 d.C. en el territorio que se extiende entre las cuencas de los ríos Copiapó y Choapa, y los sitios rupestres asociados se encuentran en su mayoría en los interfluvios de la precordillera. Es posible que ciertos sitios presenten petroglifos posteriores al complejo El Molle -culturas Las Ánimas, Diaguita y Inca-Diaguita-, pero la disociación temporal y cultural es imposible por el momento.

\section{Síntesis del Arte Rupestre del Río Grande}

A través del estudio de una serie de estaciones con arte rupestre en la cuenca del río Grande, hemos podido visualizar que ellas caen en el concepto del estilo Limarí, caracterizado especialmente por mascariformes premunidos de atavíos cefálicos muy definidos y una serie de signos característicos que se encuentran presentes en todas las estaciones, tales como el círculo con dos apéndices exteriores (más o menos) paralelos, el signo cruciforme simple o doble, el rectángulo de lados cóncavos, entre otros. En nuestro estudio, hemos podido darnos cuenta que este arte se encuentra disperso en distintos lugares y paisajes, en primer lugar, el sitio de la cumbre del cerro El Buitre, que posee un carácter cierto de cerro santuario, con un rico contenido simbólico en sus grabados. De este mismo carácter, probablemente sea el cerro Nomuco, a 


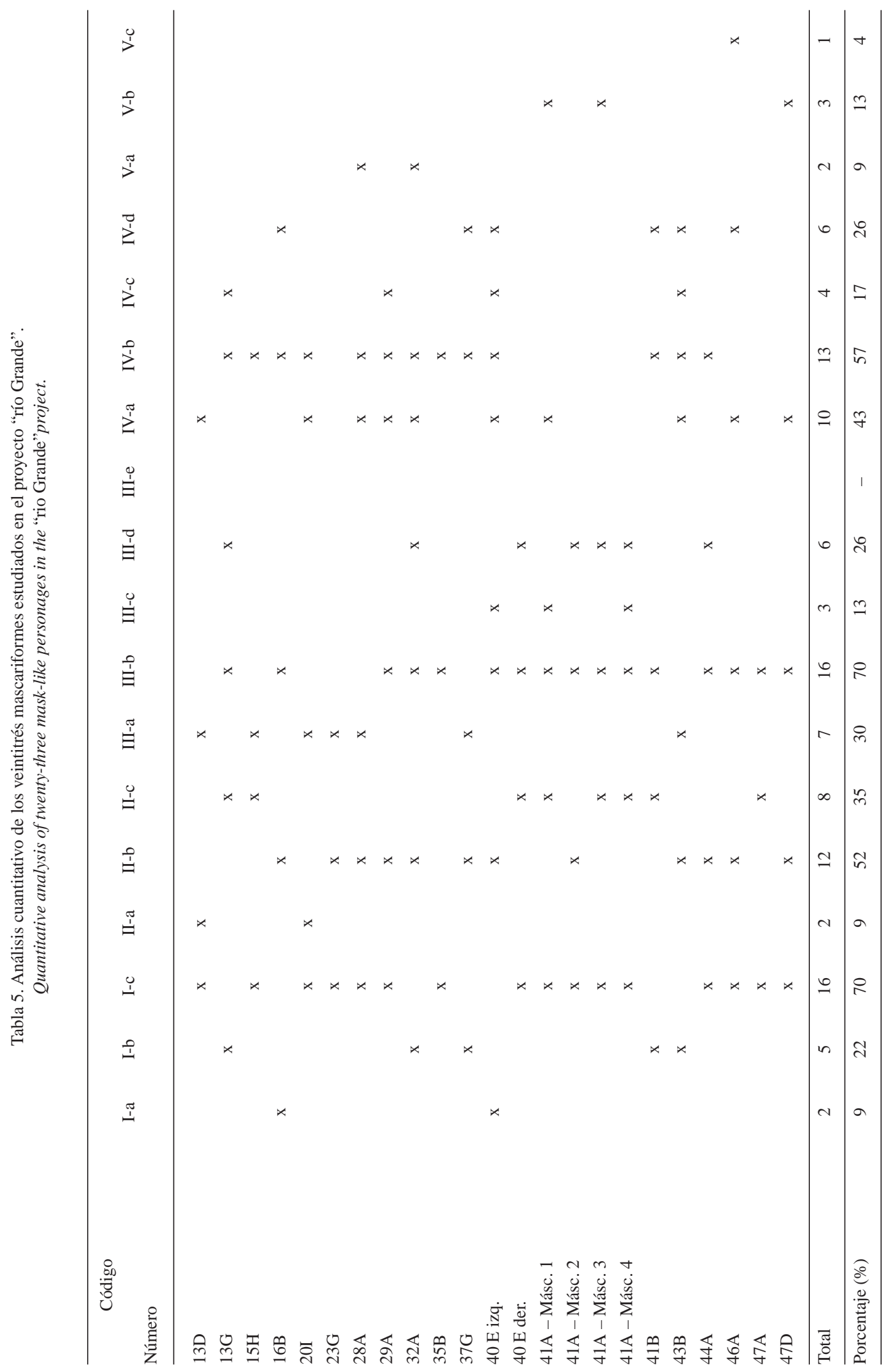


$5 \mathrm{~km}$ al NE del pueblo de San Marcos y $1 \mathrm{~km}$ al este del río Guatulame, donde pudimos observar, en el año 2001, más de 250 grabados situados en las faldas de una pronunciada pendiente. En esta estación también abundan los seis principales signos invariantes ya descritos, entre ellos, suntuosas figuras mascariformes, con una notable profusión de huellas de pie humanos y/o animales, y que nos permitió llamar este lugar "la Estación de las Huellas". Esperamos publicar pronto este interesantísimo y riquísimo sitio.

Otros sitios característicos corresponden al interior de quebradas tributarias del río Grande. En estas quebradas, tales como Las Chupallas y el grupo de Panguecillo, se encuentra un sector que ha sido destinado por los indígenas para efectuar actos rituales probablemente en comunidad con los chamanes, líderes espirituales de ellos. También en el río Grande suelen encontrarse piedras más o menos aisladas con una connotación muy especial. Buen ejemplo de este tipo es la piedra de El Cuyano Bajo que muestra con mucha eficiencia un petroglifo de primera magnitud, representando una gran máscara del más puro estilo Limarí. Otras estaciones rupestres dentro de esta área, que cabe destacar, son los campos de pastoreo comunitario como es el de la comunidad de Mialqui. En él, aparecen algunos centros aislados portadores de arte rupestre que indicaría que, posiblemente, había muchos centros parciales de adoración y culto. Estarían estos centros en relación con prácticas chamánicas de grupos pastoriles. Sin embargo, debemos decir que, a primera vista, no se descubre la relación directa entre estos grabados, aislados o en agrupación, con las prácticas religiosas. Este es un problema generalizado inherente a todas las expresiones de arte rupestre.

Agradecimientos: Dominique Ballereau agradece al Ministerio de Asuntos Extranjeros del Gobierno Francés (bajo la dirección del Departamento de Ciencias Sociales, Humanas y de la Arqueología) por la ayuda financiera y el permiso que permitieron efectuar estas misiones en 1997, 1998 y 1999. Los autores agradecen también a la señora Nina Crowte por la traducción del resumen al inglés. Agradecemos, además, a la señora Ana Montenegro, de Pulpica Alta, en cuya casa tuvimos el placer de ser alojados durante los tres días de trabajo en Las Chupallas y a su hijo y Gabriel, quienes nos llevaron cada día en auto hasta el cruce de la quebrada por el camino público.

\section{Referencias Citadas}

Ballereau, D. y H. Niemeyer

1998 Los sitios rupestres de la cuenca alta del río Illapel (Norte Chico, Chile). Chungara 28:319-352.

1999 Los sitios rupestres del valle del río Hurtado superior (Norte Chico, Chile). Chungara 31:229-292.

Castillo, G.

1985 Revisión del arte rupestre Molle. En Estudios en Arte Rupestre, Primeras Jornadas de Arte y Arqueología. El Arte Rupestre en Chile, editado por C. Aldunate, J. Berenguer, V. Castro, pp. 173-194. Museo Chileno de Arte Precolombino, Santiago.

Iribarren, J.

1975 Arqueología en la Hoya Hidrográfica del Río Limarí. IV Región Coquimbo. Manuscrito en el Museo Arqueológico de La Serena y en posesión de los autores.

Mostny, G. y H. Niemeyer

1983 Arte Rupestre Chileno. Serie Patrimonio Cultural Chileno, Colección Historia del Arte Chileno, Publicación del
Departamento de Extensión Cultural del Ministerio de Educación, Santiago.

Niemeyer, $\mathrm{H}$.

1972 Las Pinturas Indígenas Rupestres de la Sierra de Arica. Editorial Jerónimo de Vivar, Santiago.

1977 Guía de arte rupestre de Chile. En Expedición a Chile, Fascículos 35, 36 y 37, Santiago.

Niemeyer, H., G. Castillo y M. Cervellino

1989 Los primeros ceramistas del Norte Chico: Complejo El Molle (0 a 800 d.C.) En Cultura de Chile. Prehistoria, desde sus Orígenes hasta los Albores de la Conquista, editado por J. Hidalgo, V. Schiappacasse, H. Niemeyer, C. Aldunate e I. Solimano, pp. 227-263. Editorial Andrés Bello, Santiago.

Niemeyer, H. y D. Ballereau

1998 Los petroglifos del Cerro La Silla, región de Coquimbo. Chungara 28:277-317.

\section{Nota}

1 El nombre de tucúquere corresponde a un ave de rapiña de la familia de los búhos. Es el búho de mayor tamaño en Chile (Buho virginianus). 
